\title{
DIGITALCOMMONS
}

@WAYNESTATE-

Wayne State University

Wayne State University Dissertations

$1-1-2017$

\section{Developing Innovation Capability In A Mass Production Organization}

Mark Douglas Dolsen

Wayne State University,

Follow this and additional works at: http://digitalcommons.wayne.edu/oa_dissertations

Part of the Business Administration, Management, and Operations Commons, and the Industrial Engineering Commons

\section{Recommended Citation}

Dolsen, Mark Douglas, "Developing Innovation Capability In A Mass Production Organization" (2017). Wayne State University Dissertations. 1695.

http://digitalcommons.wayne.edu/oa_dissertations/1695

This Open Access Dissertation is brought to you for free and open access by DigitalCommons@WayneState. It has been accepted for inclusion in Wayne State University Dissertations by an authorized administrator of DigitalCommons@WayneState. 


\title{
DEVELOPING INNOVATION CAPABILITY IN A MASS PRODUCTION ORGANIZATION
}

by

\author{
MARK DOLSEN \\ DISSERTATION \\ Submitted to the Graduate School \\ of Wayne State University, \\ Detroit, Michigan \\ in partial fulfillment of the requirements \\ for the degree of \\ DOCTOR OF PHILOSOPHY
}

2017

MAJOR: INDUSTRIAL ENGINEERING

Approved By:

Advisor

Date 
(C) COPYRIGHT BY

MARK DOLSEN

2017

All Rights Reserved 


\section{DEDICATION}

To Mary, Margo, and the Associates of TRQSS 


\section{ACKNOWLEDGEMENTS}

This document marks the completion of a journey that started when my wife discovered through an internet search that the Industrial and Systems Engineering Department at Wayne State University had developed the Global Executive Track PhD program. I would like to thank Dr. Kenneth Chelst, Dr. Ratna Babu Chinnam, and Dr. Julia Gluesing for creating this incredible program. It has had a profound effect on my life and career.

Much of the source material for this dissertation as well as several application assignments throughout the program comes from my experience at TRQSS Inc. in Tecumseh, Ontario. In 1987, the founders of Quality Safety Systems Company created a truly unique workplace. I am fortunate to be a part of this organization.

I would like to thank my colleagues who supported me throughout this journey: Brad Hedderson, David Funnell, Kenichi Kinoshita, Ikuzo Kojima, Takeshi Harada, Eric Legary, Murray Phillips, Marilyn Woodrich, Angie Lafferty, Jennifer Scarsbrook, Rebecca Vermeulen, Carina Holowecky, and Diane Lucas.

I would also like to acknowledge the members of my Dissertation Committee for their essential contributions to the GET Program coursework, and for their guidance and patience throughout the completion of this dissertation. Thank you Dr. Ratna Babu Chinnam, Dr. Julia Gluesing, Dr. Leslie Monplaisir, Dr. Toni Somers, and Dr. Manpreet Hora.

Finally, this would not have been possible without the support of my family; Margo, Amelia, and Graham. 


\section{TABLE OF CONTENTS}

$\begin{array}{ll}\text { DEDICATION } & \text { ii }\end{array}$

ACKNOWLEDGEMENTS iii

LIST OF TABLES

LIST OF FIGURES vii

$\begin{array}{lc}\text { CHAPTER } 1 \text { INTRODUCTION } & 1\end{array}$

CHAPTER 2 RESEARCH QUESTION AND CONCEPTUAL MODEL 10

CHAPTER 3 CONCEPTUAL FRAMEWORK

Background 12

$\begin{array}{ll}\text { Literature Review } & 13\end{array}$

Development of Hypotheses and Confirmatory Model 33

Constructs

Dependent Variables $\quad 37$

Exploratory Research Cases $\quad 38$

CHAPTER 4 RESEARCH DESIGN $\quad 40$

$\begin{array}{ll}\text { Methodology } & 40\end{array}$

$\begin{array}{ll}\text { Sample } & 41\end{array}$

$\begin{array}{ll}\text { Data Collection } & 41\end{array}$

Data Analysis $\quad 42$

$\begin{array}{ll}\text { Contribution } & 42\end{array}$

CHAPTER 5 SURVEY RESEACH, RESULTS, AND ANALYSIS 44

Descriptive Statistics $\quad 45$

Exploratory Factor Analysis $\quad 46$

Confirmatory Factor Analysis $\quad 52$

Structural Equation Model $\quad 55$

Confirmatory Factor Analysis of "Support” Data Set

Structural Equation Model for Support Data Set $\quad 61$

CHAPTER 6 DEPENDENT VARIABLE DATA, ANALYSIS, AND RESULTS 65

Dependent Variable Performance Data 66

$\begin{array}{ll}\text { Analysis of Dependent Variable Data } & 70\end{array}$ 
Regression Analysis

Discussion of Survey Results and Analysis 78

CHAPTER 7 CASE STUDY RESEARCH AND ANALYSIS

Overview of the Case Study Project 86

Case Study Research Design 87

Case \#1 - Innovative finishing process for a new design buckle 91

Case \#2 Innovative Finishing Process for a retractor assembly 104

Case \#3 Innovative process for Front Retractor finishing assembly 113

Discussion of the Cases $\quad 115$

Capability improvement over time 124

Conclusions of the Case Study Research 128

CHAPTER 8 CONCLUSIONS OF THE DISSERTATION RESEARCH

Employee Engagement 131

Developing Innovation Capability 132

Role of the Supervisor and Production Work Groups 133

Conclusion

APPENDIX CONSTRUCTS AND SURVEY 136

\begin{tabular}{ll} 
REFERENCES & 141 \\
\hline
\end{tabular}

$\begin{array}{ll}\text { ABSTRACT } & 148\end{array}$

AUTOBIOGRAPHICAL STATEMENT 150 


\section{LIST OF TABLES}

Table 1 Comparison of Construct Mean Values between Data sets ................................................... 45

Table 2 Resulting Constructs for "Support" Data set after EFA .............................................................49

Table 3 Resulting Constructs for "Floor" Data set after EFA ............................................................52

Table 4 Empirical Performance Data by Team Leader Work Group ......................................................69

Table 5 Completion time for each phase of innovation process (months) ...........................................124 


\section{LIST OF FIGURES}

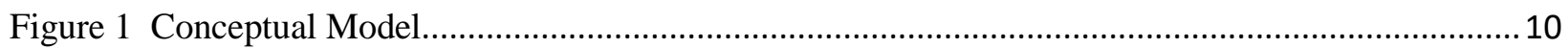

Figure 2 Pattern Matrix for "Support" Data set ............................................................................... 47

Figure 3 Pattern Matrix for "Floor" Data set ...................................................................................... 50

Figure 4 Measurement (CFA) Model for Supervisor Relationship and Organization and Resource

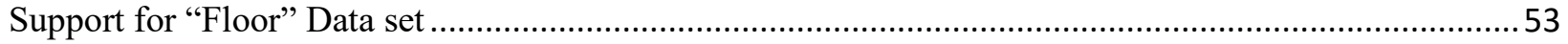

Figure 6 Structural Equation Model for Job Engagement for "Floor" Data set.......................................56

Figure 7 Estimates of Regression weights for Structural Equation Model for "Floor" Data set ...............57

Figure 8 Measurement Model (CFA) for Resource Support, Organizational Support, and Supervisor

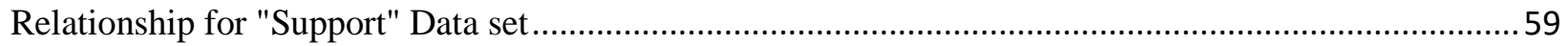

Figure 9 Measurement Model (CFA) for Effort and Emotional Engagement for "Support" Data set.......60

Figure 10 Structural Equation Model for "Support" Data set .............................................................63

Figure 11 Parameter Estimates for the SEM for "Support" Data set ....................................................64

Figure 12 Chart showing TeamLead sorted by Emotional Engagement with Attendance ........................71

Figure 13 Chart showing TeamLead sorted by Supervisor Relationship with Suggestions ...................... 71

Figure 15 Proposed Concept for Automated Buckle Finishing Line ..................................................96

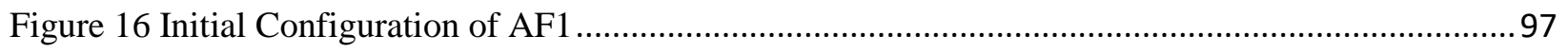

Figure 17 Chart of Historical Performance of AF1 .................................................................... 98

Figure 18 Cover/Switch subassembly delivery system............................................................... 100

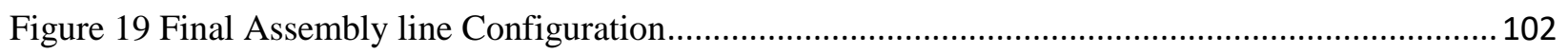

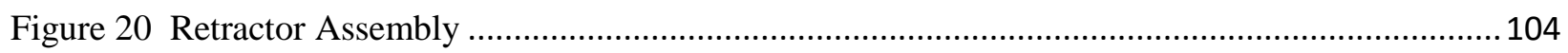


Figure 21 Historical Performance of IF1

Figure 22 Results of Production Trials for F45 ... 


\section{CHAPTER 1 INTRODUCTION}

Between 2003 and 2010, total employment in the Motor Vehicle Parts Manufacturing Industry in Canada declined from a peak of 99,531 to 59,105 , a $40 \%$ reduction in seven years (CANSIM, 2016). Some of these jobs disappeared when automobile sales plummeted in the 2008 recession, but many were gradually relocated to lower labor cost countries as firms attempted to preserve profits in the face of global competition and a strengthening Canadian currency. Automobile sales in North America have rebounded from their low point in 2010, but employment in the auto parts industry in Canada has remained flat. The average weekly wage for jobs in this industry sector is approximately $\$ 1,000$ (CANSIM, 2016), and they have an economic multiplier of approximately 5.7, making them even more valuable to the domestic economy (Cole, 2011).

Although the present effect is obvious and drastic, the future could be worse. Economists claim that innovation is required for economic growth, and a manufacturing base is a significant catalyst for innovative activity. However, as local manufacturing activity decreases, the capacity for local innovation decreases as well (Coy, 2012; Grove, 2010; Kaushal, Mayor, \& Riedl, 2011; Pisano \& Shih, 2012a; Porter \& Rivkin, 2012). This is because the manufacturing industry creates an "Industrial Commons"; a conglomeration of various skills and capabilities that reside in a cluster of different firms that evolve to support the industry. Loss of the commons results in the loss of the knowledge network required for innovation (Pisano \& Shih, 2012b). In an effort to help managers understand the importance of keeping manufacturing together with research and development, Pisano and Shih offer a framework for manufacturing location decisions based on two variables; product modularity and process maturity (Pisano \& Shih, 2012b). The results of 
using this framework are dependent on the ability of managers to assess their firm's position within industry, coupled with some clairvoyance regarding the future of process technology.

The auto industry is a significant component of many developed economies, and auto parts manufacturing is an excellent source of middle class jobs, economic activity, and opportunities for innovation. However, as part of a global industry, parts suppliers face intense pressure for price reductions and those who cannot keep pace with value added innovation seek low labor wage rate jurisdictions for significant cost reductions in the production of rapidly commoditized products. Firms operating in a high labor wage jurisdiction face a challenge of survival, and the economic stakes are high; not only are middle class manufacturing jobs at risk, but the current and future "white collar" research and management jobs are threatened as well. Given this global competitive environment, how does a mass production firm like an auto parts supplier in a high labor cost jurisdiction compete using innovation? What capabilities and conditions are required? This dissertation will addresses this problem through the study of an auto parts manufacturing firm in Ontario, Canada. In doing so, we will attempt to offer a practical course of action for managers of mass production firms facing the challenge of survival in this environment.

The literature on corporate "Competitive Strategy" stems from the seminal work of Michael Porter. According to Porter, there are three generic strategies that any firm can employ; low cost, differentiation, or focus. If a firm is not going to be in the low cost position in the industry, then it needs to differentiate itself from competitors by offering an element of uniqueness as perceived by its customers (Porter, 1980). A branch of the strategy literature referred to as the Resource Based View (RBV) suggests that firms within an industry are heterogeneous in their collection of resources, and can gain competitive advantage if they are in possession of resources that are immobile, valuable, rare, inimitable and non substitutable 
(Barney, 1991). Other authors building on the RBV make a distinction between resources and capabilities, maintaining the view that in order to be strategic, an asset or a capability must be inimitable, rare, and valuable in the sense that it satisfies a user need. A variation of this view holds that competitive advantage can be created through industry diversification based on a "Core Competence" in products or services, which by definition is difficult for competitors to imitate because it is based on the collective learning in the organization (Prahalad \& Hamel, 1990). In a seminal paper, Teece, Pisano, and Shuen introduce the concept of "Dynamic Capabilities", which is a firm's ability to reconfigure and integrate existing resources and competencies to address rapidly changing environments. Resources and competencies are built over a period of time, and the capability to adapt these to opportunities may be the key to competitive advantage for the firm (Teece, Pisano, \& Shuen, 1997). More recent authors have suggested that culture makes a contribution as well, either as a resource (Hafeez, Zhang, \& Malak, 2002), an enabler of capability development (Bates, Amundson, Schroeder, \& Morris, 1995; Jaruzelski, Loehr, \& Holman, 2011), or a source of causal ambiguity and tacit knowledge (Nonaka, 1991). The Kano theory of attractive quality suggests that a differentiation strategy is achieved by being first to satisfy unspoken customer needs with unexpected products, features, or services that surprise and delight. The ability to execute this strategy is dependent upon a capability of continuous innovation, as this differentiation is always temporary; eventually product features or firm services that once were unique become commonplace in the industry, and further innovation is required to sustain the competitive advantage (Conti, Kondo, \& Watson, 2003). Any resources, capabilities, or competencies can only provide value to a firm if the potential is realized in the context of its business of satisfying customers and realizing a profit. 
The literature suggests that a firm employing a differentiation strategy (as opposed to a strategy of cost leadership) needs to be innovative. Recent authors in the American Society for Quality (ASQ) define innovation in a business context as "the successful conversion of new concepts and knowledge into new products, services, or processes that deliver new customer value in the marketplace" (Keathley, Merrill, Owens, Meggarrey, \& Posey, 2014). In one respect, innovation is developing new ways of achieving current ends; thus, an industry leading firm that is actively pursuing innovation could be in conflict with itself (Christensen, 1997). Christensen's seminal work focuses on the disruption that occurs in industries when market shifts cause new technologies to be adopted (disruptive innovation), resulting in the destruction of market leading firms that ignored the new technologies, and continued to focus on the improvement of existing technologies (sustaining innovation). Christensen's thesis is that this is a somewhat inevitable cycle as market leaders have no incentive to divert investments toward new technologies with uncertain return. This work highlights three significant aspects about the nature of innovation: first, that technologies usually exist before they are adopted by the market, and it is market need drives the adoption of technology rather than the reverse; second, that there are degrees of innovation ranging from sustaining to disruptive; and third, that within an industry, the company that somehow manages to stay abreast of new and developing technologies and potential market shifts has a chance of survival by avoiding destruction caused by disruptive innovation. These aspects are supported by other authors when discussing the process by which innovation is realized (Gupta, 2009; Merrill, 2008). This process has three distinct phases: first, the creative portion of idea generation; second, the evaluation and selection of feasible ideas; and third, implementation. Each phase requires different managerial skills, and firms do not necessarily excel at all three (Merrill, 2008; Norausky, 2000). A recent article 
suggests that the innovation process is closely related to the continuous improvement process with the distinction that an improvement can be considered an internal benefit to the organization, whereas an innovation is something that benefits the external customer (Soltero, 2012). The ASQ authors, whose definition of innovation was referred to earlier, make an alternative distinction between innovation and improvement. Whereas all innovations are improvements, the reverse is not necessarily true. Some improvements may merely be corrections to existing conditions; these may not involve new concepts nor provide new value. However, all successful innovations are improvements; the distinction being the degree of novelty in the product, service, process, or value. Although the ASQ authors posit that improvement and innovation exist along a continuum, they do not define the border between the two. From this discussion we conclude that it stands to reason that a firm that can develop the capability to continuously improve and innovate will increase its competitive potential through a strategy of differentiation.

All implemented acts of improvement or innovation begin with an idea, which happens when a person with some particular knowledge and perspective becomes aware of a problem or an opportunity (Robinson \& Schroeder, 2006). Ideas are acts of creativity, and in earlier work, Robinson and Stern conclude that within organizations, creativity is somewhat unpredictable; there is no way of knowing in advance who is likely to be involved in a creative act that results in innovation, what that act might be, or when and how it is likely to occur. Although the successful implementation of an improvement or innovation usually results from the interaction of several people with different bodies of knowledge (Merrill, 2008), the initial creative portion relies on individual initiative, and firms should strive to create the environment for that effort to flourish, thereby maximizing the probability that good ideas will be generated and proposed 
(Robinson \& Stern, 1997). Using the framework of the Resource Based View (RBV), the privately held knowledge of a firm's employees is a unique and inimitable resource that is built over time through internal and external learning. This knowledge can lead to the development of unique firm resources such as manufacturing processes which may provide competitive advantage (Schroeder, Bates, \& Junttila, 2002). Employee knowledge has the potential to provide innovative solutions, but it is valuable only if it can be realized, and its utilization is maximized for the benefit of the firm. Robinson's later work with Schroeder examined how employers encourage and implement employee ideas in various firms, providing examples of how idea management systems that focused on maximizing employee participation resulted in an improved corporate culture that fostered trust, respect, commitment, and employee involvement in improvement activities (Robinson \& Schroeder, 2006).

The concept of employee involvement in improvement activities is not new. Robinson and Stern chronicle the earliest attempts by employers to harness the ideas of their employees through Employee Suggestion Systems. They further contrast the differences between typical suggestion systems that existed in North America and those that evolved in Japan, specifically during the industrial rebuilding that took place after World War II. The Japanese kaizen teian (improvement proposal) system evolved from the Training Within Industry Services (TWI) methodology developed in the United States in 1940 to increase the production of war materiel. These methods had been very successful in improving the performance of American factories that they were later introduced to Japanese industry by the Occupation Forces in 1953. TWI focused on factory improvement by targeting the role of the supervisor and his relationship with his employees. Consequently supervisors were given standardized training in the skills of Worker Training (Job Instruction), Methods Improvement (Job Methods), and Leadership and 
Employee Relations (Job Relations) (Robinson \& Stern, 1997). Many of the later quality improvement programs like Total Quality Management and the Baldridge Award Criteria contain employee involvement as a significant component; however, proponents of the TWI programs believe that they reach beyond employee involvement and actually foster employee engagement (Dinero, 2005; Graupp \& Wrona, 2011).

Employee engagement is a term that begins appearing in the literature in the early 2000's. By definition, engaged employees put discretionary effort into their work (Towers-Perrin, 2003). This literature stream suggests that firms with higher levels of engaged employees than their competitors achieve superior business results, underscoring the importance of an organizational environment that motivates employees to give discretionary effort to improve the performance of the organization. Key factors in creating such an environment have been suggested to include goal setting, and variety and challenge in the job along with some amount of autonomy (Medlin, 2008). Improved results come from behavioral change, which requires trust built by transformational leadership (Macey, 2008).

To summarize the discussion of this literature, there are three basic views of corporate strategy: the market positional view, which suggests that a firm not competing on low cost needs to compete through differentiation; the resource based view, which states that a firm can differentiate itself in its environment if it possesses resources, assets, or competencies that are unique, valuable, immobile and inimitable; and the dynamic capabilities view, which posits that the ability to build and reconfigure resources to take advantage of opportunities is more important than strategic positioning. The Kano theory suggests that differentiation is achieved through innovation of products, processes and services, and that continuous innovation is an essential capability as all innovations become expectations as time passes. Recent authors 
illustrate that innovation follows a process that is similar to the continuous improvement process, and both stem from the ideas of individual employees. The degree of innovation is related to the creativity of an idea, whose source and timing is difficult to predict. Historically, factory performance improvement can be achieved through employee involvement efforts that are guided and focused by an effective supervisor. An idea management system with a participation focus leads to an improved corporate culture of trust and involvement, which fosters employee engagement. A firm with higher levels of employee engagement than its competitors can achieve superior business results in the marketplace.

This research proposes to synthesize these concepts in a way that provides direction for managers of auto parts manufacturing firms in high wage rate environments toward developing a capability of continuous innovation to achieve a differentiation strategy. ${ }^{1}$ Given the following:

- that developing a capability for innovation is essential for these firms to compete with firms in low cost labor environments; that innovation is continuous improvement with some degree of novelty stemming from creative thinking; that creative thinking comes from intrinsically motivated human initiative, and every employee has the potential to contribute creative ideas toward the realization of improvement and innovation;

- that employee engagement is a reasonable representation of intrinsic motivation levels required for creative thinking

then we are interested in how auto parts manufacturing firms are achieving continuous improvement results in manufacturing operations, and to what degree these improvements are

\footnotetext{
${ }^{1}$ While the dissertation is focused on the automotive industry, findings should be relevant to other manufacturing industries that deal with engineered components and subsystems. .
} 
innovative, and what is the significance of employee engagement in the achievement of results. Specifically we will attempt to determine the following:

- Can all employees in a mass production environment be engaged? What is the influence of effective supervision on employee engagement levels within the mass production work group?

- Where employees in the mass production work group experience engagement, do work groups with higher engagement levels outperform groups with lower engagement levels? Does higher engagement result in higher levels of innovative behavior and continuous improvement achievement?

- When innovative results are achieved, how does it happen? Are there contributing factors in addition to supervisor effectiveness and employee engagement that are involved?

Ultimately, we wish to determine if employee engagement can be fostered in a mass production environment at the work group level, to what degree effective supervision is a driver of this engagement, and if engagement is a necessary antecedent for the development of innovation capability required to compete using a differentiation strategy. Also of interest are other factors that may be essential to the development and use of an innovation capability. Findings should be of interest to both practitioners as well as scholars in the area of strategy, innovation, and employee engagement. 


\section{CHAPTER 2 RESEARCH QUESTION AND CONCEPTUAL MODEL}

The Fundamental Research Question is how can a manufacturing plant operating in a high wage rate environment develop a capability of continuous innovation in order to compete with firms employing a generic strategy of low cost labor ? To address this question, a model has been developed that draws from the concepts in academic literature relating to strategy, innovation, continuous improvement, and employee engagement. This conceptual model is presented as Figure 1 below.

\section{$\underline{\text { Figure } 1 \text { Conceptual Model }}$}

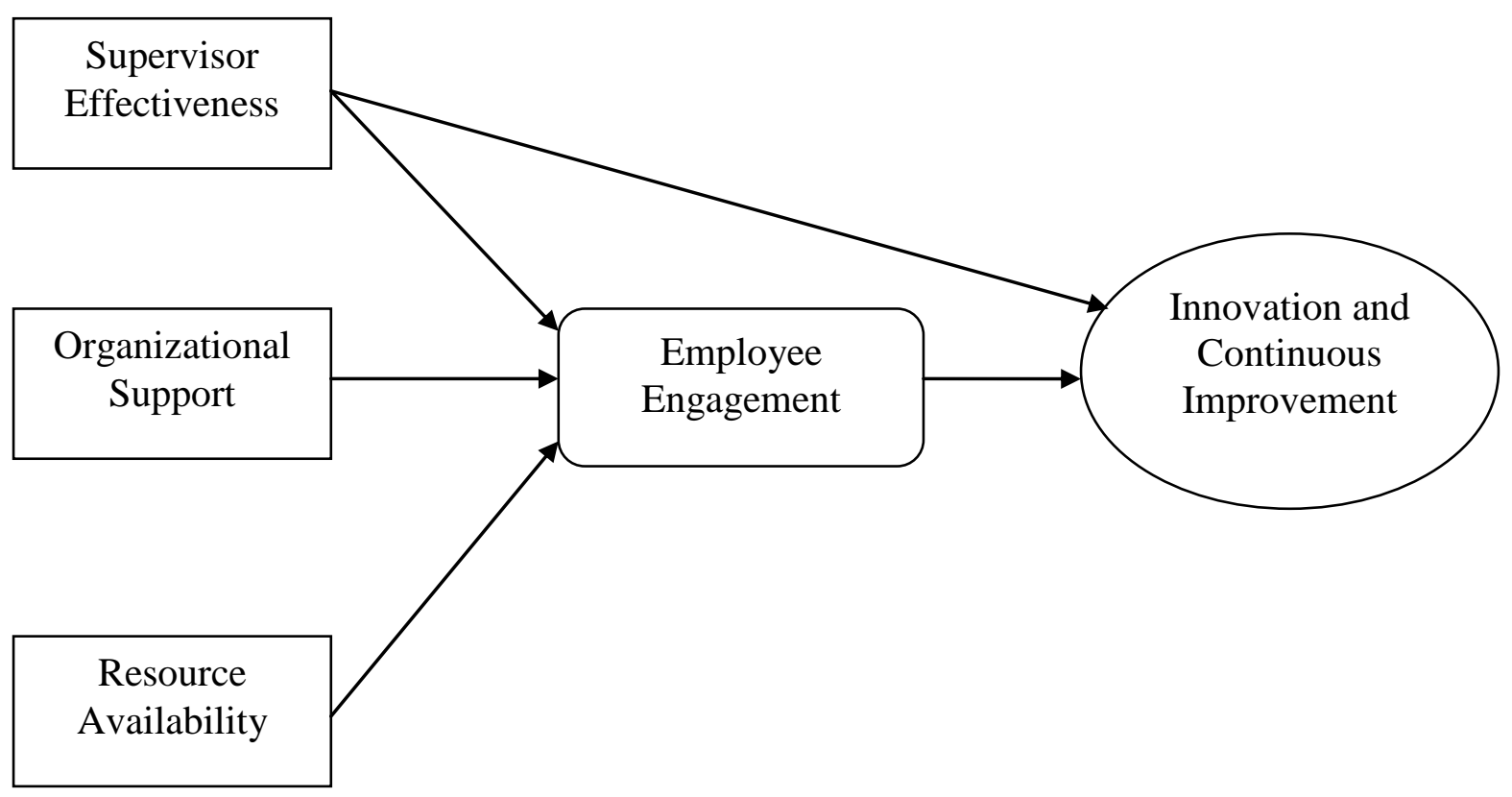


The model suggests that Innovation and Continuous Improvement performance can be determined at the Work Group level by available quantitative factory measures, and that performance levels on these measures can be positively affected by both Supervisor Effectiveness and increased levels of Employee Engagement. The literature related to TWI posits that factory improvement is directly related to a supervisor's relationship with the work group, but innovation requires creativity that comes from intrinsically motivated individual activity. According to the literature, engaged employees give discretionary effort in pursuit of company goals, and by definition, discretionary effort is a degree of intrinsic motivation; therefore, higher levels of employee engagement should result in more innovative solutions. As suggested by the literature, Employee Engagement levels will be directly influenced by effective supervision, as well as perceived organizational support for employee efforts and the availability of resources to do a proper job. In the following section, Conceptual Framework, the constructs and measures will be discussed, along with a deeper literature review supporting the hypotheses development. 


\section{CHAPTER 3 CONCEPTUAL FRAMEWORK}

\section{Background}

The global automotive industry is defined by three major market regions: Europe, North America, and Asia. This study focuses on Tier $1^{2}$ automotive parts suppliers in high labor cost environments in North America. Each global region is home to major Original Equipment Manufacturers (OEMs) that operate assembly plants in all three regions. Each region also consists of developed and developing economies, thus high labor wage rate countries as well as low labor wage rate countries. The Tier 1 suppliers to the OEMs may operate in both labor environments in one or more global regions.

In the North American region, the United States is home to General Motors, Ford Motor Company, and the Chrysler Company (now a partner of the Italian OEM Fiat). These companies (the "Detroit 3") operate in the three countries of North America (U.S., Canada, and Mexico) as well as several other countries in the other global regions. Other global OEMs operating in North America include Japan's Toyota, Nissan, Honda, Subaru, and Mazda; Germany's Volkswagen, BMW, and Daimler-Benz; and Korea's Hyundai and Kia. Most new investment in North American assembly capacity from these Global OEMs is destined for Mexico, to take advantage of the lowest wage rate environment in North America that is adjacent to the region's largest market (United States), as well as free trade agreements that Mexico has with countries in Europe, Asia, and South America. In Asia, the Global OEMs have focused on China for two reasons that stem from its large population and underdeveloped economy; first, as the middle class develops, China will be the world's largest automotive market; and second, it has proven to be a relatively low labor wage environment en route to reaching that potential. The former reason

\footnotetext{
${ }^{2}$ Tier 1 refers to a supplier that ships goods directly to the vehicle assembly plant.
} 
makes this location attractive to OEMs who require growth as their traditional markets become saturated; the latter puts huge pressure on global suppliers of auto parts that are somewhat generic and easily transported.

Most OEMs have key suppliers in their supply chains that operate with them in the various world regions. Also, these suppliers may supply more than one OEM, making the auto parts supply base a very interdependent one. To gain efficiencies in the supply chain, suppliers often locate in close proximity to the vehicle assembly plants that they support. Where this condition is not required, parts manufacturers will often seek low cost production environments, allowing them to increase profits in the short term, and support potentially lower price offerings to OEMs in the future, thereby increasing the cost pressure on all competitors. This study will focus on those auto parts suppliers operating manufacturing facilities in the high labor cost environments in North America (the United States and Canada), to examine the model for achieving a differentiation strategy through innovation in order to compete with firms seeking a low cost position by manufacturing in low labor cost environments (Mexico or low wage Asia).

The remainder of this section will review the constructs of the conceptual model and the literature supporting it.

\section{Literature Review}

This section will review the literature in four broad streams: Strategy, Competitive Advantage, Innovation and Creativity, and Employee Engagement.

\section{Strategy, Core Competencies, and Dynamic Capabilities}

The term "core competencies" comes from a 1990 Harvard Business Review article by C.K. Prahalad and Gary Hamel (Prahalad \& Hamel, 1990). The authors define core competencies as an organizations collective learning, especially in how to integrate different 
technologies and diverse production skills. A firm may be able to enter diverse markets by developing different products that are based on a core competency. They illustrate this concept by comparing and contrasting the business performance of GTE and NEC (two large conglomerates), attributing NEC's relative success to its strategy of product diversification based on a core competence in semiconductors. For a core competency to provide competitive advantage, it must provide access to a variety of markets, be of significant value to the end product, and be difficult for competitors to imitate. The key point is that technologies can be imitated, but the "comprehensive pattern of internal coordination and learning" cannot (Prahalad \& Hamel, 1990).

These concepts of value and inimitability are found in the branch of strategy literature pertaining to the Resource Based View of the firm, which asserts that in certain competitive environments, firms are heterogeneous in their stock of resources and capabilities. A firm that possesses resources or capabilities that are rare, valuable, immobile, and inimitable can use these to build competitive advantage (Barney, 1991). Hafeez, Zhang, and Malak make a clear distinction between resources, capabilities, and core competencies. All firms have resources, which are inputs to the process, and may be classified as physical, intellectual, or cultural. Capabilities that are developed from the resources begin to develop rare and valuable qualities for the firm. Key capabilities then lead to competencies that then become core; providing the firm with competitive advantage due to the high value provided by their unique nature (Hafeez et al., 2002). Whatever the nomenclature, in every case, core competencies, strategic resources, and key capabilities are firm differentiators that are built from within over a period of time.

The concept of Dynamic Capability is introduced in a seminal paper by Teece, Pisano and Shuen, offering a third paradigm to the strategy literature in addition to the Market Positioning 
View (Porter) and the Resource Based View (Barney). These authors posit that the ability to quickly reconfigure firm resources, capabilities, and competencies to respond to changes in the market environment, termed "dynamic capabilities", is the most important capability of all to retain competitive advantage (Teece et al., 1997). Many core competencies take years of consistent effort to build, but markets may shift at a faster rate; therefore, "dynamic capabilities" can become a core competency that is rare, valuable and inimitable.

An illustration of this point in the literature is in "The Honda Effect Revisited." (Mintzberg, Pascale, Goold, \& Rumelt, 1996). In this article, academics review how Honda entered and came to dominate the motorcycle market in the United States. Prior to 1960, the U.S. market was limited and dominated by Harley Davidson and a few British Manufacturers. By 1965, the market had nearly tripled in size, and Honda had more than $60 \%$ share. A retrospective case study by the Boston Consulting Group concluded that Honda had a well defined regional strategy and positioned its products appropriately in the market. However, a retrospective interview with the Honda executives who were involved at the time revealed a different story. The only strategy that Honda had was to enter the market with the same high end profitable motorcycles that they sold in Japan. This was not successful at all, as they had no presence, reputation or infrastructure in the U.S. For economical reasons, the Honda executives on assignment in California used Honda mini-bikes for their personal transportation. Mini bikes were a product that Honda had developed for the Japanese market, based on the core competence of small, powerful but economical internal combustion engines. People in the U.S. who saw this product were immediately intrigued, as the mini bike had not been introduced as a product for the U.S. market, yet it was exactly the mode of transportation that appealed to the growing youth demographic in California. The Honda team quickly responded to this demand and switched 
their strategy from trying to sell high end motorcycles to importing mini bikes. After establishing their market presence in mini bikes, Honda was able to move upscale, but this was not the initial strategy. The point is that Honda succeeded in capturing the motorcycle market in the United States because of the team's dynamic capability to respond quickly to market demands by reconfiguring company resources to supply products built on their core competency. This turned out to be more important than any knowledge or practice of strategic theory (Mintzberg et al., 1996).

For auto parts suppliers in North America, competitive advantage could be derived from the building of inimitable core competencies, and the dynamic capability of being able to rearrange those competencies to respond to changes in the marketplace. As suggested by the literature, these skills are built from within, and inimitability comes from the routines that are developed as a result of organizational learning over time. Fujimoto contends that organizational learning was responsible for a significant portion of the development of the Toyota Production System (TPS) within Toyota; his work shows that the TPS was not the result of routine processes that were focused on gaining competitive advantages, but rather the system evolved as a result of the organization's superior opportunistic learning capability (Fujimoto, 1999).

In recent work, Anand and his collaborators propose that "continuous improvement" (CI) can be a dynamic capability if there is an appropriate organizational infrastructure that promotes a culture of learning (Anand, Ward, \& Tatikonda, 2010). Their research analyzed CI cases at five large companies in various industries in order to identify critical aspects of organizational infrastructure. The subject companies used project based CI systems and focused on process improvements. Project leaders were chosen from middle management ranks; therefore the companies' engagement efforts were concentrated only on that group of employees. The authors 
conclude with several questions for future research, noting that the companies studied struggled with innovation efforts, as opposed to small process improvements, and had no infrastructure elements for harnessing the knowledge of front line workers (Anand, Ward, Tatikonda, \& Schilling, 2009). It is interesting to note that in this limited study, the companies' CI efforts were project based (therefore not truly continuous), and led by selected mid level managers, who were the recipients of any training initiatives. It would seem difficult to build an organizational dynamic capability of any kind if the infrastructure for doing so excludes most of the employees.

Dynamic Capabilities imply that an organization is able to recognize changes in its competitive environment, select an appropriate manner in which to respond to those changes, and then successfully implement those changes to respond to the competitive challenges.. This description of this competency parallels definitions of the Innovation Process and Organizational Creativity that will be discussed in a subsequent section; the academic literature suggests that firms seeking to employ a differentiation strategy require continuous innovation to do so (Conti et al., 2003).

\section{Competitive Position in the North American Auto Industry ${ }^{3}$}

The global auto industry consists of many different manufacturers supplying many different products to customers throughout the world. It could be argued that from a functional standpoint, the automobile hasn't changed much since its invention over a century ago; it remains a fairly standard product and a standard infrastructure has evolved to support its use throughout the world. For many, an automobile is necessary transportation; for all it is an aspirational purchase, a status symbol of one's social position.

As the auto industry developed in the first half of the twentieth century in North America, competitive position was determined by efficiency. The Ford Motor Company dominated the

\footnotetext{
${ }^{3}$ A summarized history of the US auto industry can be found in Ingrassia (Ingrassia, 2010).
} 
industry with the development of mass production of a single product, the Model $\mathrm{T}$, that remained unchanged for 20 years. Mass production led simultaneously to higher wages and lower prices, thereby creating a mass market for the automobile. In the next third of the century, General Motors usurped Ford's dominance of the industry by providing variety; the new middle class wanted more than just one model of car to choose from, and the GM strategy was to provide a range of vehicles that reflected the customer's purchasing ability, and to introduce new versions annually (Sloan, 1963). World War II interrupted the industry, as automobile production capacity was converted for military use, but the aftermath of the war resulted in the North American auto companies having no external competition in the short term, and General Motors, Ford, Chrysler and a few smaller manufacturers were left to supply the automotive needs of the largest market in the world. GM and Ford also had global affiliations in Europe and Asia.

By the last third of the twentieth century, the automobile industry in North America had experienced a generation of no external competition and a seemingly endless but necessary supply of inexpensive oil, a growing percentage of it from foreign countries. The OPEC embargo of 1973 was a turning point for the North American industry in that consumers were now demanding small fuel efficient vehicles that the North American manufacturers simply did not produce. This was a window of opportunity for Japanese companies like Toyota and Nissan, who had developed automobile design and manufacturing expertise after the war. To satisfy their own market and resource conditions, these companies developed the capability to produce small, fuel efficient vehicles cost effectively, as their manufacturing systems evolved in an environment of scarce resources. North American consumers discovered that these vehicles had better quality and reliability than those produced by North American manufacturers, and quality became the next source of competitive advantage. As the Japanese manufacturers refined their products for 
North American tastes, market share for the Detroit 3 began to decline at the expense of these imports. Political pressure enticed the Japanese OEMs to reduce imports by installing assembly capacity in the United States. Japanese OEMs brought their key suppliers with them to North America, making the industry subject to global competition on home soil.

Other global OEMs have established a manufacturing presence in North America as well, thereby increasing the competitiveness of the environment. However, efficiency, variety, and quality still remain the keys to competitive position, albeit in a new order. Quality has now become the barrier to entry; efficiency follows from quality, and is a requirement for business sustainability. Variety is now expected, but flexibility and responsiveness have become competitive parameters, expressed in the ability to quickly respond to market demands and delight consumers with new products and features without sacrificing quality and efficiency. This is precisely the path that Korean OEM Hyundai has taken to become a major player in the North American automobile market. Hyundai decided to in-source the design and manufacturing of all engines and transmissions in a quality improvement effort to support their industry best warranty. Next, they located their North American assembly plant in Alabama, distant from the traditional unionized northern locations. Now, Hyundai focuses on design and feature content, utilizing innovative new ideas from U.S. designers and managers (Holstein, 2013). Competitive advantage results in establishing, maintaining, and growing a market share based on this capability.

For most parts suppliers, market share comes not from satisfying the end user, but by satisfying an OEM. Many auto parts are invisible to the consumer, and are not differentiators in the vehicle purchase decision. However, quality, efficiency, and variety still define competitive position at the parts manufacturing level; while quality and efficiency are defined in much the 
same way, variety may be the range of products or even unique services that a Tier 1 supplier can provide to the OEM. Magna International, a large global auto parts supplier based in Canada, applied the lessons of the Toyota Production System (TPS) to a door latch factory in Canada, which resulted in making that operation competitive with a sister plant in China. TPS helped the factory improve quality by $60 \%$ through waste elimination, which became the path to higher productivity. Following manufacturing excellence, Magna plans to focus on the capabilities of innovation and leadership development (Keenan, 2013).

\section{Innovation and Creativity}

The mention of innovation sometimes conjures up images of a lone inventor discovering a world changing product in his garage laboratory; although invention born of individual creativity is an essential element, the innovation process involves the entire scope of taking a new idea all the way from concept to the marketplace (Pisano \& Shih, 2012b). A successful innovation must address a customer or market need in a new way, and must be implemented (Merrill, 2008). A common misconception is that companies that spend the most money on Research and Development (R \& D) are the most innovative; research shows this is not the case. In a Booz \& Company annual study, companies were categorized into three groups based on their innovation strategies, labeled "Need Seekers", "Market Readers", and "Technology Drivers". The most innovative companies were those categorized as "Need Seekers"; this group had the distinct characteristic of being open to new ideas, regardless of the source. In the study, the Need Seekers represented $60 \%$ of the most innovative companies, but only $20 \%$ of the top R\&D spenders (Jaruzelski et al., 2011). This supports the assertion that most successful innovations are driven by customer need rather than by technology (Bettencourt \& Ulwick, 2008; Martin, 2011; Merrill, 2008). 
The automobile industry is fertile ground for innovation. Designing and producing a vehicle that is desired by consumers, meets all regulatory requirements of the marketplace, having superior quality at an affordable price, and is able to generate profit for the manufacturer is a complex task that involves a web of supply chain relationships. Because of this complexity, significant investment cost and long development time, the frequency of totally new vehicle model introductions is about 4 years. The automobile itself has functionally changed little since its invention as a "horseless carriage"; however, the number of ancillary features that are involved in the vehicle system and how those features are delivered is changing continuously. For some parts suppliers, there is product innovation opportunity in helping OEMs meet new safety and environmental standards. For others, there may be opportunity to apply new technologies to component designs so that mundane functions are performed in new ways that are more appealing to end users. For many others, the innovation opportunity may be in process, service, or the business model to help the OEM customer better execute tasks. Whatever the situation, the innovative supplier must recognize opportunities that fit their strategies, generate new and creative ideas to address those opportunities, select appropriate solutions to pursue, and then successfully implement those solutions. To survive in the long run, it is necessary that the supplier be able to repeat these activities continuously.

All successful auto parts suppliers have methods and routines for process execution. When quality became the main driver of competitive position, industry standards evolved, and certification to industry standard became a business imperative for some (e.g., ISO 9000, QS 9000, TS 16949). These standards contain requirements for corrective action and continuous improvement procedures. Other improvement programs like Six Sigma aim to achieve high quality levels through the elimination of variation. However, operating standards that help 
organizations achieve excellence in execution are less helpful when applied to the creative portion at the front end of the innovation process. This struggle for firms to balance the competencies of operational excellence and innovation capability (exploitation versus exploration) is referred to in the literature as Organizational Ambidexterity (Andriopoulos \& Lewis, 2009; Birkinshaw \& Gibson, 2004; Raisch \& Birkinshaw, 2008).

Professors Alan G. Robinson and Sam Stern studied the innovation process in various organizations, looking at successfully implemented innovations and tracing their development back to the origin of the idea. They published their findings in a book called "Corporate Creativity" (Robinson \& Stern, 1997). What they found is that creativity is an unpredictable and therefore difficult to manage entity. Through their analysis of industry cases, it was almost impossible to predict who would be involved in the next creative act, what that act might be, or where and how it would occur. Most instances of creativity were the result of self initiated individual action, which was pursued in "unofficial" company activity, and generally evolved through some serendipitous event. Most innovations were eventually realized when collaboration occurred between people with diverse knowledge bases, but the creative portion stemmed from individual activity. The authors conclude that firms should not try to manage creativity, but to create the conditions that allow it to foster in all of their employees, as every person is capable of creative acts (Robinson \& Stern, 1997). This conclusion is also supported by other authors (Andriopoulos, 2001).

Professor and researcher Min Basadur defines creativity in organizations as " a continuous search for and solving of problems and a creating and implementing of new solutions for the betterment of the organization, its customers, and its members" (Basadur, 1992). Basadur models this definition as a repeating circular process with three steps, called Problem Finding, Problem 
Solving, and Solution Implementation, and that managing creativity in organizations is the activity of using a common method to lead people through these three steps (Basadur, 2004). Interestingly, the innovation process definition developed by the American Society for Quality (ASQ) is a circular process with five steps; Find the Opportunity, Connect to the Solution, Select the Solution, Make the Solution User Friendly, and Get it to Market. Although more specific, this model bears a striking resemblance to Basadur's organizational creativity process. In a study of Japanese companies, Basadur found that the subject organizations were particularly adept at the Problem Finding step of the process, which resulted in huge numbers of suggestions from their employees (Basadur, 1992). Basadur asserts that this circular process of organizational creativity is a model for organizational adaptability. Citing the work of P.E. Mott, Basadur concludes that of the three simultaneous capabilities exhibited by effective organizations (efficiency, flexibility and adaptability), it is adaptability that will enable an organization to survive in the long term. Continuous practice of the three step creativity process develops this organizational capability, and managers who can identify problems that are of strategic importance to an organization in the leadership of this process will create competitive advantage (Basadur, 2004; Basadur \& Gelade, 2006).

Creativity is expressed in ideas, and people are the source of ideas. If auto parts suppliers were able to create environments that encouraged and allowed all employees to generate creative ideas to support of innovative activity aligned with meeting business and customer needs, then that supplier would be developing unique, valuable, and inimitable resources and capabilities that would provide competitive advantage in the marketplace. Employees who are motivated to give discretionary effort toward the achievement of organizational goals are said to be "engaged."

\section{Employee Engagement and Kaizen}


Employee Engagement is a concept that begins to appear in the literature in the early 2000s and is defined as the extent to which employees put discretionary effort into their work to support the achievement of organizational goals (Towers-Perrin, 2003). The Towers Perrin 2003 report also claims that "the more highly engaged employees are, the more likely they are to put customers at the heart of what they do and how they think about their jobs" (Towers-Perrin, 2003).

Towers Perrin identifies seven qualities that employees claim as being the most important to engagement: challenge, authority, autonomy, stimulation, access to information, resources, and growth opportunities (Towers-Perrin, 2003). Senior executives are the most engaged group of employees, as their jobs by nature possess most of these qualities. From this list, it would seem difficult for employees working in production jobs in an auto parts factory to achieve high levels of engagement, as their jobs have may have very few if any of these seven qualities. From their study of 40,000 employees in North America working for organizations that employ 500 or more, Towers Perrin concludes that there are 10 drivers of employee engagement; in order of importance, they are:

1. Senior management interest in employee well being

2. Challenging work

3. Decision making authority

4. Evidence of customer focus by the company

5. Career advancement opportunities

6. Company reputation as a good employer

7. Collaborative environment / good teamwork

8. Resources to get work done 
9. Input on decision making

10. Clear vision from senior management

The role of a Human Resources department is to find ways to make the job more challenging, as this mitigates the negative impact of a demanding workload (Towers-Perrin, 2003). This would seem consistent with lessening the drudgery of factory work.

The Gallup Organization has an entire consulting practice in the area of Employee Engagement. Their essential thesis has been published in the book "12: The Elements of Great Managing” (Wagner \& Harter, 2006). Six of Gallup's 12 elements are worth noting here:

1. Knowing What's Expected

2. The opportunity to Do what I Do Best

3. Recognition and Praise

4. My Opinions Seem to Count

5. A Connection with the Mission of the Company

6. Opportunities to Learn and Grow

Although it would still seem difficult to engage employees involved in repetitive factory work, the Gallup list along with the supporting case studies in the book provide some guidance for managers as to how that might be achieved. The cases are rich with examples of how enlightened management has created a culture where employees respond with discretionary effort to support their respective organizations. A paper published by ASQ on employee engagement underscores the importance of the understanding of how one's job connects with the overall goals of the company, and more significantly, emphasizes the importance of the employee's relationship with his/her manager (Deutsch, 2011). 
This notion of putting customers first and exhibiting discretionary behavior that helps the organization achieve greater levels of customer satisfaction implies that there is some motivation for the employees to do so beyond the monetary compensation of a salary, and none of the aforementioned drivers of engagement involve financial rewards. This suggests that engagement is achieved by creating an environment that appeals to the individual employee's intrinsic motivation toward the achievement of company goals. In a recent book on the topic of motivation, author Daniel Pink identifies three elements essential for intrinsic motivation that come from research in Self Determination Theory (SDT): Autonomy, Mastery, and Purpose (Pink, 2009). Pink explains that the traditional extrinsic motivational tools of "carrots and sticks" (rewards and punishments) used extensively by businesses are appropriate for repetitive tasks, but for work requiring creativity and ingenuity, the best solutions will come from individuals who are intrinsically motivated. ${ }^{4}$ SDT further classifies types of motivation along a continuum from "Amotivation" (no motivation to act) to "Intrinsic Motivation" (motivation to act out of interest, enjoyment, and inherent satisfaction) (Ryan \& Deci, 2000). Between these extremes are 4 levels of "Extrinsic Motivation", which is action motivated by external drivers such as rewards and punishments. It could be argued that an employee giving discretionary effort to achieve company goals is somewhat extrinsically motivated, as they would probably not do the work out of pure interest. However, SDT theorizes that along the motivation continuum, action that begins as extrinsically motivated may be internalized by the individual if that action is seen to be in alignment with the employee's own values, goals, or interests. If this happens, it is termed "Autonomous Extrinsic Motivation" and the behavioral results are similar to those driven by intrinsic motivation (Gagne \& Deci, 2005). This research also suggests that the best way to move employees toward autonomous extrinsic motivation is to strive to align the importance of

\footnotetext{
${ }^{4}$ Pink cites several academic authors and their work in the area of Self Determination Theory (SDT) (p70-73).
} 
work tasks with personal values and interests and to provide a supportive work environment (Gagne \& Deci, 2005). This reveals a critical connection between innovation and employee engagement that is of interest for auto parts suppliers: creativity is essential for innovation, and good creative work is the result of intrinsic motivation. SDT suggests that a workplace that provides the aforementioned drivers of employee engagement can move employees toward a state of autonomous extrinsic motivation, which results in behavior similar to that which comes from intrinsic motivation. Therefore, an engaged workforce should be more capable of innovation than one that is not engaged. If an auto parts supplier can succeed in engaging employees who are involved in mostly repetitive factory work, how does it do that, and how does it harvest the fruit of that engagement?

In their book Corporate Creativity, Professors Robinson and Stern chronicle the earliest attempts by employers to harness the ideas of their employees in a chapter on the history of the Employee Suggestion System. The key point of this chapter is the contrast between suggestion systems typically used in the Western world that emphasize cost reduction, and offer extrinsic financial rewards based on the annual cost savings generated by the implemented suggestion, and the Japanese kaizen teian ("continuous improvement proposal") systems that emphasize participation rates and use recognition as a form of motivation. One of the very first suggestion systems was introduced in a Scottish shipyard in 1880 by an enlightened owner/manager named William Denny. An extremely successful suggestion system was used at American Airlines (AA), and was responsible for tremendous amounts of cost savings over the years. However, as the authors point out, two of the most innovative ideas at AA, frequent flier miles and the reservation system, were not products of the suggestion system; they were the result of intrinsically motivated employees self initiating unofficial activities (Robinson \& Stern, 1997). 
Suggestion systems were introduced in Japan during the American occupation after the end of World War II. At that time, members of General Douglas MacArthur's staff recalled the Training Within Industry (TWI) programs that were effective in improving factory performance in the U.S. during the war effort and decided to use this methodology to help rebuild Japan's industrial infrastructure. ${ }^{5}$ The TWI methodology focused on the relationship between the supervisor and the factory workers, and provided standardized training for the supervisor in Job Instruction (how to train the workers), Job Methods (how to improve factory processes), and Job Relations (how to manage people). During wartime, TWI helped U.S. factories improve operations by more than $25 \%$ on various performance measures, yet after the war, the service was disbanded (Huntzinger, 2002). Whether or not it was Japan's desperate circumstances after the war or the collective nature of the national culture, the TWI programs flourished in Japanese industries, particularly at Toyota, who realized that in order to compete with foreign carmakers they had to rely on employee suggestions to reduce manufacturing costs. Toyota used the TWI programs extensively; the Methods course became the basis for the kaizen (continuous improvement) methodology developed by Shigeo Shingo, and the Instruction and Relations courses are still taught (although modernized) within Toyota today (Shook, 2007). Adopting the philosophy of TWI, Toyota incorporated the responsibility for kaizen activity into the job description of the supervisor (Fujimoto, 1999). As Basadur discovered, Japanese suggestion systems do not provide large extrinsic rewards for ideas, nor are they strictly focused on cost reduction, but they generate huge quantities of suggestions from a large percentage of the employee population. These systems emphasize employee involvement, and use all ideas, good and bad, as teaching opportunities. As a result, these systems promote continuous learning and self action based on

\footnotetext{
${ }^{5}$ Robinson and Stern provide an excellent historical summary of the TWI programs and their significance in the success of Japanese industries today. Toyota is the exemplar in the use of these programs.
} 
intrinsic or autonomous extrinsic motivation which is so crucial to the development of organizational capabilities and an environment of creativity. Other authors studying "Japanese" suggestion systems based on the kaizen principle conclude that their success (and therefore transferability) is based more on organizational culture than national culture (Recht \& Wilderom, 1998).

Professor Alan Robinson followed up his earlier work with another collaborator, Dean Schroeder of Valparaiso University. Robinson and Schroeder examined suggestion systems at several companies in a variety of industries. From their research they developed criteria for an effective employee idea system, which is defined as one that implements 12 or more ideas per employee per year (Robinson \& Schroeder, 2009). Their eight criteria for an effective idea system are (Robinson \& Schroeder, 2006):

1. Ideas are Encouraged and Welcomed

2. Submitting Ideas is Simple

3. Evaluation of Ideas is Quick and Effective

4. Feedback is Timely, Constructive and Informative

5. Implementation is Rapid and Smooth

6. Ideas are reviewed for additional potential

7. People are Recognized, Success is Celebrated

8. Idea System Performance is Measured, Reviewed, and Improved

These eight criteria agree with the important elements of the Creativity Transformation model proposed by researchers who studied best practices in employee suggestion systems at specific divisions of three companies in the Netherlands (van Dijk \& van den Ende, 2002). Other authors who have studied employee suggestion systems state that according to expectancy 
theory, offering valued rewards that are linked to performance will motivate employees to think creatively and use the suggestion system to offer innovative ideas (Fairbank \& Williams, 2001). In opposition to this belief, Robinson and Schroeder devote an entire chapter to the pitfalls of trying to motivate idea generation through the promise of financial rewards. This is congruent with Pink's examination of why extrinsic motivation fails to generate creative solutions (Pink, 2009; Robinson \& Schroeder, 2006). Other studies in Self Determination Theory suggest that the environment in which performance-contingent rewards are administered overrides the effect of the reward itself, and that an "autonomy supportive interpersonal climate" will result in higher levels of intrinsic motivation even if rewards are given (Gagne \& Deci, 2005). SDT also suggests that the interpersonal styles of supervisors and managers is important in creating a climate that fosters autonomous motivation in employees (Gagne \& Deci, 2005). An interesting conclusion in the Robinson and Schroeder book is that companies who implemented effective idea systems did so in an attempt to improve the organizational culture rather than as a method of reducing costs. As a result, the improved culture fostered employee engagement, which resulted in myriad creative ideas for improvement driven by intrinsically motivated individual action (Robinson \& Schroeder, 2006). Basadur made a similar finding in his study of Japanese organizations; the primary objective of their Employee Suggestion Systems was worker motivation, as they believed that workers motivation increased when they were given a chance to be creative on the job (Basadur, 1992). The Idea Management system, driven by specific management action became the vehicle to improve the culture, align employee action with management strategy, and harvest the creative ideas of all employees. As Robinson found in his earlier work, an idea happens when a person with knowledge and perspective becomes aware of a problem or opportunity (Robinson \& Stern, 1997); creative solutions emerge when that person is allowed 
and encouraged to act on his/her intrinsic motivation. Supporting Basadur's earlier assertion, Robinson and Schroeder also found that problem finding was an essential element in successful idea management systems, as it is much easier for front line workers to first identify problems, then work together on developing creative solutions (Robinson \& Schroeder, 2014). These authors also studied why organizations who had specific "lean initiatives" failed to adopt high performance idea systems as part of their effort. They concluded that many lean initiatives focus on the tools of lean, which can be copied; an effective idea management system requires a fundamental change in the roles of employees and managers, which is more difficult (Robinson \& Schroeder, 2009). This assertion is supported in a recent article by noted Toyota expert Professor Jeffrey Liker, which explains the role of "lean" managers at Toyota, and perhaps why Toyota is so often studied but seldom successfully replicated (Liker \& Ballé, 2013).

Perhaps the most recent attempt to identify and explain how Toyota achieves the success that it does is the publication of Mike Rother's work, Toyota Kata. A kata is a routine that is practiced in order to develop a skill, and Rother describes two of these routines used extensively by Toyota; the "improvement kata" (practiced by all employees but especially required of supervisors), and the "coaching kata", practiced by managers (Rother, 2010). The improvement kata is essentially a series of focused repetitive iterations of the Plan-Do-Check-Act (PDCA) problem solving cycle popularized by Deming, with a few key antecedents. First, the practitioner must understand the "Ideal Condition" for the system or process that he is attempting to improve, which is a quantifiable description of desired performance. The second antecedent is the "Current Condition", quantified in the same terms. Typically, the gap between Current and Ideal condition is not an impossible chasm, but nor can it be closed with a simple, known implementation. The practitioner would then have a hypothesis about what obstacles are 
preventing the ideal condition from being achieved, and after choosing one of these to begin work on, would conduct an "experiment" toward an interim target. If the experiment was successful, the required process modifications would be implemented immediately; if not, the results would be used as knowledge toward future improvement ideas. The power in the kata is in the speed and frequency of conducting experiments; eventually, the biggest problems will surface and be resolved quickly, and if the target conditions have been properly aligned with company strategy, organizational performance will steadily improve (Rother, 2010; Soltero \& Boutier, 2012). The other powerful element of the improvement kata is that it engages the entire workforce in a process of learning via the scientific method. The practitioners are conducting experiments to validate a hypothesis; the result will be improvement if the result is true, but even when the result is false, knowledge acquisition has occurred. Repetitive practice of the improvement kata is then a model for continuous improvement and organization learning (Rother, 2010; Soltero \& Boutier, 2012).

This process is similar to the organizational creativity model proposed by Basadur, and the antecedents to the improvement kata serve to focus the activity in the critical step of Problem Finding. Basadur later expanded on the second and third steps in his creativity process, Problem Solving and Solution Implementation in a model he called the Innovative Thinking Process. This is a repetitive circular process having 4 steps relating to problem solutions; Generating, Conceptualizing, Optimizing, and Implementing. In the model, each step exists in a quadrant on a Cartesian plane, with the two axes being "Knowledge Utilization" (x) and "Knowledge Apprehension" (y). The model illustrates that knowledge can be apprehended by physical experience (experimentation) or by mental processing (thinking) and these are set at the extremes of the y axis. Similarly, knowledge can be used for creating solution options and for evaluating 
solution options and these form the extremes of the $\mathrm{x}$ axis (Basadur, 2004; Basadur \& Gelade, 2006). Basadur's research indicates that individuals will have preferences for how they apprehend and utilize knowledge, which would cause them to favour one of the innovative thinking steps over the others; therefore, a successful realization of an innovative solution would require a group of individuals whose knowledge management preferences collectively cover all of the steps in the process (Basadur, 2004; Basadur \& Gelade, 2006).

The innovation process in an organization can be more fully understood by synthesizing Basadur's model with the Toyota improvement kata. Developing capabilities requires the rigorous and frequent practice of the improvement kata, and real improvement comes from continuously finding and solving problems that are strategically important to the organization. Also, individual and learning takes place via the scientific method through practice of the improvement kata. However, Basadur's model recognizes that knowledge can be apprehended in other ways outside of the experiential activities within the organization, and real innovation requires that new knowledge is applied in the generation of ideas and creative solutions.

\section{Development of Hypotheses and Confirmatory Model}

Competitive position in the automotive industry is earned by providing value in the supply chain. According to the examples of successful companies referred to earlier (Ford, Toyota, Hyundai, Magna) this begins with operational excellence; competitive pricing, superior quality, desirable variety, and reliable delivery, especially for products that are rigidly defined by standards and specifications. Based on these criteria, Toyota manufacturing facilities are among the most competitive in the industry. If an auto parts manufacturing facility wished to be globally competitive, they might choose to follow the Magna example cited earlier and adopt the Toyota Production System (TPS) as standard operating procedure. However, it would be impossible to 
remain competitive in the long run without developing the organizational capabilities possessed by Toyota that enabled them to create the TPS in the first place, such as superior evolutionary learning capability (Fujimoto, 1999) and exemplary implementation of a kaizen teian (continuous improvement proposal) system rooted in the theories of TWI (Fujimoto, 1999; Shook, 2007). Recent authors echo this sentiment, stating that an organization wishing to duplicate Toyota's success should not copy the tools and techniques of TPS, but rather develop an adaptable workforce through daily practice of continuous improvement routines at every level of the organization (Soltero \& Boutier, 2012). The philosophy of the TWI Service was that the best way to improve the performance of a factory is by focusing on the role of the first line supervisor and his or her relationship with the work group. We could extend this to say that the best route to developing organizational adaptability through continuous improvement and innovation would also be to focus on the activities of the first line supervisor work group.

In this research we will use the construct of Employee Engagement as a measure of the level of "autonomous extrinsic motivation" within work groups in a mass production factory. As suggested by the literature on Self Determination Theory, an "engaged" workforce should be capable of higher levels of creativity that a workforce that is less engaged. Of particular interest is the level to which work groups in a mass production environment experience engagement, contrasted with those work groups in a more traditional "white collar" environment. We are specifically interested in the influence of the supervisor relationship on these engagement levels, versus other influences such as available resources of perceived organizational support. This leads to the following hypotheses:

- H1: Work groups in the mass production environment will have lower engagement levels than work groups in professional and technical support functions. 
- H2: Supervisor relationship has a positive influence on engagement levels of the work group.

We are then interested in the relationship between engagement levels of work groups and demonstrated results stemming from innovative behaviour and continuous improvement activities. This leads to the following hypotheses:

- H3: Work groups with higher engagement levels achieve better performance results from innovation and continuous improvement activity than those with lower engagement levels.

- H4: Work groups with higher engagement levels will exhibit higher levels of innovative behavior than those with lower engagement levels.

These hypotheses are the basis for the research model.

\section{Constructs}

\section{Employee Engagement}

The drivers of Employee Engagement are typically not elements found in the job descriptions for factory work. The Gallup Organization's twelve item construct called the Gallup Workplace Audit (GWA) is proprietary and takes a very broad view of engagement. The Utrecht Work Engagement Scale (UWES) is the most popular measure used by scholars, but some researchers argue that it confounds the measurement of engagement with its antecedent conditions. Recent work has unveiled a new construct for Job Engagement that identifies three factors: physical engagement, cognitive engagement, and emotional (Rich, Lepine, \& Crawford, 2010). This construct was tested on groups of firefighters and nurses, two employee categories (like mass production factory workers) typically not present in corporate engagement studies. However, one similarity between corporate professionals and firefighters and nurses is that all 
have a clear line of sight between their daily work and the ultimate customer of their services; it is unclear if mass production factory workers experience this same alignment. For our research we will use this most recent 18 item scale for job engagement.

\section{Perceived Organizational Support}

One of the drivers of employee engagement is that the employees have a positive perception of the organization and that they can see a connection between the work that they do and the results achieved by the organization. The construct of Perceived Organizational Support developed by Eisenberger et al has six factors that consider these perceptions (Eisenberger, Armeli, Rexwinkel, Lynch, \& Rhoades, 2001). In this context, the employee perceptions are more important than the mission statement of the company or even the opinions of executives; thus in this research we will use this construct to measure this effect on employee engagement levels.

\section{Resource Supply}

One of the drivers of Employee Engagement is the perception of having the appropriate resources available to do a good job. Resources may be material, tools, information, money or time. Scott and Bruce developed a construct for measuring resource supply as a driver of innovative behavior (Scott \& Bruce, 1994). They found that when studying a Research and Development (R\&D) lab where resources were plentiful, marginal supply of resources was less meaningful to the employees. However, in a lean factory environment that seeks to eliminate all types of perceived waste, the findings might be different. Also, this construct is of interest because it deals specifically with resources required to be creative, not just those required to reliably execute repetitive tasks. Hence we will use Scott and Bruce's construct for Resource 
Supply to measure the employees' perception and determine its effect on levels of Employee Engagement in a mass production organization.

\section{Supervisor Relationship}

The effectiveness of the Supervisor relationship with the workers will be measured using a seven item construct based on Leader-Member Exchange Theory (LMX) (Graen \& Uhl-Bien, 1995). This construct focuses on the working relationship between supervisors and their direct reports and includes the dimensions of respect, trust, and obligation. The seven items focus on the assessment of the leader in terms of capabilities and behaviors rather than favorable personality traits.

\section{Dependent Variables}

Empirical data available from existing factory measures will be used to measure the dependent variable of innovation and continuous improvement performance in the work group. As such, we need to select data that reflects the traits we are looking for. One indicator of innovative behavior stemming from intrinsically motivated individual activity is the submission of suggestions. Data for employee participation in the suggestion system is available and can be summarized at the work group level and normalized to account for work groups of different sizes. Another indicator of the intrinsically motivated behavior required for innovative solutions can be found in attendance data. Although attendance in the work place could be considered to be extrinsically motivated behavior (as employees are not compensated when they are absent), there is a certain portion of attendance that is considered discretionary, that is, casual absences that are allowed without disciplinary action. This attendance data can also be normalized at the work group level to create an index for comparison of work groups, to investigate the relationship between engagement levels and the use of allowable absenteeism. Work Group 
Productivity data is a good proxy for the results of continuous improvement activities, as it captures the results of many improvement efforts such as reductions in cycle time, scrap, machine downtime, and other forms of waste. This broad metric captures continuous improvement activities occurring on a daily basis in each work group as they strive to increase the output of good product with fewer resources. As stated in the literature, quality performance, although becoming an expectation in industry, is still a differentiator between auto parts suppliers. Internal factory quality data will be used to create an index that can be used to compare the relative performance of work groups with respect to consistently producing quality products for the next level customer in the supply chain. Data for these four measures will be collected for a five month period surrounding the survey administration and results. The data may have to be interpreted or normalized for relative comparison and to preserve confidentiality; however the integrity of the data will remain in order to ensure objective results. Further details will be discussed in Chapter 6.

\section{Exploratory Research Cases}

According to the literature, engaged employees will achieve superior results and contribute creative ideas toward continuous improvement initiatives: this is the unique resource or capability that an organization needs to realize a strategy of differentiation through innovation against competitors in low wage environments. Innovation occurs when new knowledge is applied to enable previously unmet needs to be satisfied, or to enable existing needs to be met in new ways. Innovation requires creative ideas; ideas come from people, and occur when a person with particular knowledge and perspective recognizes a problem or an opportunity and takes action. Creativity is unpredictable; any person is capable of being the source of a creative idea, and no one knows what that might be or how and when it might happen. Organizations cannot 
force creativity to happen, but they can focus on providing an environment that increases the probability of its occurrence (Robinson \& Stern, 1997). Creativity and the will to act come from intrinsic motivation, or from internalized extrinsic motivation (Gagne \& Deci, 2005; Pink, 2009). In this research we are also interested in how innovation is actually achieved. Therefore three research cases will be developed for exploratory purposes. In each case we will examine the implementation of a significant process innovation to explore the conditions surrounding each implementation. Through case study research we will attempt to determine: the actual process of innovation used by the organization; the factors or conditions required for successful process innovation; and the effectiveness of the organization's capability. From this research, conclusions and recommendations will be drawn in an attempt to answer the research question. 


\section{CHAPTER 4 RESEARCH DESIGN}

\section{Methodology}

This research is focused on the development of innovation capabilities in a mass production factory as a competitive strategy and will use mixed methods in the exploration and explanation of this topic. From the literature, we have a prior hypothesis and conceptual model that we are testing; this research will use various quantitative methods to measure the relationships between the constructs of interest and empirical results at the unit of analysis.

Accepted survey instruments will be used to measure the constructs of Job Engagement, Resource Supply, Perceived Organizational Support, and Leader Member Exchange. Available data from factory operations in the manufacturing facilities will be used to measure the relative performance of work groups with respect to Continuous Improvement activities and level of Innovative behavior. Structural Equation Modelling and Regression analysis will be used to compare the relationships between the constructs and the achieved results at the work group level, and to determine the statistical significance of any relationships.

Additionally, the qualitative method of case study research will be used to examine specific process innovation projects in an attempt to illustrate how and why these particular results were realized in practice. The case studies will be used to illustrate the extent that the theoretical constructs derived from the literature were actually realized in practice; additionally, case study analysis may reveal the importance of one or more conditions required for the successful realization of innovative solutions. The case studies will provide background information, illustrate methodologies, and highlight specific points of strength or weakness of the different Work Groups relative to the achievement of innovative solutions. 


\section{Sample}

We are primarily interested in work groups within auto parts manufacturing plants in high labor cost jurisdictions in North America. Therefore this study will focus on the North American facility of the TRAM Group (Tokai Rika North America) manufacturing seat belt assemblies in Southwestern Ontario, Canada. In addition to providing a significant number of supervisors and work groups, the author has access to plant level performance data in these facilities.

A specific reason that this facility is of interest to this study is that Tokai Rika is a member of the Toyota Group of companies, and this North American plant has been established for over 20 years. As such, this plant should be among the best practitioners of the Toyota Production System (TPS) in North America. The competitiveness of the auto industry in Canada is a critical issue for the levels of government in Ontario and Canada as well as for the industry itself, and TPS is seen as a key component of that competitiveness. This research will attempt to look beyond the process hardware and uncover the implementation levels of the "software" of TPS at the work group level, perhaps providing some indication of future competitive ability in the area of continuous innovation.

\section{Data Collection}

Surveys containing the construct items will be administered by the Human Resources (HR) department. This will help ensure the integrity of the responses as HR surveys are a common practice in this organization.

Case studies will be developed by the author, through site visits, document reviews, and interviews with various levels of management as well as those directly involved with continuous improvement systems and implemented improvement projects. The author also has the benefit of 
participant observation in the cases. Standard questions will be used as a starting point; as situations reveal themselves, these may be modified, or specific areas may be pursued.

\section{Data Analysis}

The analysis of quantitative data will be done with the statistical package IBM SPSS v23 (including AMOS).

Case study interviews will be recorded in the words of the participants and informants. Exhibits will be provided to support the case material, although some alteration may be required for anonymity. Names will not be used and some performance data may be indexed for confidentiality.

\section{Contribution}

This research will make a unique contribution to the academic literature in three ways:

1. Engagement levels of factory workers will be studied. Few studies in the literature have applied the concept of Employee Engagement to factory workers to determine if improved performance is the result.

2. This study will use actual factory performance data to measure the dependent variable rather than relying on a self-reported executive survey as a measure of innovative activity.

3. This study attempts to identify necessary organizational conditions for innovation through case study research of actual, implemented process innovations. These cases will also illustrate the contributions of the various work groups in the context of a major innovation project. 
Additionally, this study will be of interest to practitioners and managers in manufacturing facilities in high labor cost environments, as they may be searching for operational levers to achieve a differentiation strategy. 


\section{CHAPTER 5 SURVEY RESEACH, RESULTS, AND ANALYSIS}

A survey was developed to measure the constructs outlined in the previous section. The actual instruments and citations are listed in the Appendix. To facilitate ease of completion, all items were worded in the form of a statement so that the answer could be indicated on a 5 point Likert scale $(1=$ Strongly Disagree to $5=$ Strongly Agree $)$. The statements were then arranged on the survey in random order so that construct items were not grouped together and the particular nature of the survey could not easily be discerned. In addition to the 37 construct statements, the survey also asked for tenure (circle a range) and employment status (full time or temporary). The survey was 1 page, 2 sided, and could be completed in less than 15 minutes. The actual survey instrument is included in the Appendix.

The survey was given to all employees of TRQSS in October, 2015, and was administered by the Human Resources Department. This is not an unusual practice for the company. Survey respondents were not asked to indicate the name of their team leader, but the survey was administered to one team leader work group at a time; completed survey sheets were collected and sealed in an envelope so that the results could be analysed at the work group level. In addition to the factory employees, the survey was administered to all management and technical support groups as well, again segregated by team leader or manager work group.

In all there were 727 survey responses that were usable in the study, which consisted of 603 respondents whose daily work involves mass production of parts, and 124 respondents who work in management or technical support functions. This response rate is over $80 \%$ of the company population, which would be an adequate representation of the whole. 


\section{Descriptive Statistics}

Based on the literature, we have an a priori assumption that employee engagement levels for associates who work in daily mass production will be different (lower) than those employees who work in management or technical support. This is due to the fact that employees in daily mass production would tend to experience fewer of the engagement drivers cited in the literature, such as decision making authority, customer focus, and a direct connection with upper management. Because of this assumption, the survey response data was divided into two sets; one for employees in mass production roles (named "Floor", $\mathrm{N}=603$ ) and one for management and technical support employees (named "Support", N=124). Prior to any in depth analysis, the Descriptive Statistics for each data set were reviewed and compared as shown in Table 1.

Table 1 Comparison of Construct Mean Values between Data sets

\begin{tabular}{|l|l|l|l|}
\hline \multicolumn{1}{|c|}{ Construct (Items) } & \multicolumn{1}{|c|}{ Support } & \multicolumn{1}{|c|}{ Floor } & \multicolumn{1}{|c|}{ Mean } \\
\hline Cognitive Engagement (C1 - C6) & 4.444348 & 4.119581 & 0.3248 \\
\hline Physical Engagement (P1 - P6) & 4.401429 & 4.191937 & 0.2095 \\
\hline Emotional Engagement (E1 - E6) & 4.081172 & 3.646566 & $\mathbf{0 . 4 3 4 6}$ \\
\hline Supervisor Relationship (L1 - L7) & 3.678872 & 3.414736 & 0.2641 \\
\hline Organizational Support (O1 - O6) & 3.070089 & 2.811980 & 0.2581 \\
\hline Resource Support (R1 - R6) & $\mathbf{2 . 8 5 0 5 0 3}$ & $\mathbf{2 . 7 9 3 0 1 9}$ & $\mathbf{0 . 0 5 7 5}$ \\
\hline
\end{tabular}

For every construct, the mean levels from the "Support" data set were higher than those from the "Floor" data set, with the greatest difference being in the Emotional Engagement and Cognitive Engagement constructs respectively. Interestingly, there was very little difference in 
the mean levels for the construct of Resource Support, which is how employees perceived the availability of resources to develop creative ideas; for both groups it, was the lowest rated construct. This brief review suggests that the a priori assumption may be true, so further statistical analysis was undertaken on each data set separately.

\section{Exploratory Factor Analysis}

Exploratory Factor Analysis and Factor Reliability were performed on each data set separately using Principal Axis Factoring in IBM SPSS. We are performing this step to determine if there are any links or covariation between any of the theoretical constructs.

\section{Data Set "Support"}

The survey instrument consisted of 37 items designed to measure 6 factors. The Pattern Matrix resulting from the Factor Analysis identified 8 factors, although Factors 7 and 8 consisted of items that cross loaded to other factors (See Figure 2).

All of the items representing the constructs of Physical Engagement (6 items) and Cognitive Engagement (6 items) loaded to 1 Factor. Three of these twelve items also cross loaded to Factor 8; however, the differences between the loading values are all less than 0.2, suggesting that these items could be omitted.

All 7 items designed to measure Supervisor Relationship loaded onto Factor 2, with item L5 being relatively weak and cross loaded to factor 7 . The weakness of the loading value and the difference of only 0.126 suggest that this item could also be removed. 
$\underline{\text { Figure } 2 \text { Pattern Matrix for "Support" Data set }}$

\begin{tabular}{|c|c|c|c|c|c|c|c|c|}
\hline \multicolumn{9}{|c|}{ Pattern Matrix ${ }^{a}$} \\
\hline & \multicolumn{8}{|c|}{ Factor } \\
\hline & 1 & 2 & 3 & 4 & 5 & 6 & 7 & 8 \\
\hline $\mathrm{C} 2$ & .973 & & & & & & & \\
\hline $\mathrm{C} 3$ & .863 & & & & & & & \\
\hline $\mathrm{C} 6$ & .838 & & & & & & & \\
\hline P2 & .783 & & & & & & & \\
\hline P4 & .729 & & & & & & & \\
\hline P3 & .700 & & & & & & & \\
\hline P5 & .679 & & & & & & & .503 \\
\hline P1 & .614 & & & & & & & \\
\hline P6 & .600 & & & & & & & \\
\hline C1 & .590 & & & & & & & .403 \\
\hline $\mathrm{C} 4$ & .567 & & & & & & & \\
\hline C5 & .560 & & & & & & & .456 \\
\hline L6 & & .921 & & & & & & \\
\hline L7 & & .851 & & & & & & \\
\hline L2 & & .830 & & & & & & \\
\hline L1 & & .765 & & & & & & \\
\hline L3 & & .751 & & & & & & \\
\hline L4 & & .733 & & & & & .392 & \\
\hline 03 & & & .808 & & & & & \\
\hline 01 & & & .802 & & & & & \\
\hline 06 & & & .647 & & & & .337 & \\
\hline 04 & & & .578 & & & & & \\
\hline 02 & & & .562 & & & & & \\
\hline 05 & & & .556 & & & & & \\
\hline E3 & .350 & & .393 & & & & & \\
\hline R3 & & & & .794 & & & & \\
\hline $\mathrm{R} 2$ & & & & .783 & & & & \\
\hline R6 & & & & .580 & & & .352 & \\
\hline R1 & & & & .522 & & & & \\
\hline E2 & & & & & 1.082 & & & \\
\hline E6 & & & & & .646 & & & \\
\hline E1 & & & & & .612 & & & \\
\hline E5 & & & & & .534 & & & \\
\hline E4 & & & & & .421 & & & \\
\hline R4 & & & & & & .739 & & \\
\hline R5 & & & & & & .689 & & \\
\hline L5 & & .341 & & & & & .467 & \\
\hline
\end{tabular}

Factor 3 contained all items designed to measure Perceived Organizational Support (O1 O6) as well as a weakly loaded item E3 (designed to measure Emotional Engagement), which 
also cross loaded weakly onto Factor 1 . All other items reflecting Emotional Engagement (E1, E2, E4, E5, and E6) loaded onto Factor 5. Factor 4 factor included four of the six items designed to measure Perceived Resource Support, with the exception of R4 and R5, which loaded to a unique sixth factor. Reviewing those specific items on the survey reveals that they were both "reverse coded"; variation in responses due to misinterpretation of these statements could account for this unique loading.

After adjusting the construct items to align with the factors based on these results of the EFA, Factor Reliability Analysis was performed using SPSS.

Factors 1 and 2 had high Cronbach's Alpha (0.923 and 0.919 respectively) with no improvement suggested if any items were removed. Factor 3 yielded a CA of 0.845 with suggested improvement if item O5 was removed. Reliability analysis of the 5 item factor resulted in a CA of 0.885 with further improvement opportunity if item O6 was removed: the modified 4 item factor yields a CA of 0.894 with no further improvement opportunity. Factor 4 and 5 produced reasonable $\mathrm{CA}$ values with no modifications. Factor 6 , which consisted of the 2 reverse coded items, had a poor CA with poor correlation between the 2 items. Consequently, this factor was dropped.

After Factor Reliability Analysis, the configuration of Constructs for the "Support" data set is shown in Table 2. Factor 1 was named "Effort", as it contains all the items pertaining to both Physical and Cognitive Engagement. 
Table 2 Resulting Constructs for "Support" Data set after EFA

\begin{tabular}{|c|l|l|c|}
\hline \multicolumn{2}{|c|}{ Data Set "Support" } & \multicolumn{1}{|c|}{ Name } & CA \\
\hline Items & \multicolumn{1}{|c|}{ Nactor \# } & \multicolumn{1}{|c|}{ Effort } & 0.923 \\
\hline 1 & $\mathrm{C} 2, \mathrm{C} 3, \mathrm{C} 4, \mathrm{C} 6, \mathrm{P} 1, \mathrm{P} 2, \mathrm{P} 3, \mathrm{P} 4, \mathrm{P} 6$ & Supervisor Relationship & 0.919 \\
\hline 2 & $\mathrm{~L} 1, \mathrm{~L} 2, \mathrm{~L} 3, \mathrm{~L} 4, \mathrm{~L} 6, \mathrm{~L} 7$ & Organization Support & 0.894 \\
\hline 3 & $\mathrm{O} 1, \mathrm{O} 2, \mathrm{O} 3, \mathrm{O} 4$ & Resource Support & 0.830 \\
\hline 4 & $\mathrm{R} 1, \mathrm{R} 2, \mathrm{R} 3, \mathrm{R} 6$ & Emotional Engagement & 0.881 \\
\hline 5 & $\mathrm{E} 1, \mathrm{E} 2, \mathrm{E} 4, \mathrm{E} 5, \mathrm{E} 6$ & & \\
\hline
\end{tabular}

\section{Data Set "Floor"}

The Pattern Matrix resulting from from the EFA of data set "Floor" is shown in Figure 3. Although the Pattern Matrix indicates six factors, the sixth contains only one weak cross loading of an item that strongly loads onto Factor 1. In the same manner as the Support data set, all items pertaining to Cognitive and Physical Engagement loaded together on Factor 1 (12 items). Factor 2 shows where the analysis starts to differ between the two data sets, as 5 of the 6 items representing Organization Support and 4 of the 6 items representing Resource Support loaded together on this factor. In this data set there is less of a distinction between these 2 constructs. The remaining 3 items for these constructs loaded onto Factor 5, with the loading values being relatively weak. Interestingly, these three items were all "reverse coded" in the original survey; these factor loadings are perhaps an indication that these responses were the result of mixed or misinterpretations among the respondents in this data set. 
Figure 3 Pattern Matrix for "Floor" Data set

Pattern Matrix ${ }^{\mathrm{a}}$

\begin{tabular}{|c|c|c|c|c|c|c|}
\hline & \multicolumn{6}{|c|}{ Factor } \\
\hline & 1 & 2 & 3 & 4 & 5 & 6 \\
\hline C6 & .920 & & & & & \\
\hline P4 & .885 & & & & & \\
\hline C3 & .839 & & & & & \\
\hline P2 & .813 & & & & & \\
\hline P6 & .779 & & & & & -309 \\
\hline P1 & .774 & & & & & \\
\hline $\mathrm{C} 2$ & .752 & & & & & \\
\hline P3 & .716 & & & & & \\
\hline P5 & .672 & & & & & \\
\hline C5 & .648 & & & & & \\
\hline C1 & .631 & & & & & \\
\hline C4 & .614 & & & & & \\
\hline 03 & & .719 & & & & \\
\hline R6 & & .718 & & & & \\
\hline 01 & & .717 & & & & \\
\hline 06 & & .699 & & & & \\
\hline 02 & & .685 & & & & \\
\hline 04 & & .683 & & & & \\
\hline R3 & & .683 & & & & \\
\hline R2 & & .678 & & & & \\
\hline R1 & & .645 & & & & \\
\hline L2 & & & .857 & & & \\
\hline L7 & & & .831 & & & \\
\hline L6 & & & .829 & & & \\
\hline L1 & & & .786 & & & \\
\hline L4 & & & .731 & & & \\
\hline L3 & & & .720 & & & \\
\hline L5 & & & .541 & & & \\
\hline E6 & & & & .781 & & \\
\hline E3 & & & & .766 & & \\
\hline E1 & & & & .723 & & \\
\hline E4 & & & & .657 & & \\
\hline E5 & & & & .651 & & \\
\hline E2 & .326 & & & .427 & & \\
\hline 05 & & & & & .510 & \\
\hline R5 & & & & & .463 & \\
\hline R4 & & & & & .421 & \\
\hline
\end{tabular}

Extraction Method: Principal Axis Factoring.

Rotation Method: Promax with Kaiser Normalization. ${ }^{\text {a }}$

a. Rotation converged in 6 iterations. 
As with the Support data set, the 7 items measuring Supervisor Relationship loaded together on one Factor, with L5 being the weakest loading (although it did not cross load). The 6 items measuring Emotional Engagement loaded together on 1 Factor, but in this case E2 was the weakest value with a close cross loading onto Factor 1, suggesting that it could be omitted. Ironically, in the Support data set, E2 was the strongest loading item within the factor and E3 was dropped. The following table shows the difference in these two items:

\begin{tabular}{|c|l|l|}
\hline Item & \multicolumn{1}{|c|}{ Statement } & \multicolumn{1}{c|}{ Result } \\
\hline E2 & I feel energetic at my job & Cross loaded with Effort in "Floor" data set \\
\hline E3 & I am interested in my job & Cross loaded with Effort in "Support" data set \\
\hline
\end{tabular}

In the Floor data set, it seems unclear if item E2 is indicating Emotion Engagement or Effort. In the Support data set, the same can be said for item E3. Given that jobs within the Floor data set are more physical in nature, and jobs within the Support data set are more cognitive in nature, this is understandable, as the Effort Factor as interpreted by both data sets contains both Physical and Cognitive Engagement items. ${ }^{6}$

After adjusting the constructs based on these results of the EFA, Factor Reliability Analysis was performed using SPSS. As a result of this analysis, Factor 5 yielded a Cronbach's Alpha value of 0.455 and was eliminated. The remaining 4 factors are shown in Table 3 with their respective $\mathrm{CA}$ values.

\footnotetext{
${ }^{6}$ Several of the statements in the various engagement constructs are only subtly different in wording.
} 
Table 3 Resulting Constructs for "Floor" Data set after EFA

\begin{tabular}{|c|l|l|c|}
\hline \multicolumn{2}{|c|}{ Data Set "Floor" } & \multicolumn{1}{|c|}{ Name } \\
\hline Items & \multicolumn{1}{|c|}{ CA } \\
\hline 1 & $\mathrm{C} 1, \mathrm{C} 2, \mathrm{C} 3, \mathrm{C} 4, \mathrm{C} 5, \mathrm{C} 6, \mathrm{P} 1, \mathrm{P} 2, \mathrm{P} 3, \mathrm{P} 4, \mathrm{P} 5, \mathrm{P} 6$ & Effort & 0.935 \\
\hline 2 & $\mathrm{~L} 1, \mathrm{~L} 2, \mathrm{~L} 3, \mathrm{~L} 4, \mathrm{~L} 6, \mathrm{~L} 7$ & Supervisor Relationship & 0.919 \\
\hline 3 & $\mathrm{O} 1, \mathrm{O} 2, \mathrm{O} 3, \mathrm{O} 4, \mathrm{O} 6$ & $\begin{array}{l}\text { Organization and } \\
\text { Resource Support }\end{array}$ & 0.908 \\
\hline 4 & $\mathrm{R} 1, \mathrm{R} 2, \mathrm{R} 3, \mathrm{R} 6$ & Emotional Engagement & 0.915 \\
\hline
\end{tabular}

Given that our first hypothesis pertains to the Job Engagement levels of employees who work in daily mass production roles, further analysis will focus first on the "Floor" data set.

\section{Confirmatory Factor Analysis}

With the results obtained from the EFA, Confirmatory Factor Analysis was performed using IBM AMOS v23. Having adjusted the original survey constructs to reflect the results of the EFA for each data set, we now wish to test these modified constructs statistically. The literature suggests that the constructs of Effort and Emotional Engagement together create the second order construct called Job Engagement (Rich et al., 2010), and that Job Engagement levels will be influenced by the constructs Supervisor Relationship and Organization and Resource Support (Deutsch, 2011; Harter, 2002; Towers-Perrin, 2003). The Measurement Model used for the Confirmatory Factor Analysis for the constructs Supervisor Relationship and Organization and Resource Support is shown in Figure 4. Analysis of the Floor data set using this model suggested that covariance existed between some of the error terms of the items comprising the Organization and Resource Support construct. After these modifications to the model (shown by the covariance arrows in the graphic) the Comparative Fit Index (CFI) was 0.970 and the Root Mean Square Error of Approximation was 0.057, with a 90\% confidence interval of 0.049 to 0.066 . Values of 0.95 or higher for CFI and 0.05 or lower for RMSEA are considered representative of 
a well fitting model (Byrne, 2010). The resultant parameter estimates are shown on the model in

Figure 4, and all were significant at the $\mathrm{P}>0.001$ level.

Figure 4 Measurement (CFA) Model for Supervisor Relationship and Organization and $\underline{\text { Resource Support for "Floor" Data set }}$

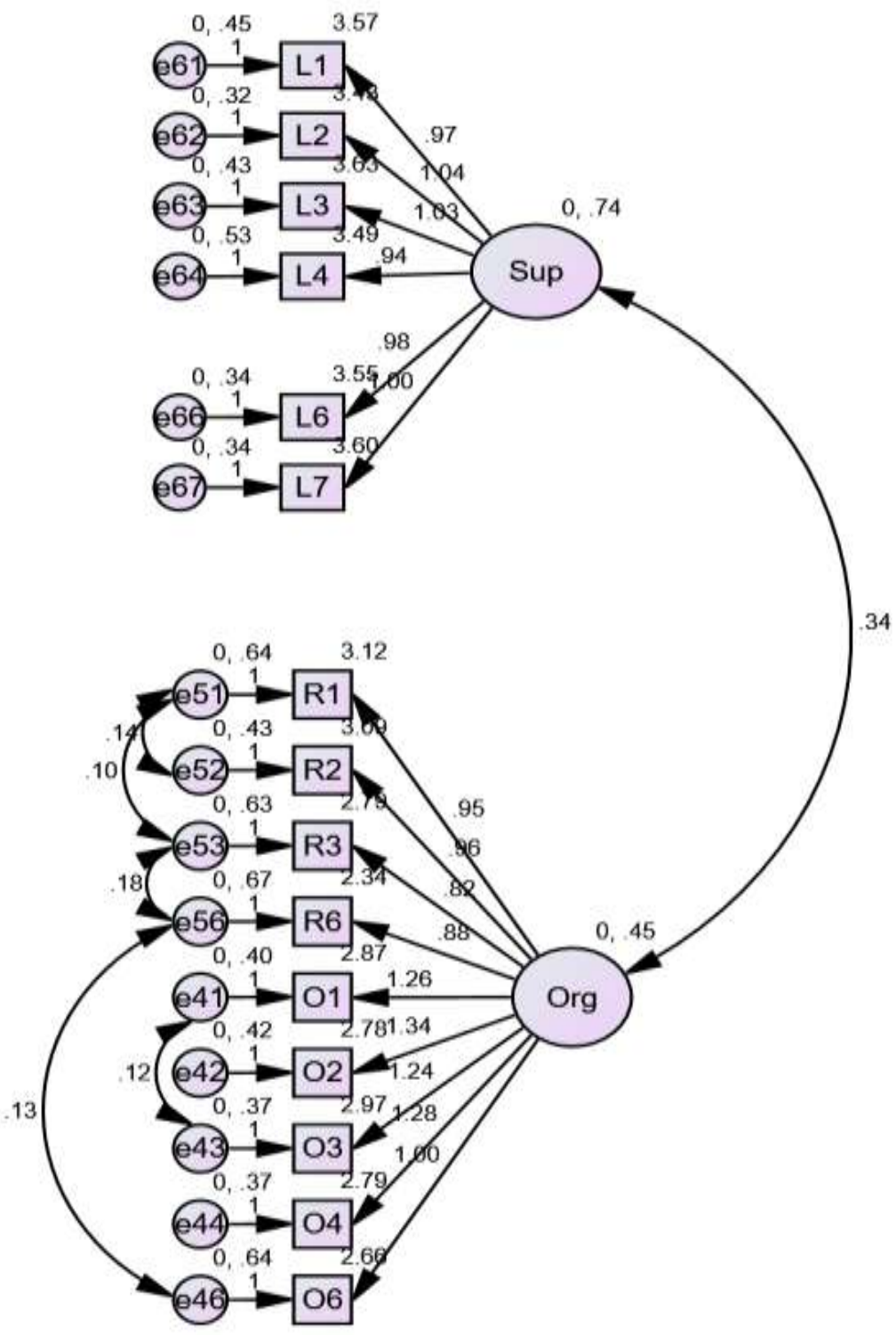


Next, a Measurement Model was constructed for the constructs Effort and Emotional Engagement, and we performed a Confirmatory Factor Analysis using the response data from the Floor data set. This CFA model is shown in Figure 5.

Figure 5 Measurement (CFA) Model for Effort and Emotional Engagement for "Floor" Data set

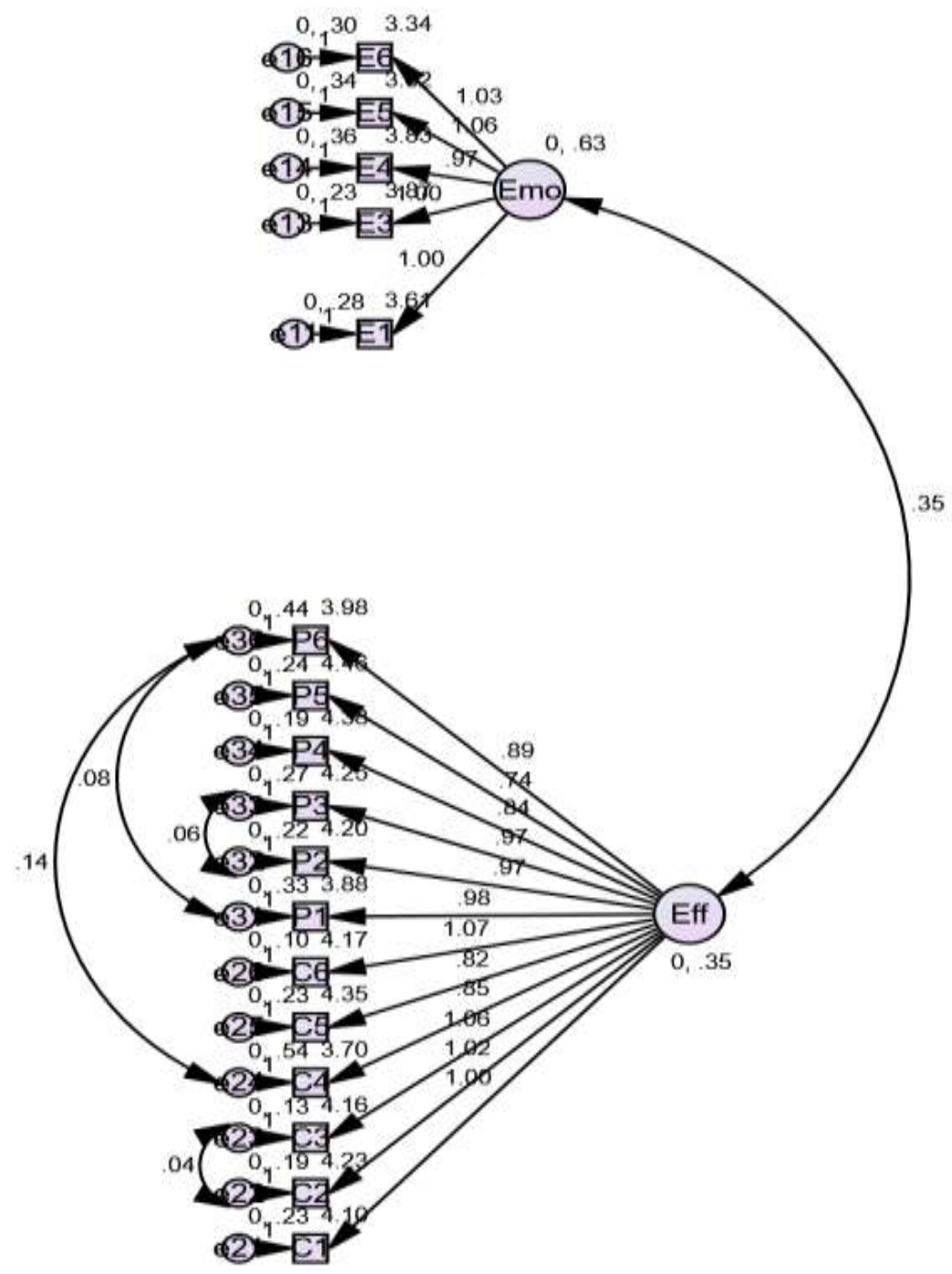


As shown in the graphic, the analysis indicated covariance between some of the error terms for the items comprising the Effort construct. The Model Fit indices were CFI=0.952 and RMSEA $=0.072$ with a $90 \% \mathrm{CI}$ of 0.065 to 0.078 . The level of this latter index is not ideal, but all the estimates for parameter means and variances were strong and significant at the 0.001 level, and the Modification Indices suggested no further significant improvements to be made to the model, so we will accept that the factors are measured by the items as shown in the model.

Attempts to validate the construct of Job Engagement as a second order construct consisting of the latent factors Effort and Emotional Engagement using AMOS were unsuccessful, as with only two factors, the model is under identified (Byrne, 2010).

\section{Structural Equation Model}

Since our Conceptual Model indicates that Job Engagement levels are influenced by one's perception of Organization and Resource Support and the relationship with one's Supervisor, we will use AMOS to create a Causal Model using the confirmed constructs. This Structural Equation Model is shown in Figure 6. Since a second order factor of Job Engagement couldn't be created, relationships between the independent and dependent constructs were modeled directly. For the full structural equation model, the fit indices were CFI=0.952 and $\mathrm{RMSEA}=0.049$ with a $90 \% \mathrm{CI}$ of 0.045 to 0.053 , indicating that this model well represents the data set. Estimates of the regression weights are shown in the table in Figure 7. 
Figure 6 Structural Equation Model for Job Engagement for "Floor" Data set

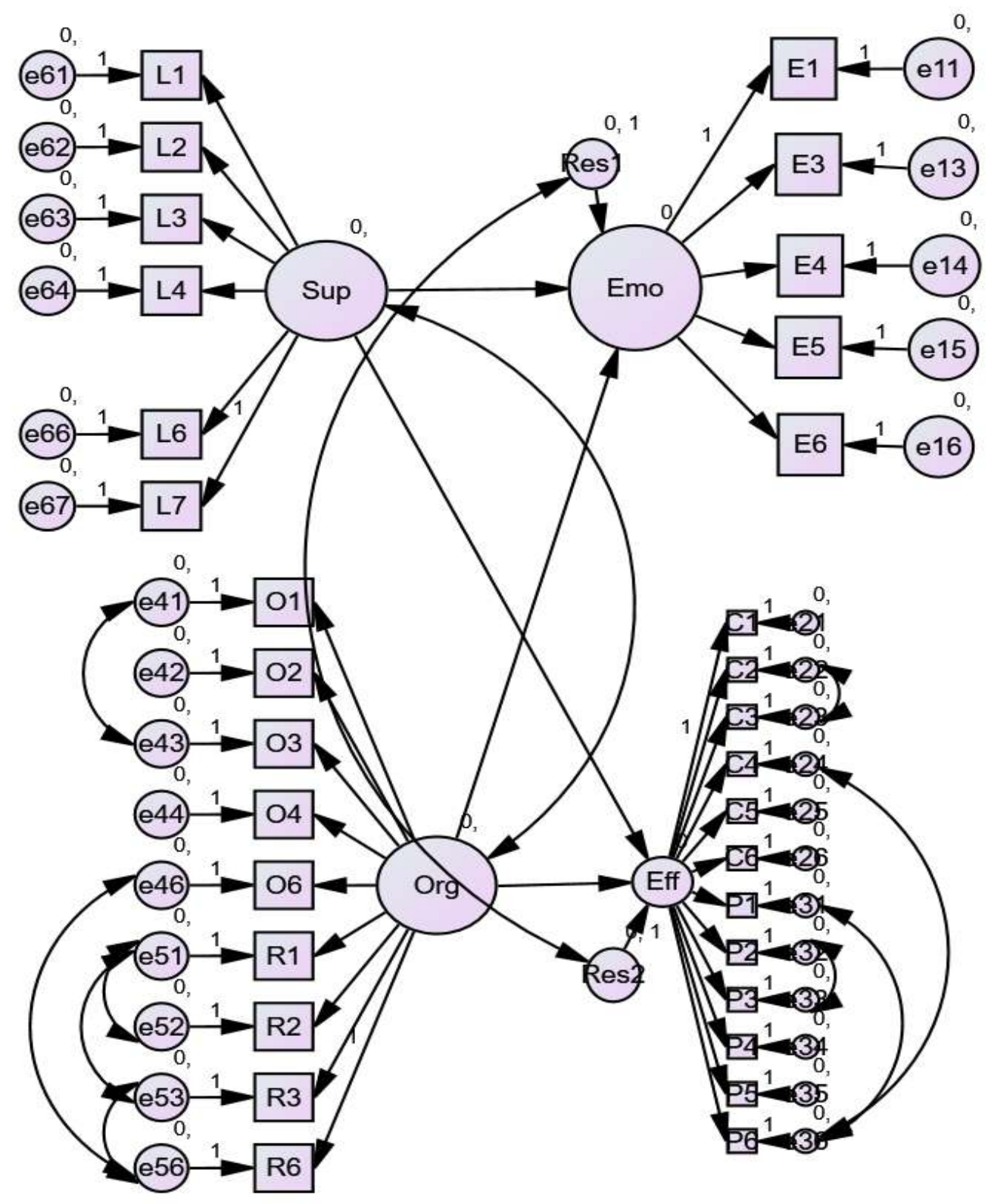


Figure 7 Estimates of Regression weights for Structural Equation Model for "Floor" Data set

\begin{tabular}{|c|c|c|c|c|c|c|c|}
\hline & & & Estimate & S.E. & C.R. & $\mathrm{P}$ & Label \\
\hline Emotional & $<--$ & Supervisor & .099 & .039 & 2.523 & .012 & par_9 \\
\hline Emotional & $<---$ & Organization & .895 & .081 & 11.025 & $* * *$ & par_19 \\
\hline Effort & $<--$ & Supervisor & .056 & .035 & 1.581 & .114 & par_34 \\
\hline Effort & $<--$ & Organization & .416 & .059 & 7.061 & $* * *$ & par_35 \\
\hline Emotional & $<--$ & Residual1 & .531 & .024 & 21.736 & $* * *$ & par_36 \\
\hline Effort & $<--$ & Residual2 & .524 & .024 & 22.032 & $* * *$ & par_37 \\
\hline E3 & $<---$ & Emotional & .989 & .040 & 24.877 & $* * *$ & par_1 \\
\hline $\mathrm{E} 4$ & $<--$ & Emotional & .983 & .043 & 22.800 & $* * *$ & par_2 \\
\hline E5 & $<--$ & Emotional & 1.078 & .044 & 24.467 & $* * *$ & par_3 \\
\hline L7 & $<--$ & Supervisor & 1.000 & & & & \\
\hline L6 & $<---$ & Supervisor & .980 & .041 & 23.742 & $* * *$ & par_4 \\
\hline L4 & $<--$ & Supervisor & .939 & .045 & 20.643 & $* * *$ & par_5 \\
\hline L3 & $<--$ & Supervisor & 1.032 & .045 & 23.030 & $* * *$ & par_6 \\
\hline L2 & $<---$ & Supervisor & 1.044 & .042 & 24.788 & $* * *$ & par_7 \\
\hline L1 & $<--$ & Supervisor & .970 & .044 & 21.982 & $* * *$ & par_8 \\
\hline E1 & $<--$ & Emotional & 1.000 & & & & \\
\hline E6 & $<--$ & Emotional & 1.038 & .042 & 24.494 & $* * *$ & par_10 \\
\hline R6 & $<--$ & Organization & 1.000 & & & & \\
\hline R3 & $<---$ & Organization & .933 & .069 & 13.616 & $* * *$ & par_11 \\
\hline R2 & $<--$ & Organization & 1.099 & .081 & 13.490 & $* * *$ & par_12 \\
\hline R1 & $<--$ & Organization & 1.089 & .088 & 12.410 & $* * *$ & par_13 \\
\hline O6 & $<---$ & Organization & 1.130 & .080 & 14.044 & $* * *$ & par_14 \\
\hline $\mathrm{O} 4$ & $<--$ & Organization & 1.461 & .099 & 14.795 & $* * *$ & par_15 \\
\hline $\mathrm{O} 3$ & $<--$ & Organization & 1.411 & .096 & 14.641 & $* * *$ & par_16 \\
\hline $\mathrm{O} 2$ & $<--$ & Organization & 1.524 & .104 & 14.714 & $* * *$ & par_17 \\
\hline $\mathrm{O} 1$ & $<---$ & Organization & 1.437 & .099 & 14.577 & $* * *$ & par_18 \\
\hline $\mathrm{C} 1$ & $<---$ & Effort & 1.000 & & & & \\
\hline $\mathrm{C} 2$ & $<--$ & Effort & 1.021 & .047 & 21.911 & $* * *$ & par_23 \\
\hline $\mathrm{C} 3$ & $<--$ & Effort & 1.062 & .045 & 23.789 & $* * *$ & par_24 \\
\hline $\mathrm{C} 4$ & $<---$ & Effort & .851 & .060 & 14.243 & $* * *$ & par_25 \\
\hline C5 & $<--$ & Effort & .821 & .044 & 18.657 & $* * *$ & par_26 \\
\hline C6 & $<--$ & Effort & 1.075 & .043 & 24.927 & $* * *$ & par_27 \\
\hline $\mathrm{P} 1$ & $<--$ & Effort & .981 & .053 & 18.665 & $* * *$ & par_28 \\
\hline $\mathrm{P} 2$ & $<---$ & Effort & .971 & .047 & 20.664 & $* * *$ & par_29 \\
\hline P3 & $<---$ & Effort & .968 & .050 & 19.510 & $* * *$ & par_30 \\
\hline P4 & $<--$ & Effort & .841 & .042 & 19.805 & $* * *$ & par_31 \\
\hline P5 & $<---$ & Effort & .745 & .043 & 17.368 & $* * *$ & par_32 \\
\hline P6 & $<---$ & Effort & .886 & .056 & 15.852 & $* * *$ & par_33 \\
\hline
\end{tabular}


The Regression Estimates shown in Figure 7 indicate that the Supervisor Relationship has very little impact on either Emotional Engagement or Effort, and neither estimate is significant at the 0.001 level. However, the model indicates that the largest impact on Emotional Engagement levels of the employees in the Floor data set is their perception of Organizational and Resource Support; for every one point increase in the construct Organization and Resource Support as measured by the 9 items shown, Emotional Engagement increases by 0.895, and this relationship is significant at the 0.001 level. Organization and Resource support also has a statistically significant influence on Effort, but the regression weight is only half as strong (0.416).

\section{Confirmatory Factor Analysis of "Support" Data Set}

Next we perform Confirmatory Factor Analysis on the results of the EFA for the Support data set. One major difference that emerged from the EFA between the two data sets was that the Support data set was able to identify the constructs of Organizational Support and Resource Support as separate factors. Confirmatory Factor Analysis (CFA) was performed using IBM AMOS v23 on the measurement model for the Support data set. The results are shown in Figure

8. The model shows that covariance exists between some of the various error terms. The model exhibits a CFI of 0.952, which is good, and a RMSEA of 0.080, which is less than ideal; however, suggested modification indices offered relatively minor improvement. All of the factor estimates shown in Figure 8 are strong and statistically significant at the 0.001 level. 
Figure 8 Measurement Model (CFA) for Resource Support, Organizational Support, and Supervisor Relationship for "Support" Data set

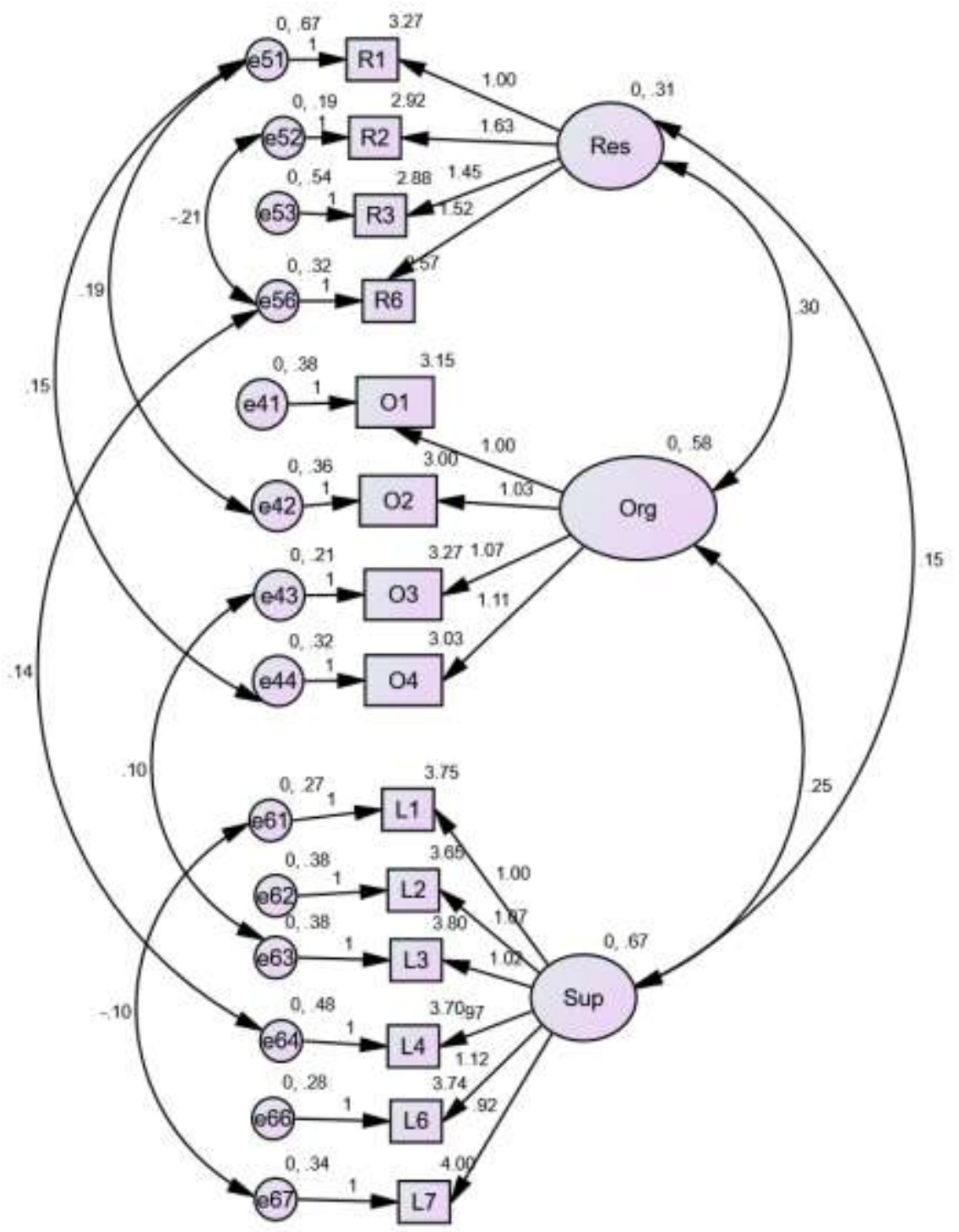

For the Support data set, the factors of Effort and Emotional Engagement were similar to the Floor data set. Confirmatory Factor Analysis was performed on this measurement model for the Support data set as well. The result is shown in Figure 9. 
Figure 9 Measurement Model (CFA) for Effort and Emotional Engagement for "Support" Data $\underline{\text { set }}$

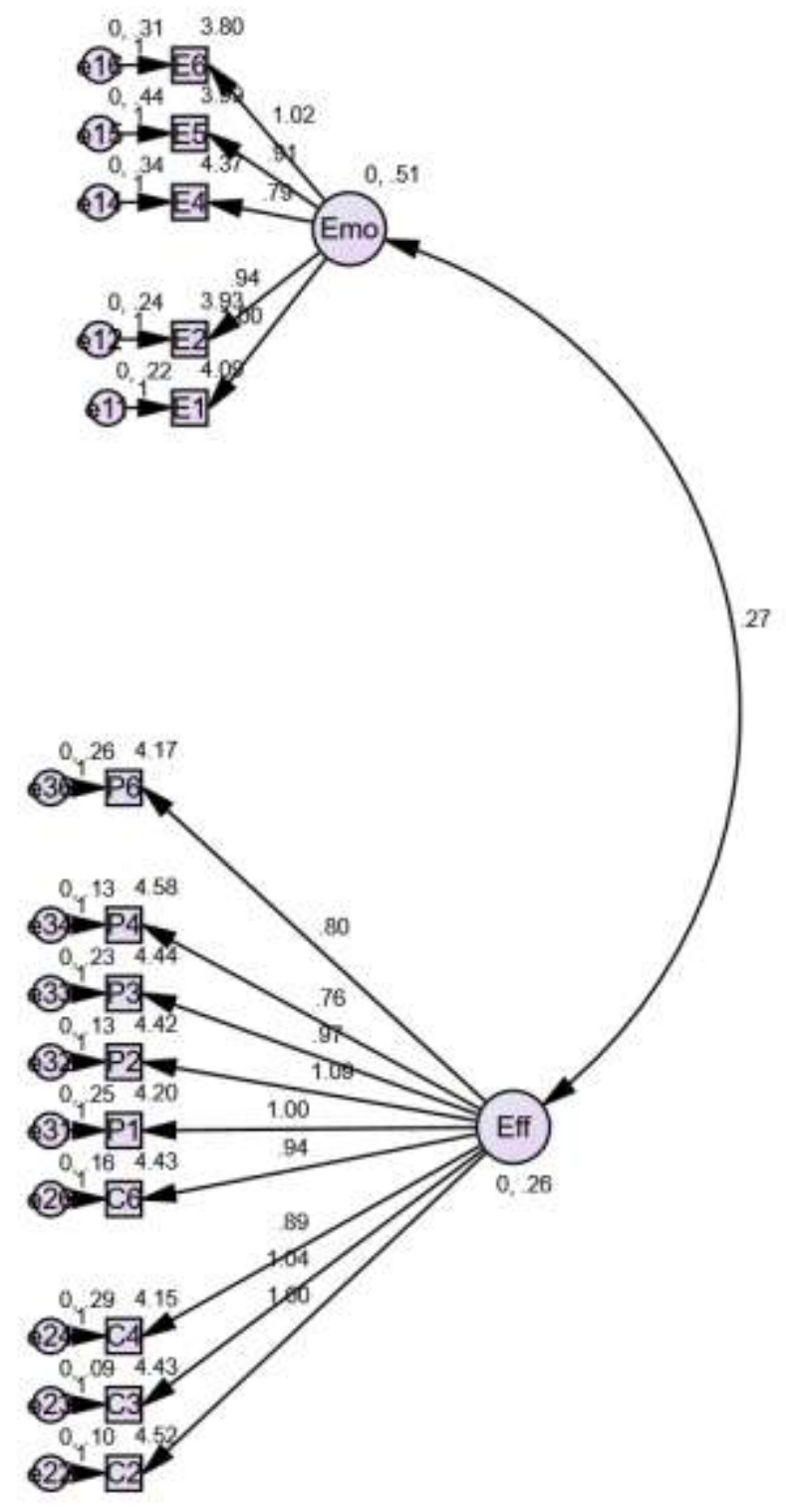

All parameter estimates shown in Figure 9 are significant at the 0.001 level. The Model fit indices were very good, with CFI $=0.965$ and $\mathrm{RMSEA}=0.063$, with a $90 \%$ confidence interval of 0.036 to 0.086 . 


\section{Structural Equation Model for Support Data Set}

Our Conceptual Model indicates that Job Engagement levels are influenced by one's perception of Organization and Resource Support and the relationship with one's Supervisor. We will use AMOS to create a Causal Model between the confirmed constructs, which is slightly different for the Support data set than it was for the Floor data set. After suggested modifications for covariance between error measures, the resulting Structural Equation Model is shown in Figure 10. Since a second order factor of Job Engagement couldn't be created, relationships between the hypothesized independent and dependent factors were modeled directly. For the full structural equation model, the fit indices were CFI $=0.888$ and RMSEA $=0.081$ with a $90 \%$ CI of 0.070 to 0.091 . These indices suggest that this model doesn't fit the Support data set as well the corresponding model did for the Floor data set. This could be a result of the fact that the Support data set, which includes management as well as technical support specialists in the company, is smaller and more diverse than the Floor data set. However, some interesting observations emerge from examination of the Parameter Estimates, shown in Figure 11.

First, as observed with the Floor data set, the largest and most significant influence on Emotional Engagement levels is the perception of Organizational Support. This is where the similarities end however; while the relationship is significant at the 0.001 level, the magnitude of this estimate is just over half of what it was for the Floor data set at 0.486 . For the Support data set, Supervisor Relationship had a significant influence on Emotional Engagement as well with a parameter estimate of 0.296 . This relationship did not exist in the model for the Floor data set, but for the Support data set, the supervisor in question is most likely a manager at a minimum and in some cases a member of the company senior management team. This observation is consistent with some of the research findings in the literature (Deutsch, 2011). Another 
interesting observation is that for the Support data set, perception of Resource Availability had almost no influence whatsoever on Emotional Engagement levels. This observation runs counter to some of the literature that cites resource availability as a driver of engagement (Towers-Perrin, 2003).

The results of the analysis also indicate that none of the independent construct variables had much influence at all on the factor called Effort, which is the combination of the survey constructs of Physical and Cognitive Engagement. All of the estimates were weak, and only the influence of Supervisor Relationship was significant at the 0.001 level. All of this suggests that there may be other factors influencing the relatively high engagement levels of this group that are not captured by the constructs in this survey.

In the next section we will follow our Conceptual Model and use the constructs confirmed in this analysis as independent variables, and look for statistically significant relationships with factory data that represents our dependent variable of innovation and continuous improvement. 
$\underline{\text { Figure } 10 \text { Structural Equation Model for "Support" Data set }}$

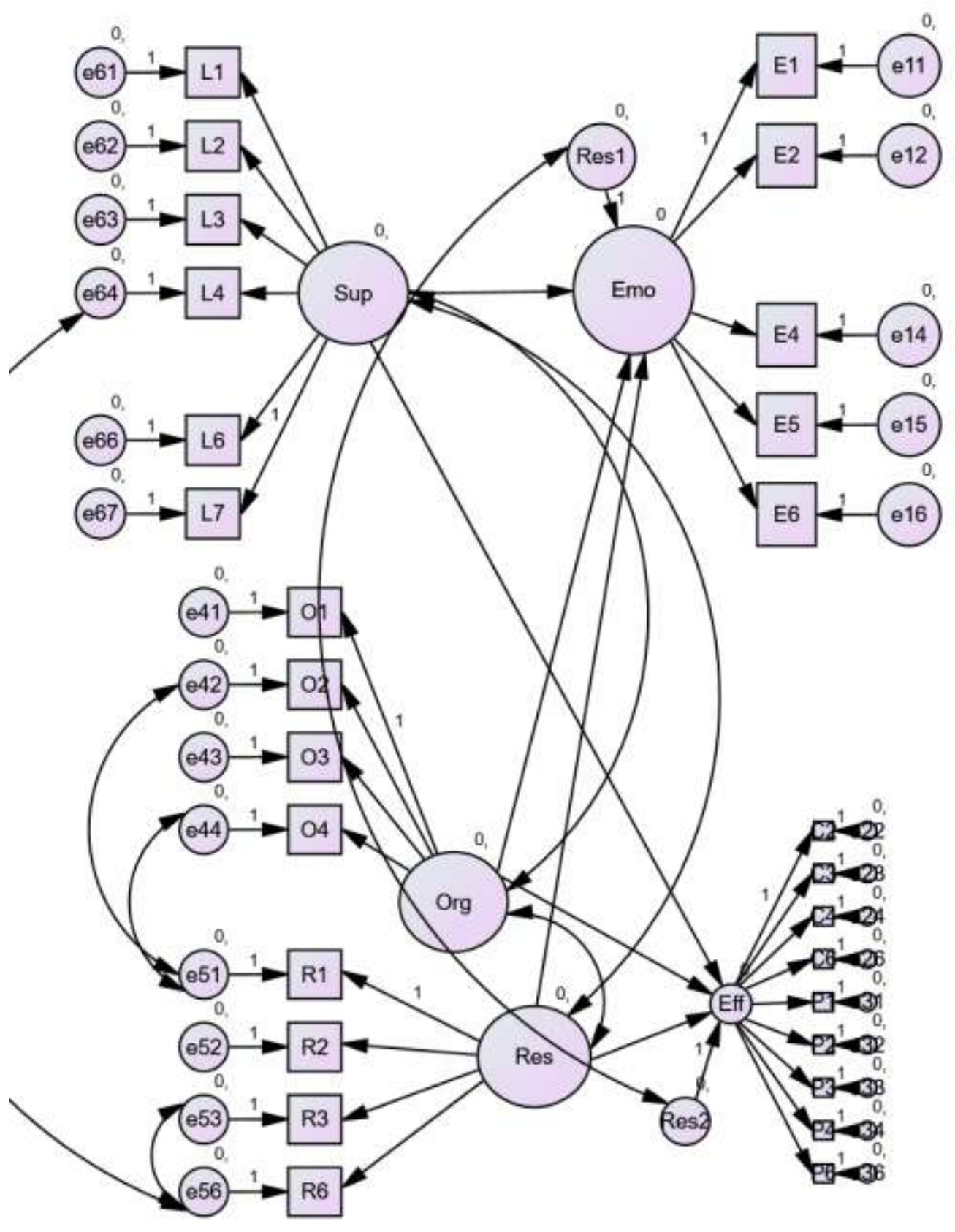


Figure 11 Parameter Estimates for the SEM for "Support" Data set

\begin{tabular}{|c|c|c|c|c|c|c|c|}
\hline & & & Estimate & S.E. & C.R. & $\mathrm{P}$ & Label \\
\hline Emotional & $<--$ & Supervisor & .296 & .087 & 3.403 & $* * *$ & par_9 \\
\hline Emotional & $<--$ & Organization & .486 & .135 & 3.596 & $* * *$ & par_14 \\
\hline Emotional & $<--$ & Resources & .033 & .156 & .212 & .832 & par_21 \\
\hline Effort & $<---$ & Supervisor & .227 & .070 & 3.235 & .001 & par_30 \\
\hline Effort & $<--$ & Organization & .151 & . 104 & 1.445 & 148 & par_31 \\
\hline Effort & $<--$ & Resources & .061 & .127 & .485 & .627 & par_32 \\
\hline E2 & $<--$ & Emotional & .925 & .091 & 10.156 & $* * *$ & par_1 \\
\hline E4 & $<--$ & Emotional & .796 & .093 & 8.571 & $* * *$ & par_2 \\
\hline E5 & $<--$ & Emotional & .931 & .106 & 8.768 & $* * *$ & par_3 \\
\hline L7 & $<--$ & Supervisor & 1.000 & & & & \\
\hline L6 & $<--$ & Supervisor & 1.230 & .120 & 10.225 & $* * *$ & par_4 \\
\hline L4 & $<--$ & Supervisor & 1.063 & .120 & 8.836 & $* * *$ & par_5 \\
\hline L3 & $<--$ & Supervisor & 1.125 & .118 & 9.533 & **** & par_6 \\
\hline L2 & $<--$ & Supervisor & 1.209 & .123 & 9.854 & $* * *$ & par_7 \\
\hline L1 & $<--$ & Supervisor & 1.082 & .112 & 9.681 & $* * *$ & par_8 \\
\hline E1 & $<--$ & Emotional & 1.000 & & & & \\
\hline E6 & $<--$ & Emotional & 1.034 & .100 & 10.364 & $* * *$ & par_10 \\
\hline O4 & $<--$ & Organization & 1.135 & .114 & 9.958 & **** & par_11 \\
\hline $\mathrm{O} 3$ & $<--$ & Organization & 1.097 & .104 & 10.533 & **** & par_12 \\
\hline $\mathrm{O} 2$ & $<--$ & Organization & 1.069 & .112 & 9.579 & $* * *$ & par_13 \\
\hline $\mathrm{O} 1$ & $<--$ & Organization & 1.000 & & & & \\
\hline $\mathrm{R} 1$ & $<--$ & Resources & 1.000 & & & & \\
\hline R2 & $<--$ & Resources & 1.336 & .187 & 7.144 & $* * *$ & par_16 \\
\hline R3 & $<--$ & Resources & 1.227 & .191 & 6.438 & $* * *$ & par_17 \\
\hline R6 & $<--$ & Resources & 1.106 & .175 & 6.329 & $* * *$ & par_18 \\
\hline $\mathrm{C} 2$ & $<--$ & Effort & 1.000 & & & & \\
\hline C3 & $<--$ & Effort & 1.047 & .082 & 12.722 & $* * *$ & par_22 \\
\hline $\mathrm{C} 4$ & $<--$ & Effort & .893 & .111 & 8.048 & $* * *$ & par_23 \\
\hline C6 & $<--$ & Effort & .937 & .091 & 10.263 & **** & par_24 \\
\hline P1 & $<--$ & Effort & .999 & .109 & 9.192 & $* * *$ & par_25 \\
\hline P2 & $<--$ & Effort & 1.089 & .092 & 11.854 & $* * *$ & par_26 \\
\hline P3 & $<--$ & Effort & .964 & . 104 & 9.251 & **** & par_27 \\
\hline P4 & $<--$ & Effort & .766 & .081 & 9.472 & **** & par_28 \\
\hline $\mathrm{P} 6$ & $<--$ & Effort & .800 & .104 & 7.697 & $* * *$ & par_29 \\
\hline
\end{tabular}




\section{CHAPTER 6 DEPENDENT VARIABLE DATA, ANALYSIS, AND RESULTS}

Having developed and confirmed factors representing Organization and Resource Support, Supervisor Relationship, Emotional Engagement, and Effort, and analyzed the relationships between them, we are now interested in the relationship of these constructs to the factory data representing our dependent variable of innovation and continuous improvement results at the supervisor work group level.

To begin this analysis, the data set "Floor", consisting of 603 respondents working in mass production roles, was condensed to the unit of analysis of the Supervisory Work Group. The 603 respondents came from 30 different groups, so a smaller data set called TeamLead was created. Maintaining the factors and items from the previous analysis, estimates for Effort, Emotional Engagement, Supervisor Relationship, and Organization and Resource Support were calculated from the survey data for each Team Leader work group.

We are interested in comparing the relative performance of these work groups using data that is available within the operation, as well as any relationship between these performance levels and the previously measured constructs. Based on the literature, our hypothesis a priori is that work groups with higher levels of Job Engagement will have higher levels of performance. Since engagement is defined as giving discretionary effort toward achieving company goals (Towers-Perrin, 2003), we will look for performance data that measures achievement of company goals as well as that which indicates a level of discretionary effort. As our model seeks to identify the relationship between engagement and innovative behavior and continuous improvement, our factory data must also represent this performance as well. For our analysis, we will use data from the time period August 1 to December 31 2015, which spans 2 months before and after the administration of the survey in the month of October 2015. 


\section{Dependent Variable Performance Data}

\section{Suggestions Submitted (“Suggest”)}

TRQSS has a suggestion system that is structurally comparable to a Japanese kaizen teian system (Robinson \& Stern, 1997). Submitted suggestions do not have to go through a financial analysis for acceptance, and there are no large extrinsic rewards for implemented suggestions. For the past few years (including the period under study), participation rates in the system have been fairly low, as the system has not been strongly promoted by management. Despite the lack of promotion and extrinsic rewards, there were ideas being documented and submitted in the system by employees within the Floor data set. The submission of a suggestion would indicate a measure of individual activity born of intrinsic motivation, as the act itself is voluntary and done on personal time. For each work group in the TeamLead data set, the total number of suggestions submitted within the period by the members of the group was divided by the number of employees in the group to create a "higher is better" indicator. There were some work groups for which there was no data available within the period.

\section{Attendance ("Attend")}

The literature suggests that higher engagement levels result in better attendance (TowersPerrin, 2003). In Ontario, all employees are granted 10 Emergency Leave (EL) days from work that can be taken at their discretion to cover all manner of unforeseen personal circumstances that may need attention during regular working hours. This legislation is designed to protect workers from harsh employment practices; while employees are not compensated for EL days, their use of them cannot be counted against their attendance record nor considered in any form of disciplinary action toward the employee. In addition there are a number of sick days granted by the employer and several ways in which excusable absence is allowed and compensated 
(bereavement, vacation, etc.). Although attendance in the workplace is extrinsically motivated by wages, some level of attendance is considered discretionary, as some level of absence is not punished by policy. According to literature, employees who are not engaged may not choose to attend work if the situation was somewhat voluntary. An analysis of this discretionary absence by the employees within each work group was done. To calculate a comparative index, the total number of discretionary absence hours used by each employee within the work group was subtracted from the total available working hours for the period. The attendance ratio was calculated; the higher the number, the better.

\section{Productivity ("Productivity")}

Productivity is a measure of the effectiveness of the utilization of Direct Labor hours in the production of goods. All end items (finished goods and subassemblies) produced in the Assembly department have a standard amount of direct labor hours required to produce the end item. These standards are determined by the Production Engineering department, and are used in cost calculations and for developing quotations for new business proposals. Productivity is the ratio of standard direct labor hours to actual direct labor hours used in the production of a quantity of goods and is measured for every work group every day. Since productivity focuses on the performance of direct labor to a standard, incidents such as parts shortages or machine downtime (which would have a negative impact but are considered uncontrollable by the operators) are excluded from the calculation. ${ }^{7}$ Productivity is the basic indicator of continuous improvement activity implementation in the work group as all work group activities relating to increasing the output of good product while reducing the input of labor resources are reflected in this measure. Although different work groups produce goods with differing labor content, the

\footnotetext{
${ }^{7}$ The company has other Key Performance Indicators (KPIs) that include these events.
} 
index is normalized to a percentage so that all production work groups can be compared. A higher ratio for Productivity indicates better performance.

\section{Quality ("Quality")}

Another company goal is quality, and as mentioned earlier, it can still be a differentiator in the marketplace. When a quality problem happens in a production area, a Defect Containment Sheet (DCS) is generated. Defects can be caused by supplier processes as well as the processes within the work group. For this analysis we looked at the total number of defective parts that were reported by DCS within each work group during the time period, then removed the parts that were created by supplier processes. The remaining number of defects for which the work group was responsible was then divided by the total production quantity for the period to obtain "defective parts per million produced" ratio for each group ( $\mathrm{ppm})$. A lower number for this ratio indicates better performance.

Table 4 shows the construct means and dependent variable performance data by work group. 
Table 4 Empirical Performance Data by Team Leader Work Group

\begin{tabular}{|c|c|c|c|c|c|c|c|c|}
\hline Team Leader & Effort & Emotion & Supervisor & OrgRes & Suggest & Attend & Productivity & Quality (ppm) \\
\hline 1 & 3.972986 & 3.570420 & 3.784222 & 2.666115 & 0.2222 & 0.9862 & & \\
\hline 2 & 4.175000 & 3.492446 & 3.338889 & 2.680237 & 0.0667 & 0.9911 & 0.8590 & 107.5982 \\
\hline 3 & 4.171479 & 3.614815 & 3.806183 & 2.856330 & 0.0000 & 0.9816 & 1.0470 & 28.4206 \\
\hline 4 & 4.336075 & 3.757143 & 4.285714 & 2.984127 & 0.4286 & 0.9812 & & \\
\hline 6 & 4.354060 & 4.005405 & 3.400901 & 2.813942 & 0.0000 & 0.9819 & 0.8850 & 394.3690 \\
\hline 8 & 4.221273 & 3.971429 & 3.547619 & 3.071429 & 0.2143 & 0.9832 & 0.9240 & 352.2482 \\
\hline 9 & 4.162243 & 3.933364 & 3.793103 & 3.164751 & 0.0000 & 0.9888 & 0.9550 & 349.4225 \\
\hline 10 & 4.303571 & 4.014286 & 3.133373 & 2.744346 & 0.0714 & 0.9940 & & \\
\hline 11 & 4.274194 & 3.574194 & 3.080645 & 2.737589 & 0.0000 & 0.9814 & 0.8720 & 368.3133 \\
\hline 12 & 3.921053 & 3.294737 & 3.456140 & 2.743932 & 0.1053 & 0.9772 & 0.8000 & 535.2378 \\
\hline 13 & 4.250000 & 3.695238 & 3.960317 & 2.862434 & 0.0000 & 0.9863 & 0.9320 & 335.1259 \\
\hline 14 & 3.969425 & 3.456445 & 3.215163 & 2.658738 & 0.1154 & 0.9821 & 0.9190 & 482.3071 \\
\hline 15 & 4.083333 & 3.314286 & 3.507937 & 2.761905 & 0.0952 & 0.9757 & & \\
\hline 16 & 3.598512 & 2.989474 & 3.763158 & 2.278220 & 0.1579 & 0.9795 & & \\
\hline 17 & 4.037037 & 3.277778 & 3.222222 & 2.593138 & 0.0000 & 0.9820 & 0.7710 & 967.5493 \\
\hline 18 & 4.311111 & 3.706667 & 2.800000 & 2.808327 & 0.0000 & 0.9813 & & \\
\hline 19 & 3.953125 & 3.275000 & 2.995306 & 2.618056 & 0.0625 & 0.9684 & 0.9390 & 1094.9871 \\
\hline 20 & 4.161765 & 3.941176 & 3.764706 & 3.216498 & 0.0000 & 0.9861 & 0.8570 & 338.9309 \\
\hline 21 & 4.289216 & 4.021963 & 4.053775 & 3.207089 & 0.1765 & 0.9843 & 0.9310 & 719.9062 \\
\hline 22 & 3.990196 & 3.458824 & 3.147059 & 2.830065 & 0.0588 & 0.9653 & 1.0070 & 34.0100 \\
\hline 23 & 4.098843 & 3.602510 & 3.149823 & 2.993772 & 0.0588 & 0.9688 & 0.8070 & 71.6271 \\
\hline 24 & 4.305347 & 3.519561 & 2.771681 & 2.393755 & 0.0000 & 0.9733 & 0.7760 & 0.8403 \\
\hline 25 & 4.166667 & 3.881818 & 3.565350 & 2.939394 & 0.0455 & 0.9819 & 1.0010 & 540.4675 \\
\hline 27 & 4.265152 & 4.012284 & 4.530303 & 2.791534 & 0.0000 & 0.9902 & & \\
\hline 28 & 4.333459 & 3.953463 & 3.829016 & 2.979995 & 0.0000 & 0.9878 & 1.0660 & 2.5508 \\
\hline 30 & 4.026321 & 3.409106 & 3.896825 & 2.793184 & 0.4286 & 0.9770 & & \\
\hline 31 & 4.138889 & 3.866667 & 4.046123 & 3.081481 & 0.0000 & 0.9820 & 1.0010 & 3.0497 \\
\hline 32 & 4.215522 & 3.673149 & 3.594715 & 2.847385 & 0.1724 & 0.9855 & 0.9160 & 581.2953 \\
\hline 34 & 4.250000 & 3.680000 & 3.933333 & 3.068629 & 0.2000 & 0.9757 & & \\
\hline 35 & 4.180556 & 3.516667 & 3.847222 & 2.712963 & 1.0833 & 0.9742 & & \\
\hline
\end{tabular}

\section{Notes:}

1. The data set consists of 30 cases; the Team Leader numbers are discontinuous, as work groups in the "Support" data set have been excluded.

2. Work groups in Injection Molding, Material Handling, and Warehouse Operations have no comparable data for Productivity and Quality. Consequently, this data is missing for these groups within the set. 


\section{Analysis of Dependent Variable Data}

Structural Equation Modeling for the complete data set of workers in the daily mass production environment showed that Engagement levels, represented by the factors Effort and Emotional Engagement, were primarily driven by the perception of the Organization's support for their efforts and the Resources available to do the job. The SEM also indicated that the Supervisor Relationship was not a significant driver of Engagement for this group. We are now interested in determining if a relationship exists between Engagement levels and actual results, and also if Supervisor Relationship has a bearing on any of the actual results.

Prior to performing any regression analysis, the data were first sorted to determine if any patterns emerged. This sort revealed two relationships to be explored further. Microsoft Excel was used to sort the data set two ways: first, by the factor Emotional Engagement (Emotion) in descending order, then by Supervisor Relationship (Supervisor) in the same manner. After each sort, a simple chart was plotted to examine any patterns that might emerge and warrant further investigation. Figure 12 shows the chart of the data set sorted by Emotional Engagement (descending order). Emotional Engagement levels vary from a high of slightly more than 4 (out of 5 on the Likert scale) to a low of 2.989 between the 30 work groups, and as the trend line shows, this is a linear relationship with little variance. The corresponding data for Attendance (Attend) exhibits a trend line with similar slope, but much greater variation. A simple linear regression between these variables will be analyzed using IBM SPSS. 
Figure 12 Chart showing TeamLead sorted by Emotional Engagement with Attendance

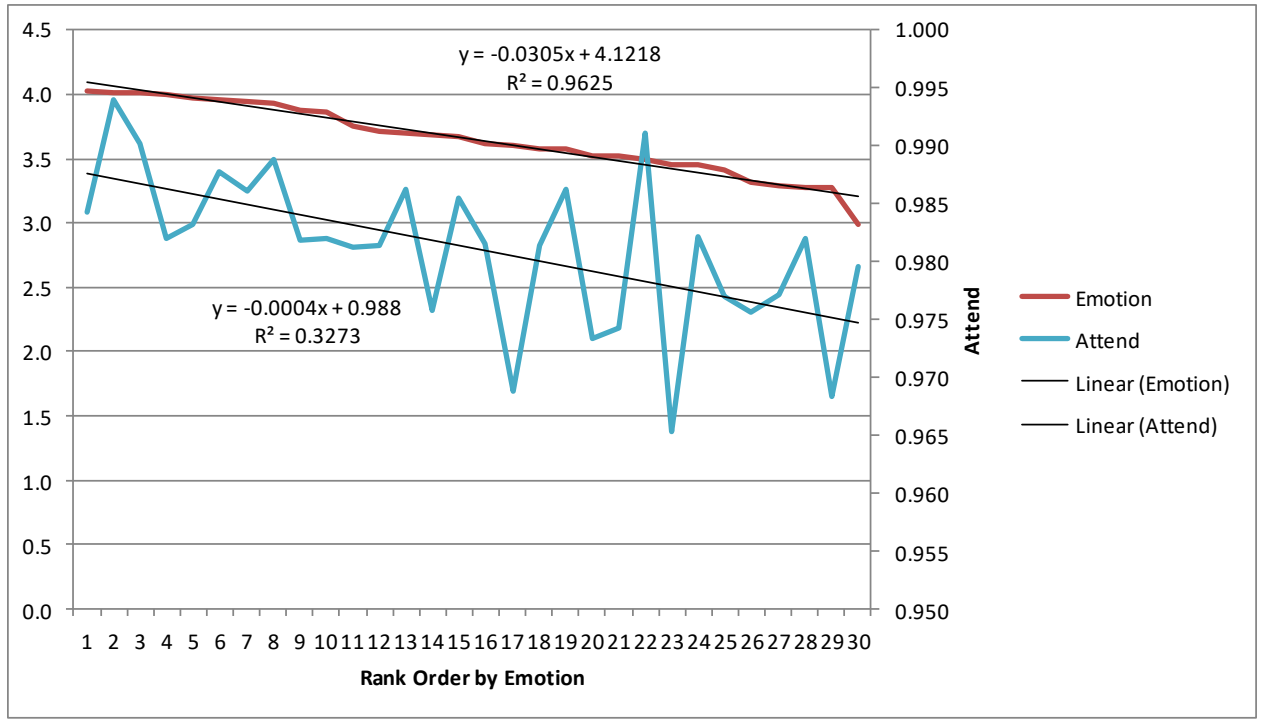

Figure 13 Chart showing TeamLead sorted by Supervisor Relationship with Suggestions

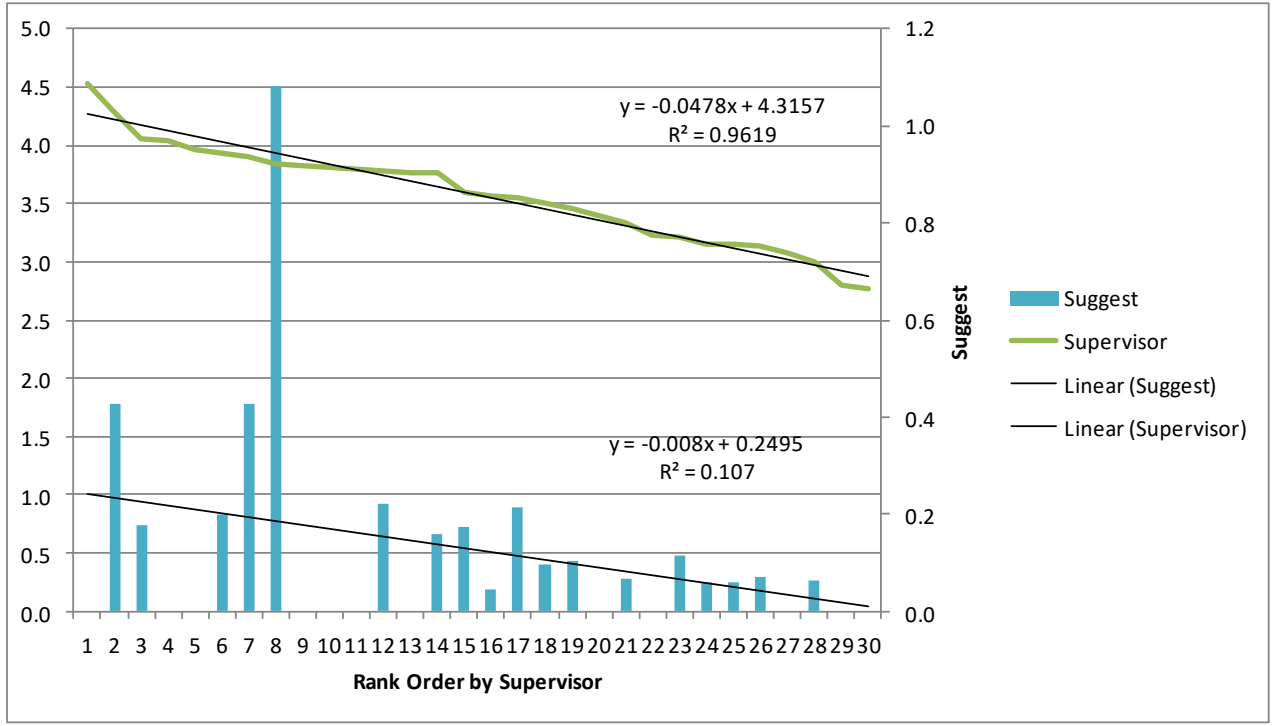

Figure 13 charts the data set sorted by Supervisor Relationship (Supervisor) in descending order, with the corresponding data for Suggestions Submitted (Suggest) plotted in a column chart on a secondary axis. The factor Supervisor has a greater range than Emotional, from a high of 4.53 to a low of 2.77 , but the trend exhibits a linear relationship with little variance. The data for 
Suggest reveals an interesting pattern: there seems to be a general trend that work groups with higher levels of Supervisor Relationship submit more suggestions than those with lower scores on that factor. However, there is large variation within the ranges, with several groups throughout the entire range having submitted no suggestions in the period under study. These relationships will be studied further using IBM SPSS.

When these two constructs and performance measures were interchanged, no pattern was observed.

\section{Regression Analysis}

\section{Attendance $\rightarrow$ Emotional Engagement}

Treating the factor Emotional Engagement (Emotion) as an Independent variable and Attendance (Attend) as the dependent variable, we used IBM SPSS to perform a linear regression analysis. The SPSS output of this analysis follows:

\begin{tabular}{|r|r|r|r|}
\hline \multicolumn{4}{|c|}{ Model Summary } \\
\hline R & R Square & $\begin{array}{c}\text { Adjusted R } \\
\text { Square }\end{array}$ & $\begin{array}{c}\text { Std. Error of the } \\
\text { Estimate }\end{array}$ \\
\hline .547 & .299 & .274 & .006 \\
\hline
\end{tabular}

The independent variable is Emotion.

\begin{tabular}{|l|r|r|r|r|r|}
\hline & ANOVA & \\
\hline Regression & Sum of Squares & Df & Mean Square & F & Sig. \\
Residual & .000 & 1 & .000 & 11.952 & .002 \\
Total & .001 & 28 & .000 & & \\
\hline
\end{tabular}

The independent variable is Emotion.

\begin{tabular}{|c|c|c|c|c|c|}
\hline \multicolumn{6}{|c|}{ Coefficients } \\
\hline & \multicolumn{2}{|c|}{ Unstandardized Coefficients } & \multirow{2}{*}{$\begin{array}{c}\text { Standardized } \\
\text { Coefficients } \\
\text { Beta }\end{array}$} & \multirow[b]{2}{*}{$t$} & \multirow[b]{2}{*}{ Sig. } \\
\hline & $\mathrm{B}$ & Std. Error & & & \\
\hline Emotion & .014 & .004 & .547 & 3.457 & .002 \\
\hline (Constant) & .932 & .014 & & 64.872 & .000 \\
\hline
\end{tabular}




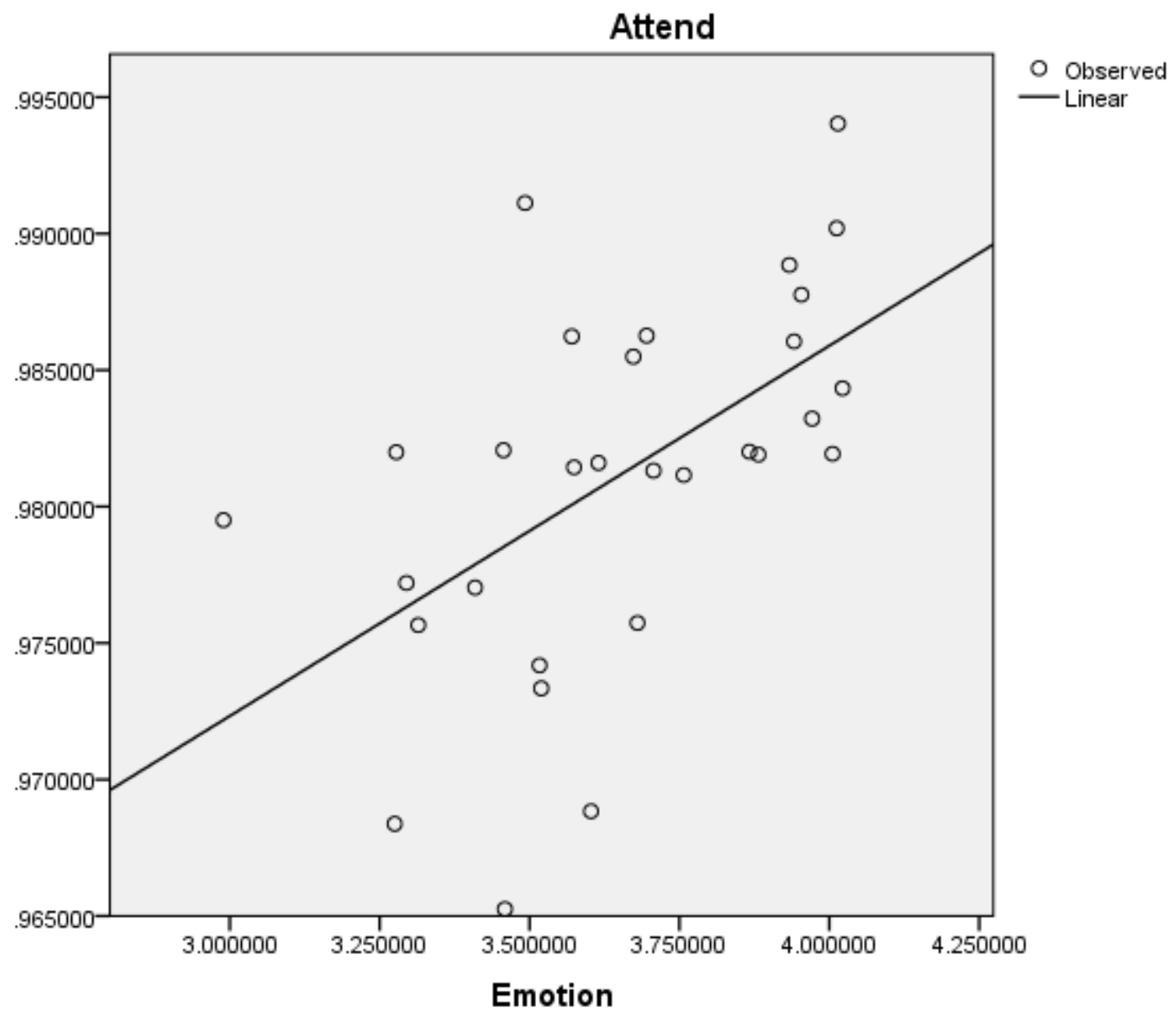

The relationship is linear, albeit with a $\mathrm{R}^{2}$ value of 0.299 , not strong, as there are large differences in the relative measure of the dependent variable Attend for similar levels of the independent variable Emotion. The coefficient $\beta_{1}$ is small $(0.014)$, due to the magnitude of the scale for the variable Attend, but significant at the $\mathrm{P}=0.002$ level.

\section{Suggestions Submitted $\rightarrow$ Supervisor Relationship}

Next we perform a regression analysis using Supervisor Relationship (Supervisor) as the independent variable and Suggestions Submitted (Suggest) as the dependent variable. Initial analysis of the data as presented showed no significant relationship. However, there are several work groups that did not participate in the suggestion system in the period under study, 
regardless of the value of the variable Supervisor. Similarly, as seen in the chart in Figure 13, there is one data point for Suggest near the high end for the value of the variable Supervisor that is nearly triple the size of any surrounding data points. This seems to be an outlier. After removing these cases from the data set, we can determine if a relationship exists between the variables for the groups that did participate in the suggestion program. The IBM SPSS output results of the analysis of the modified data set (17 cases) are shown below.

Model Summary

\begin{tabular}{|r|r|r|c|}
\hline$R$ & R Square & \multicolumn{1}{c|}{$\begin{array}{c}\text { Adjusted R } \\
\text { Square }\end{array}$} & $\begin{array}{l}\text { Std. Error of the } \\
\text { Estimate }\end{array}$ \\
\hline .787 & .620 & .595 & .075 \\
\hline
\end{tabular}

The independent variable is Supervisor.

ANOVA

\begin{tabular}{|l|r|r|r|r|r|}
\hline & Sum of Squares & $\mathrm{df}$ & Mean Square & $\mathrm{F}$ & Sig. \\
\hline Regression & .138 & 1 & .138 & 24.458 & .000 \\
Residual & .084 & 15 & .006 & & \\
Total & .222 & 16 & & & \\
\hline
\end{tabular}

The independent variable is Supervisor.

\begin{tabular}{|c|c|c|c|c|c|}
\hline \multicolumn{6}{|c|}{ Coefficients } \\
\hline & \multicolumn{2}{|c|}{ Unstandardized Coefficients } & \multirow{2}{*}{$\begin{array}{c}\text { Standardized } \\
\text { Coefficients } \\
\text { Beta }\end{array}$} & \multirow[b]{2}{*}{$\mathrm{t}$} & \multirow[b]{2}{*}{ Sig. } \\
\hline & $\mathrm{B}$ & Std. Error & & & \\
\hline Supervisor & .254 & .051 & .787 & 4.945 & .000 \\
\hline (Constant) & -.743 & .183 & & -4.060 & .001 \\
\hline
\end{tabular}




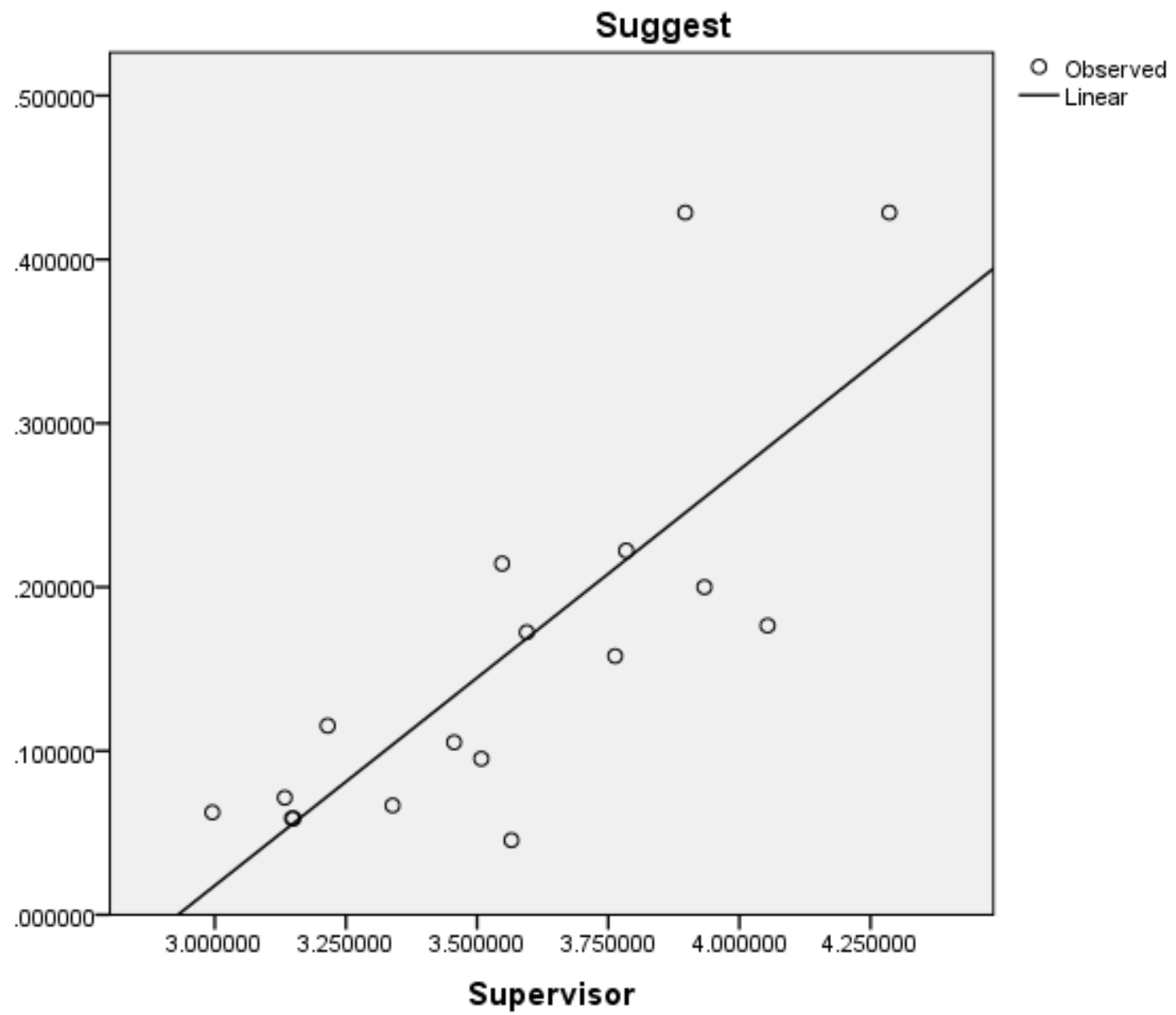

For the 17 work groups who participated in the existing suggestion system in the period under study, a relatively strong $\left(\mathrm{R}^{2}=0.620\right)$ positive linear relationship exists between the levels of participation and the relationship with the supervisor. Further investigation is required to understand why several groups did not participate at all, and why one group participated at a relative level that was orders of magnitude above all the others.

We will now look for any significant correlation results between the survey constructs of Emotional Engagement and Supervisor Relationship and continuous improvement results as indicated by the dependent variable data for work group productivity.

\section{Productivity $\rightarrow$ Emotional Engagement}


Literature suggests that engagement indicates a willingness to exercise discretionary effort in the achievement of the organizations goals. Regression analysis was run with Productivity as a dependent variable and Emotional Engagement as the independent variable. The results, shown below, indicate a weak linear relationship that is not statistically significant at a $\mathrm{P}=0.05$ level.

\section{Model Summary}

\begin{tabular}{|r|r|r|c|}
\hline$R$ & R Square & \multicolumn{1}{|c|}{$\begin{array}{c}\text { Adjusted R } \\
\text { Square }\end{array}$} & $\begin{array}{c}\text { Std. Error of the } \\
\text { Estimate }\end{array}$ \\
\hline .430 & .185 & .140 & .087 \\
\hline
\end{tabular}

The independent variable is Emotion.

\section{ANOVA}

\begin{tabular}{|l|r|r|r|r|r|}
\hline & Sum of Squares & Df & Mean Square & F & Sig. \\
\hline Regression & .031 & 1 & .031 & 4.086 & .058 \\
Residual & .138 & 18 & .008 & & \\
Total & .169 & 19 & & & \\
\hline
\end{tabular}

The independent variable is Emotion.

\section{Coefficients}

\begin{tabular}{|c|c|c|c|c|c|}
\hline & \multicolumn{2}{|c|}{ Unstandardized Coefficients } & \multirow{2}{*}{$\begin{array}{c}\text { Standardized } \\
\text { Coefficients } \\
\text { Beta }\end{array}$} & \multirow[b]{2}{*}{$\mathrm{t}$} & \multirow[b]{2}{*}{ Sig. } \\
\hline & B & Std. Error & & & \\
\hline Emotion & .158 & .078 & .430 & 2.021 & .058 \\
\hline (Constant) & .342 & .289 & & 1.185 & .251 \\
\hline
\end{tabular}

\section{Productivity $\rightarrow$ Supervisor}

Training Within Industry Service suggested that the key to factory improvement was the relationship between the supervisor and the work group. Regression analysis was used to examine the relationship between Productivity as the dependent variable and and Supervisor Relationship as the independent variable. The output results are shown below. Although the $\mathrm{R}^{2}$ value is low, indicating large variance in the actual measured values of the dependent variable, the linear relationship is significant at the $\mathrm{P}=0.01$ level. 


\begin{tabular}{|r|r|r|r|}
\hline \multicolumn{4}{|c|}{ Model Summary } \\
\hline R & R Square & $\begin{array}{c}\text { Adjusted R } \\
\text { Square }\end{array}$ & $\begin{array}{c}\text { Std. Error of the } \\
\text { Estimate }\end{array}$ \\
\hline .564 & .318 & .280 & .080 \\
\hline
\end{tabular}

The independent variable is Supervisor.

ANOVA

\begin{tabular}{|l|r|r|r|r|r|}
\hline & Sum of Squares & df & Mean Square & F & Sig. \\
\hline Regression & .054 & 1 & .054 & 8.386 & .010 \\
Residual & .115 & 18 & .006 & & \\
Total & .169 & 19 & & & \\
\hline
\end{tabular}

The independent variable is Supervisor.

\begin{tabular}{|c|c|c|c|c|c|}
\hline \multicolumn{6}{|c|}{ Coefficients } \\
\hline & \multicolumn{2}{|c|}{ Unstandardized Coefficients } & $\begin{array}{c}\text { Standardized } \\
\text { Coefficients }\end{array}$ & \multirow[b]{2}{*}{$\mathrm{t}$} & \multirow[b]{2}{*}{ Sig. } \\
\hline & B & Std. Error & Beta & & \\
\hline Supervisor & .144 & .050 & .564 & 2.896 & .010 \\
\hline (Constant) & .422 & .174 & & 2.424 & .026 \\
\hline
\end{tabular}




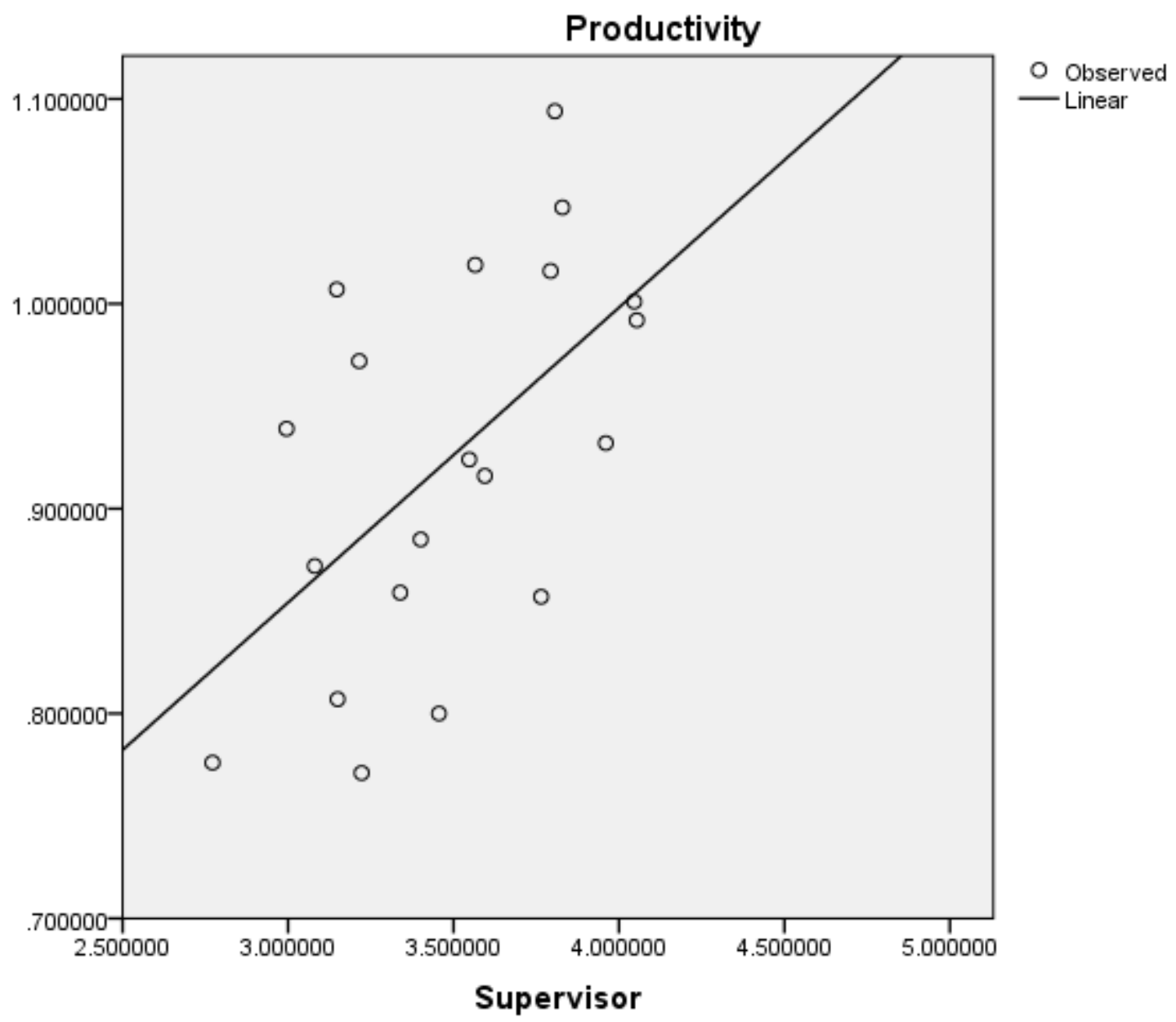

\section{Quality}

Similar regression analysis was performed using Quality as a dependent variable, and both Emotion and Supervisor as independent variables. No significant linear relationships emerged from this analysis. There is a possibility that there is too much variability within the index, or that as constructed, the index is not an accurate measure of work group performance as there are too many external factors.

\section{Discussion of Survey Results and Analysis}

\section{Constructs and Factor Analysis}


The survey instrument contained statements designed to measure three distinct engagement constructs: Physical, Cognitive, and Emotional. However, exploratory factor analysis revealed that respondents did not distinguish between Physical and Cognitive Engagement. This could be because the wording of some of the statements was very similar, and since the statements were interspersed throughout the survey, these subtleties were not distinguishable. Consequently, the constructs for Physical and Cognitive Engagement were combined into one factor called "Effort", The construct of Emotional Engagement was uniquely identified in factor analysis. Since we are interested in the potential difference in engagement levels between the employees in mass production roles and those in management and technical support roles, the respondents were separated into two data sets representing this difference. Observation of the descriptive statistics from all survey respondents revealed that the greatest difference in construct means occurred on the construct of Emotional Engagement; that is, the employees in mass production roles experienced lower levels of Emotional Engagement than employees in management and technical support roles. This observation that is consistent with the literature, as employees in the latter group are exposed to more of the drivers of emotional engagement such as job autonomy, decision making authority, and growth opportunities. The survey construct which revealed the least difference in mean scores between the two data sets was Resources, that is, the perception that one is given the appropriate resources to develop creative ideas.. For both data sets, this was the construct with the lowest score and very little difference between the means. Regardless of one's job, the perception of the survey respondents is that adequate resources are not provided to pursue creative ideas and innovative solutions. . Factor analysis also revealed that for the respondents in mass production roles ("Floor" data set), a distinction could not be made between 
the constructs of Resources and perceived Organizational Support. Subsequent analysis would treat the two employee data sets separately ("Floor" and "Support").

\section{Evaluation of Hypotheses}

Our first hypothesis states that Work Groups in the mass production environment will have lower engagement levels than work groups in professional and technical support functions. While this appears to be true for the descriptive statistics at the respondent level, we must further group the respondents in each data set into work groups, defined as the set of employees reporting to the same supervisor or team leader. There are 30 work groups in the "Floor" data set and 8 work groups in the "Support" data set. The graph in Figure xx shows the ranking of all 38 work groups by mean Emotional Engagement in descending order.

Figure 14 Work Groups sorted by Emotional Engagement level

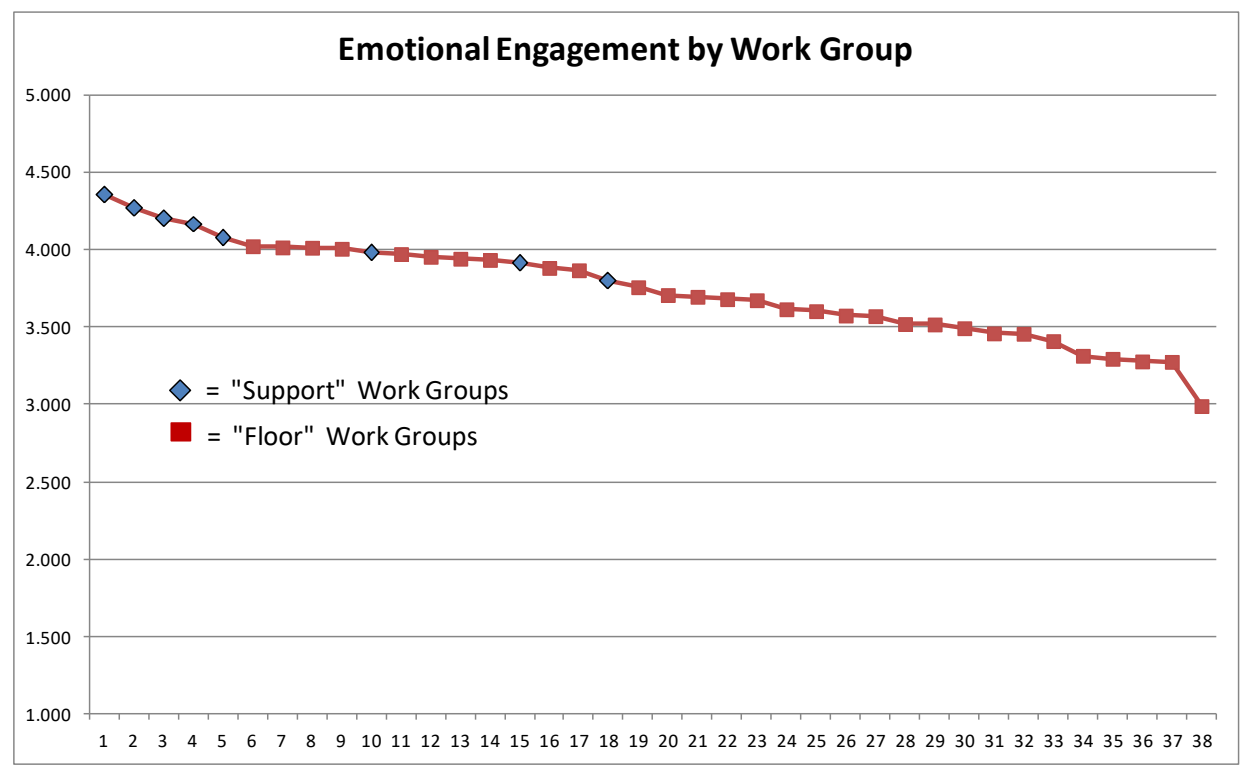

As seen in the graph, the five work groups with the highest mean Emotional Engagement scores are from the Support data set, and the twenty work groups with the lowest Emotional Engagement mean scores are from the Floor data set. (The first, third and fourth ranking work 
groups are all Production Engineering groups; the number 2 ranking group is the management staff.) However, there are 3 other work groups in the Support data set that have Emotional Engagement scores lower than some of the Work Groups in the Floor data set. Although all of the Support work groups have Emotional Engagement scores that are above the median and mean for all work groups, Hypothesis 1 is rejected.

Based on the literature, Hypothesis 2 states that Supervisor Relationship has a positive influence on engagement levels of the work group. However, as was revealed in the Structural Equation Model for the Floor data set, the perception of Organization and Resource Support was the largest influence on both Emotional Engagement levels and the combined Physical and Cognitive Engagement construct called Effort. Contrary to what was suggested in the literature, the influence of Supervisor relationship was very low and statistically insignificant for this data set.

Interestingly, the results were slightly different for the Support data set. While the Organization support factor was the largest and most significant influence on Emotional Engagement, the magnitude of this influence was about half of what it was for the Floor data set. Supervisor Relationship also had a significant influence on Emotional Engagement for this group. Although this group had high levels of Effort, this did not seem to be the result of any of the constructs measured in this survey, with the slight exception of Supervisor Relationship, which was small and significant at a lower level. As a result we would accept Hypothesis 2 as true for Emotional Engagement levels of Support work groups only, but reject it for every other situation.

Hypothesis 3 states that work groups with higher engagement levels achieve better performance results from innovation and continuous improvement activity than those with lower 
engagement levels. Correlation of work group engagement levels with factory data representing the results of innovative behavior and continuous improvement activity revealed that only higher levels of discretionary attendance had a positive correlation to work group engagement levels. Work group productivity, a proxy for continuous improvement results, had a stronger correlation with the Supervisor Relationship construct. Work group quality, another proxy for continuous improvement results, did not correlate with either the Emotional Engagement or Supervisor Relationship constructs, suggesting that there were other influences and variables in the quality results not captured by the constructs measured in the survey. Generally, it appears that hypothesis 3 is rejected for the work groups in the Floor data set, but it remains unclear for the work groups in the support data set. Further research is required to determine this.

Hypothesis 4 states that work groups with higher engagement levels will exhibit higher levels of innovative behavior. The factory data representing innovative behavior is participation in the suggestion system, as this participation requires individual action and is completely voluntary. Once again, higher levels of participation in the suggestion system at the work group level had a stronger correlation with Supervisor Relationship, and no significant correlation with Emotional Engagement levels. Once again, from this quantitative analysis the innovative performance of the most highly engaged work groups (Production Engineering and Management) remains unclear, as the factory data does not measure their activity. Further research using other methods is required, and this will be undertaken in the next section.

\section{Conclusions}

When examining the influence of engagement levels on factory work group achievement, this study concludes that only attendance levels were driven by engagement; work group productivity and suggestion submissions were driven more by the work group relationship with 
the supervisor. This latter result is more surprising, as the literature on employee engagement and self determination theory would suggest that participation in a suggestion system would be the result of intrinsic motivation, or a willingness to give discretionary effort toward workplace goals, which is the definition of employee engagement (Towers-Perrin, 2003). However, it is worth noting that overall participation in the suggestion system is low, and it is worth further examination to determine if there are other factors that may be influencing this result.

These results suggest that direct production work group performance may be related more to motivation than engagement levels. Paul Marciano suggests that engagement and motivation are not the same thing, but that high levels of engagement can be a buffer against factors in the workplace that reduce motivation (Marciano, 2010). Marciano also suggests that Engagement and Disengagement are not opposites of each other, but actually two different constructs, and that good supervision is necessary to prevent Disengagement (Marciano, 2010). This is analogous to Fredrick Herzberg's two factor theory of motivation. Herzberg concluded that supervision was not a motivator, but a "hygiene factor"; that is, more of it would not increase motivation, but less of it would certainly decrease motivation (Herzberg, 2003). The analogy with Marciano's theory is that while good supervision is necessary to prevent disengagement, higher levels of good supervision beyond a certain threshold may not improve engagement. To determine if this is the case, a construct for disengagement could be developed and a similar survey could be conducted to see if the Supervisor Relationship is more closely correlated with levels of disengagement. Marciano also expands on the conceptual definition of engagement, stating that the influence on the employee to apply discretionary effort to his work comes from a heightened emotional or intellectual connection to the job, organization, manager, or coworkers 
(Marciano, 2010). This definition suggests two more possible influences on engagement levels (job and coworkers) in addition to organization and manager, which were studied here.

Another possible explanation comes from the work of the Hay Group, whose work draws a distinction between the constructs of engagement and enablement; while organizational support may be a driver of the former, supervision and resources are actually drivers of the latter (Royal \& Agnew, 2012). These authors contend that performance results require a blend of both engagement and enablement; engaged employees who do not feel enabled end up frustrated. Future research could examine a correlation between performance results and a construct for employee enablement as well as employee engagement to determine if engaged employees are feeling frustration by a lack of enablement.

This study suggests that the levels of emotional engagement experienced by workers in a mass production environment are limited, and driven primarily by the employees' perception of the organization and the resources provided to do the job. Engagement levels for these employees may influence their attendance rate, but other measures of performance will be influenced by the relationship with the direct supervisor. In other words, engagement might get them to show up, but the supervisor must get them to perform. In light of this finding, companies that are expending effort and expense to engage employees with a goal toward improving performance would be wise to understand the drivers and limitations of these efforts for employees in various roles within the company. As there are limits to how much direct production associates can be emotionally engaged, and that their work group performance is determined more by their relationship with their supervisor, companies may be wise to ensure that employees working in the various levels of supervision are engaged, as they will have the most influence on company performance. If the performance of interest is innovation, and 
innovation demands the creativity that comes from intrinsic motivation indicated by high levels of emotional engagement, then it is most likely that innovation will come from the management and technical specialist employees in the Support data set. The quantitative study could not explore the results of innovative behavior for the management and technical support groups as there are no available factory measures for these groups. However, we are still interested in exploring the relationship of these most highly engaged work groups in developing an innovation capability in a mass production organization. In the next section we will use case studies of actual implemented innovations to explore how the innovation actually happened in the organization, and the relationship between innovation and continuous improvement to further refine our prescriptive advice in answer to our research question. 


\section{CHAPTER 7 CASE STUDY RESEARCH AND ANALYSIS}

From the quantitative study of work groups within an auto parts manufacturing firm, we determined that the Production Engineering and Management work groups had the highest levels of employee emotional engagement. Emotional engagement is being used as a proxy for the autonomous intrinsic motivation necessary for creative problem solving that could potentially yield innovative solutions. However, the earlier study was unable to evaluate the results of the engagement levels of these work groups using available factory data. We turn to another research method in an attempt to evaluate our fourth hypothesis, that the work groups with the highest engagement levels will exhibit the highest levels of innovative behavior.

\section{Overview of the Case Study Project}

This case study project comprises the second portion of the doctoral dissertation. The topic of the research is developing an innovation capability in a mass production factory. In order to explore how one firm has evolved in developing this capability, we will examine three cases of independent examples of major assembly process innovations implemented over a 4 year period at a supplier of automotive seat belt assemblies in Ontario, Canada (TRQSS). Through the case studies we will explore why and how these specific innovative solutions came to be implemented in actual practice. We will also look for effectiveness of the implemented innovations, and whether or not any improvement in the firm's ability to develop and implement innovative solutions has improved over time. Case study is an appropriate research method as we are attempting to explain how and why a series of actual events occurred over a period of time, and our extent of control over events is low ${ }^{8}$ (Eisenhardt \& Graebner, 2007; Yin, 2009). Analysis will consist of pattern matching against theory derived from the literature. Elements of

\footnotetext{
${ }^{8}$ The author was a participant in some case events.
} 
commonality will be explored to determine if certain conditions are more prevalent or important than others.

\section{Case Study Research Design}

\section{Underlying Theory}

According to the literature, the continuous improvement process and the innovation process are analogous; the distinguishing feature of innovation is the extent of novelty in the solution which is a result of the creativity of the originating idea. According to Basadur, creativity is a 3 step iterative process of problem finding, problem solving, and solution implementing applied to the betterment of an organization, its customers, or its members (Basadur, 2004). Robinson and Stern contend that the implementation of an innovation in a corporation involves some self-initiated individual activity (usually unofficial), the subsequent collaboration of individuals with diverse knowledge bases, and some serendipity (Robinson \& Stern, 1997). Additionally, literature asserts that creative ideas come from intrinsic motivation and not as a response to the incentives of extrinsic rewards. Innovation can be the result of creative ideas that emerge in the problem solving process which follows problem finding. The author believes that creativity is motivated by some kind of constraint ("necessity is the mother of invention"); in the absence of constraint, implementation of solutions born of existing proven routines will prevail (Schein, 2010).

The cases chosen for study will be analyzed for the presence or absence of these theoretical conditions and the conformance or non-conformance to these theoretical patterns and to what degree.

1. Do the case examples follow the innovation process as documented by ASQ, and the creative thinking process modelled by Basadur.? 
2. Are the most highly engaged work groups producing the most creative ideas?

\section{Case Selection}

The cases chosen for analysis were each an example of the implementation of an innovative assembly process in the finishing assembly area at TRQSS. The innovative solutions were all conceived at TRQSS; that is, they were not merely localizations of the parent company's processes, or the result of benchmarking competitors processes. As each case is a new equipment installation, the Production Engineering and Management work groups are deeply involved, which is critical to evaluating our fourth hypothesis. Additionally, during the period in which these cases took place, there were no significant changes in the external environment (such as recession or corporate changes); as such it was a period of relative stability for the company. Therefore, causal relationships can be better determined by evaluation of the case events.

\section{Validity and Reliability}

\section{Construct Validity}

To meet the test of Construct Validity for case study research, we will follow the recommendations proposed by Yin (Yin, 2009). The cases will be compared based on the effectiveness of the execution of the creative thinking model as proposed by Basadur (Basadur, 1992, 2004), and evaluated based on the time taken to achieve the desired results. This will provide an objective measure for analysis, and ensure that data is not gathered based on subjective judgements. Following Yin's recommendations, multiple data sources will be used to collect data. First, all cases are capital equipment procurement and installation, and the organization has established routines for the request and approval of equipment. These documents will be used to establish what was being proposed, how it was to be implemented, and what was the expected benefit. The Production Engineering organization also has excellent 
records of design changes to projects as they evolve, so changes from the original proposal can be identified. Production records are kept electronically for 7 years, so actual results of the implemented processes can be used. Interviews with key personnel were conducted as well; although different individuals within work groups were involved in the three cases, some key personnel were common, such as Managers in the Production Engineering and Production departments. Additionally, the author is a management employee of the organization, and therefore has direct observation of events, some participant observation in some aspects of events, and access to email and other documentation to establish a chain of evidence. Finally, case drafts were read by 3 informants; a Production Engineering manager, a Production Section manager, and an Engineering designer for corroboration and accuracy. Internal Validity

Since we are using case study research for explanatory purposes, we are concerned with Internal Validity (Yin, 2009). Since ample documentation exists for all three cases, participants can be interviewed (and there were no major personnel changes within the organization during this period), and performance data exists and is available, few inferences need to be made. Since we are comparing the performance of innovation implementation within one organization during a stable period, the objective results and the inferences derived from pattern matching should provide a valid base for fair comparison.

\section{External Validity}

Since we are dealing with multiple cases within one organization, the question about external validity must be addressed. Since we are dealing with a relatively simple theoretical model of organizational creative thinking (Problem Finding, Problem Solving, Solution Implementing), which was developed from case study research of several organizations, findings could be applicable to any mass production firm that has internal responsibility for 
manufacturing process design and mass production. Additionally, we are dealing with work groups that are common to mass production firms; an unanswered question is the extent to which individual firm differences may contribute to the efficiency of innovation implementation.

\section{Relaibility}

The concern with reliability is that a subsequent researcher should be able to study the same three cases for the same purpose and arrive at the same conclusions. Recommendations for achieving reliability are to follow a case study protocol and build a database for retention of collected evidence. As previously mentioned, ample documentation and performance data exist in the records of the firm, and key participants remain as employees. One significant difference is that a subsequent researcher would not have the advantage of participant observation afforded the author. The case study protocol contains an overview of the case study project, field procedures, case study questions, and a guide for the report (Yin, 2009)(Yin). As the overview has been previously documented in this Chapter, the Field Procedures and Questions are listed in the next section. The individual Case Studies will follow.

\section{Case Study Protocol}

\section{Field Procedures}

Cases for study have been identified by the author. Available documentation will be reviewed; participants/informants will be interviewed and/or asked for a written account. Empirical data with respect to the results of case subject implementations may be used. The author has substantial access to the worksite, documents, and participants/informants. Key informants will be asked to read a draft of the Case Studies for accuracy.

Case Study Questions (Level 2 questions to be addressed by the case) 
1. What was the existing circumstances/need that determined that some action was to be taken?

2. What was the existing method/process/procedure for addressing the circumstances/need?

3. How was the implemented (innovative) solution developed? Why was it chosen over the alternatives?

4. Who was involved and what was their role? (Job titles - not names)

5. How is it/did it work compared with what was expected?

6. What was the reaction of the organization?

\section{Case \#1 - Innovative finishing process for a new design buckle}

A front seat belt system consists of 3 separate assemblies; a retractor, a height adjuster, and a buckle. The first two assemblies are mounted on the outboard side of the vehicle, whereas the buckle is typically mounted to the inboard side of the front seat. The buckle function is to receive the metal tongue which is attached to the webbing of the retractor assembly, and keep it locked within the assembly until the occupant releases it by pressing a red button on the buckle just above the tongue engagement point. The front seat buckle consists of the buckle head, which contains all the mechanical components responsible for latch and release, mounted to a metal anchor strap that is attached to the seat frame with a bolt. The buckle head is encased in a decorative plastic cover, usually colour matched to the interior of the vehicle. The front buckle also contains an electrical switch that is linked to the latching mechanism, which is used to send a signal to deactivate the warning light on the dashboard when the tongue is properly latched. Attached to the switch is a wire harness that extends from the buckle head and terminates at a connector that will join the mating connector during vehicle assembly. Wire harnesses vary in 
length and connector configuration, based on vehicle type and seat complexity (manual versus power).

TRQSS had been supplying a standard buckle design for more than 10 years. It was reliable, and economical, as it had minimal components. However, over the years there were some warranty issues. Customers returned their vehicles to the dealers for buckle replacement when the buckles stopped latching reliably; analysis of returned parts showed that this was usually due to the presence of foreign material inside the buckle (food, liquid, pennies, paper, chewing gum, etc.). The standard buckle had a rather large tongue opening, which made it easy for the occupant to locate, but was also large enough to allow foreign material to enter. The standard buckle switch mounted to the bottom of the buckle after the cosmetic cover had been installed. This installation point resulted made it easy for the operator to assemble, but it had the unfortunate effect of trapping any foreign material that happened to get inside the buckle head through the large tongue opening.

Tokai Rika design engineers had developed a new design for the buckle to eliminate these warranty concerns. A significant change that would affect the assembly process of the buckle was the redesign of the switch. In order to open the bottom of the buckle to prevent trapping foreign material, the position of the switch had to be moved from the bottom to the side of the buckle. To engage with the latch mechanism, the switch would have to be assembled to the buckle head before the cover was installed; and that resulted in the buckle cover changing from a one piece design to a two piece design. Like most new technology introductions, the new design would be introduced on a few vehicles first, and then adopted by other vehicles at their respective model change timing. Eventually, the new buckle would become the standard for all vehicles. 


\section{Assembly Process}

Both the new buckle and the current buckle heads were made on automated assembly lines.

One advantage of the new design was that the metal anchor strap could be attached to the metal frame of the buckle head with one large metal rivet within the automated assembly line. The current buckle required a secondary operation where 2 small rivets were used to attach the anchor strap to the buckle head on a manually operated press. In both cases however, the buckle subassembly would be presented to the finishing lines in the same configuration; a mechanical buckle head (without the decorative cover) attached to the metal anchor strap. The finishing lines performed the operations that made each buckle assembly unique to its vehicle; adding the appropriate switch and wire harness configuration, assembling the appropriate buckle cover(s), testing the buckle assembly for latch and switch function, taping the wire harness to the strap according to specification, and packaging the assemblies in the customer approved returnable containers for shipping. Typically these finishing lines were manual operations, with the most significant machinery being the cover installation presses and the functional and switch test machines. These lines were replicated according to volume requirements, with one finishing line able to produce up to 2,000 pieces per shift depending on the number of operators used.

\section{New Buckle finishing assembly}

The new buckle was scheduled for launch in September of 2013. Process design planning began in the summer of 2012, appropriate lead time to meet the customer requirement of executing pre-production builds 6 months in advance of the launch. In July, the Manager of Production Engineering (PE) submitted a Capital Expenditure Request (CER) for the assembly equipment required to produce approximately 12,000 of the new design buckles per day. The proposal was to replicate the existing finishing line concept that had been used effectively for 
years; 4 individual finishing lines that would receive the buckle head/metal strap assembly from the automated cell, and perform the remaining assembly and test functions required for each individual vehicle. The major difference from the current buckle assembly method was that the buckle cover was now 2 pieces rather than 1, and that the switch with wire harness would have to be assembled to the lower buckle cover before the covers could be assembled to the buckle assembly. For this reason, the proposed system included a central area for the switch assembly operation that would then supply all 4 finishing lines. The entire system would require 21 operators over 2 shifts to perform all of the finishing assembly functions. Because of the magnitude of this investment, the CER had to be approved by the Vice President.

The assembly concept was proven, but there was a problem with the resulting assembly cost. Despite the fact that the new buckle had more components and consequently more assembly operations and labor than the product it was replacing, the customer was expecting a price reduction from the current older technology buckle. This is often the case with auto parts that are considered to be commodities. Therefore, TRQSS had to come up with an assembly process that resulted in less direct assembly $\operatorname{cost}^{9}$ than the traditional method. This had to be done quickly as the available lead time was only sufficient to install a conventional system.

While reviewing the CER for the buckle finishing process, the Vice President could see that the target for direct assembly cost was not achieved, and that the proposal required 4 cover presses and 4 function and switch test machines of the conventional design, meaning that the company would be locked into that method for another 4 year vehicle cycle. Also, the replications of these machines resulted in longer lead time for the equipment supplier. The VP

\footnotetext{
${ }^{9}$ The components of Direct Assembly Cost are direct labor, direct depreciation, and direct usage items per unit produced.
} 
asked the PE Manager to consider another assembly process design that somehow combined these common elements and reduce the capital expenditure.

The PE department worked with the equipment supplier who had previously provided the buckle head/metal anchor strap automated assembly line, and 6 weeks later they resubmitted the CER for a proposed "Innovative Concept" buckle finishing line. This line was centered on a centralized system for cover pressing and assembly testing; the switch to buckle cover assembly (a manual operation) would feed subassemblies to the beginning of the line directly, and the wire harness taping operation and packaging would remain manual operations at the end of the line. The main line was a Bosch asynchronous pallet conveyor system; operators were responsible for loading the switch subassembly and the buckle subassembly to the pallet, and plugging the end connector of the switch wire harness to a custom designed universal receptacle on the pallet. Upper buckle covers would be fed by a vibratory bowl to a Denso robot that would perform the assembly. The pallet would then enter a station where the buckle latching and switch operation test would be conducted. After a successful test result, an operator would disconnect the wire harness connector and remove the assembly from the pallet, sending it to the operators responsible for taping the wire harness to the strap and packaging the assembly. This proposal required 5 fewer operators overall to produce the same quantities as in the original conventional proposal. Figure 14 shows the layout of the automated buckle finishing line as proposed. After an additional 4 weeks of work, the PE department and the vendor were able to reduce the capital expenditure estimate by $30 \%$ ! The "Innovative Concept" proposal now required fewer operators and less capital investment that the conventional proposal. Although there were some details to be worked out, the engineering team and the equipment vendor were confident that the risk was minimal as the technologies involved were proven in production. Subsequently, the CER 
proposal for the Innovative Concept was approved in October, 2012 for delivery to TRQSS in May of 2013. The new line would start mass production for the first vehicle to use this buckle in September, 2013, giving TRQSS 4 months to prepare for this milestone.

Figure 15 Proposed Concept for Automated Buckle Finishing Line

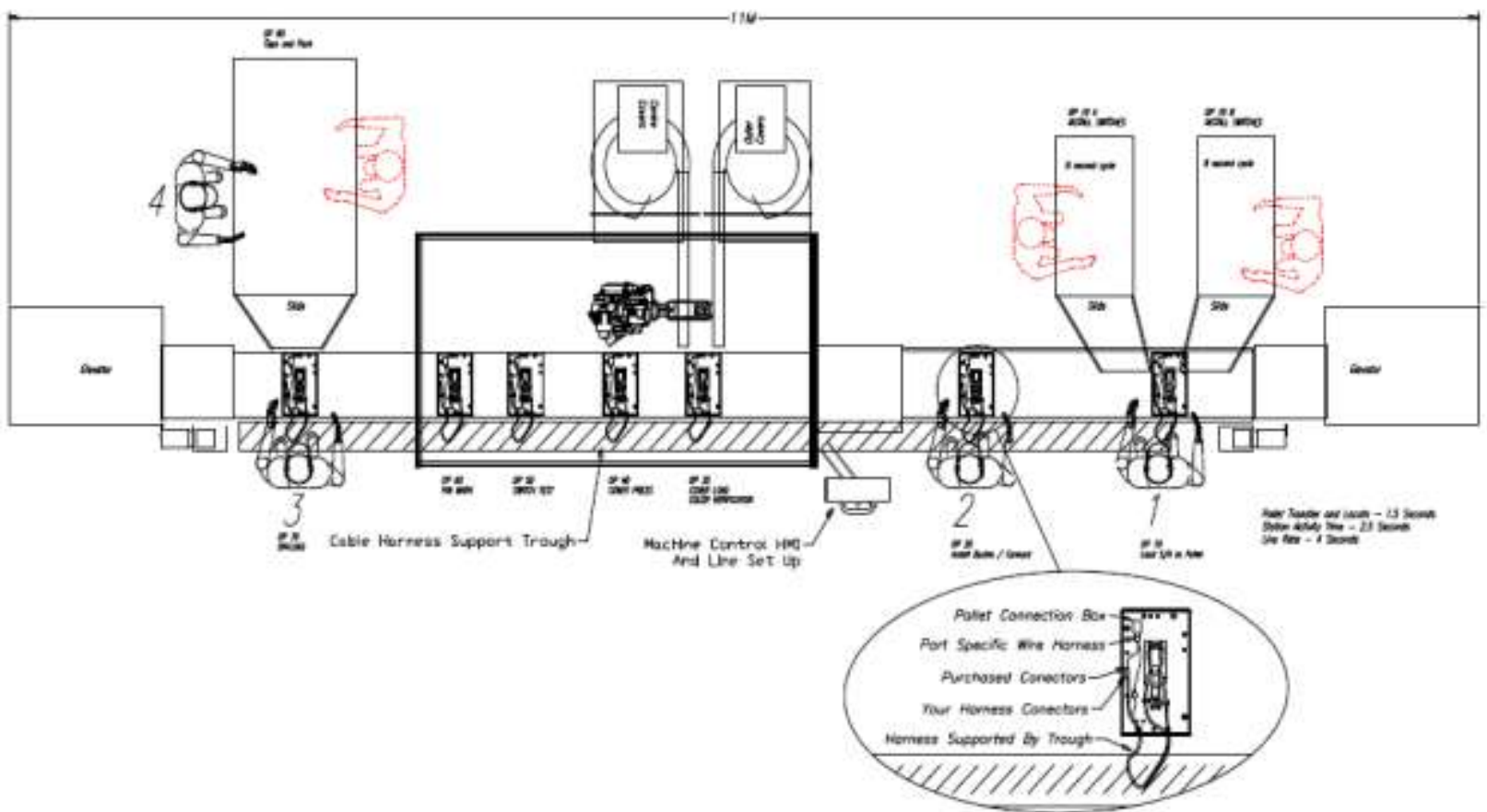

\section{Changes from Concept to Installation}

In the six month period of machine construction, some of the processes underwent significant change. However, the Production Engineering department and the machine vendor knew that despite changes, the equipment cost, cycle time, and number of operators could not increase from the original proposal. The most significant change involved the switch operation test. The universal receptacle concept proved unfeasible, so it was decided to use the actual connectors for the test; however, the large number of different connectors could not be accommodated on the Bosch pallet. Consequently, a larger receptacle panel had to be installed 
directly at the test station and the idea of using the pallet as a receptacle was abandoned. This had the following effects:

1. The first two manual operations could be combined, as it was no longer necessary to plug in the wire harness to the pallet

2. An operator would be required to plug the wire harness into the receptacle panel at the test stand; however, after a successful test, the connector could be automatically ejected

3. Since the wire harness could be disconnected automatically, it was feasible to use a Denso robot to unload the buckle from the pallet (this increased the equipment cost slightly but was more than offset by the removal of 1 operator; as such, the engineering change was approved)

Figure 16 shows the layout of the line when it was installed at TRQSS. Since it was the first automated buckle finishing line, it was called AF1.

\section{Figure 16 Initial Configuration of AF1}

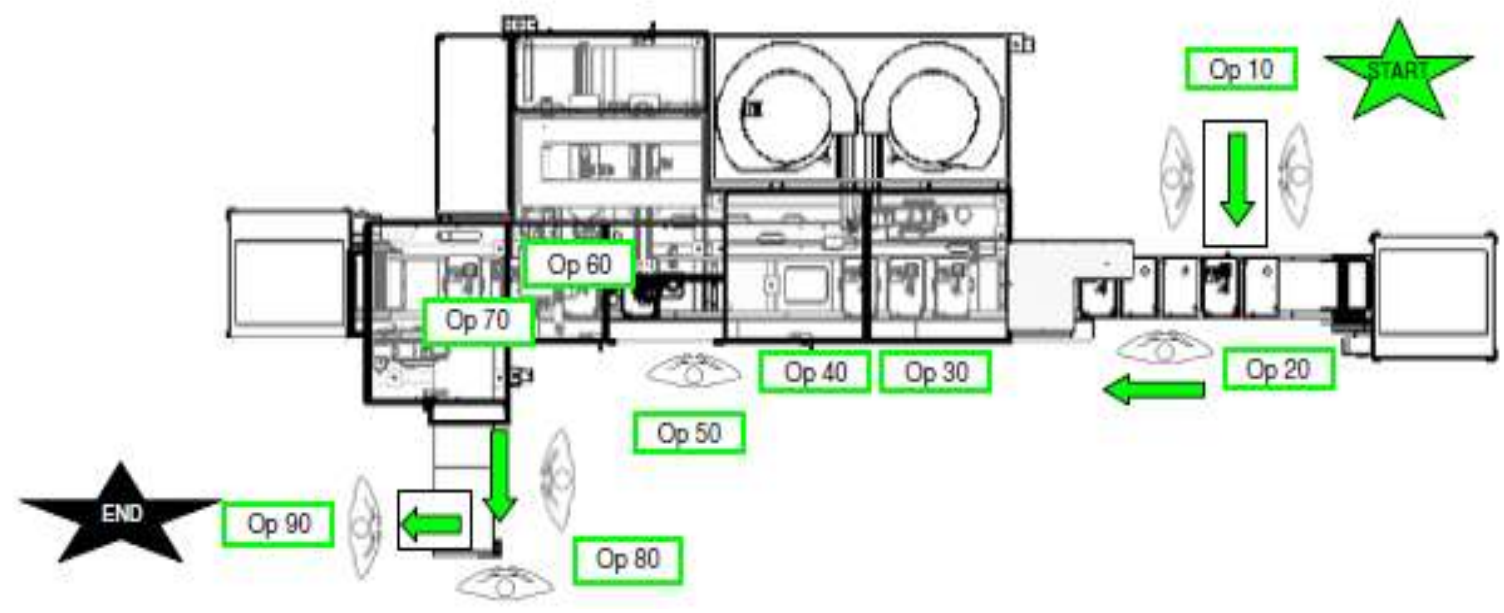

\section{Line Installation and Initial Performance}


The line was installed and the first parts were produced at TRQSS in May 2013. Figure 17 shows the monthly performance history of the automated buckle finishing line (AF1) from inception until June 2016.

Figure 17 Chart of Historical Performance of AF1

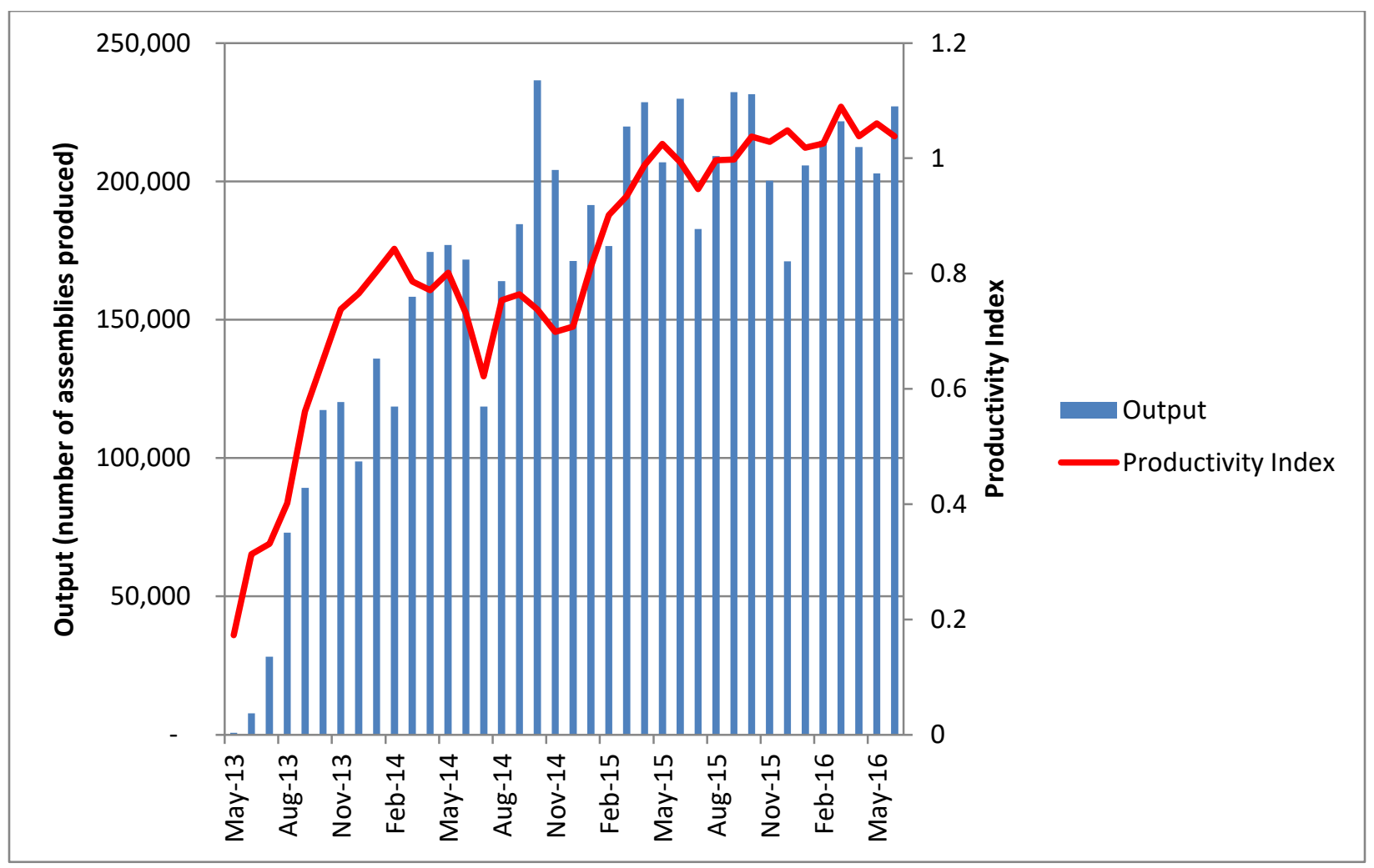

As seen in the graph, significant production volume began in August of 2013, and escalated from an initial monthly quantity of 75,000 pieces to a steady volume of 125,000 pieces by the year end. Initial productivity index was .35 (35\% of the design target) but reached almost .77 by year end. Production Engineering and Maintenance departments continued to refine the switch testing equipment but the primary cause of this productivity increase originated elsewhere.

The struggles at OP 20 
At OP 20, an operator was responsible for assembling the buckle head subassembly to the lower cover switch assembly, and loading the resulting assembly to the Bosch pallet. The cover/switch subassembly was produced by two operators working on the back side of the machine. The operators placed the subassemblies in quantities of 5 into a rigid plastic returnable container, commonly used throughout the plant. Five of the corresponding buckle head subassemblies would be placed in the same box and fed to the operator at OP 20 on a gravity fed conveyor. At OP 20, the operator had to retrieve a cover/switch subassembly and a buckle head subassembly from the same box, assemble them together, and place it on the pallet, maintaining a cycle time of 5 seconds. Watching this operation in practice revealed several problems. The buckle heads and the wire harnesses sometimes moved around within the box as it travelled down the gravity conveyor. When the operator had to retrieve the parts, they were often out of position and the wire harnesses were tangled among themselves. In the worst case, while untangling the wire harnesses, the switch could become disassembled from the buckle cover. All of this meant that OP 20 could not keep up with the line.

A Mechanical Designer was assigned to fix the situation. Working with the operators, he designed a method for holding the cover/switch assembly after it had been produced, and easily transporting it to the operator at OP 20, delivering it at the exact height and orientation required. Additionally, this design delivered the subassemblies in quantities of 8 , which the work group decided was the appropriate number as it matched the box quantities of the finished goods at the other end of the line. With this method, the buckle head subassemblies could then be transferred directly from the automated assembly line to OP 20 in the existing box in a quantity of 24 ; the minimum lot size for a build of finished goods would be set at 3 boxes, and no re-packing of buckle head subassemblies was necessary. With this new material handling device, the operator 
at OP 20 could complete his task with time to spare; one hand could access the cover/switch subassembly, the other hand could access the buckle head subassembly, and in a smooth motion the two subassemblies could be joined and placed to the pallet. Because of the design of the cover/switch subassembly carrier, the various lengths of the wire harnesses did not matter; they never became tangled again after they were initially assembled, and there was no risk of disassembly. See figure 18 for a picture of this system.

Figure 18 Cover/Switch subassembly delivery system

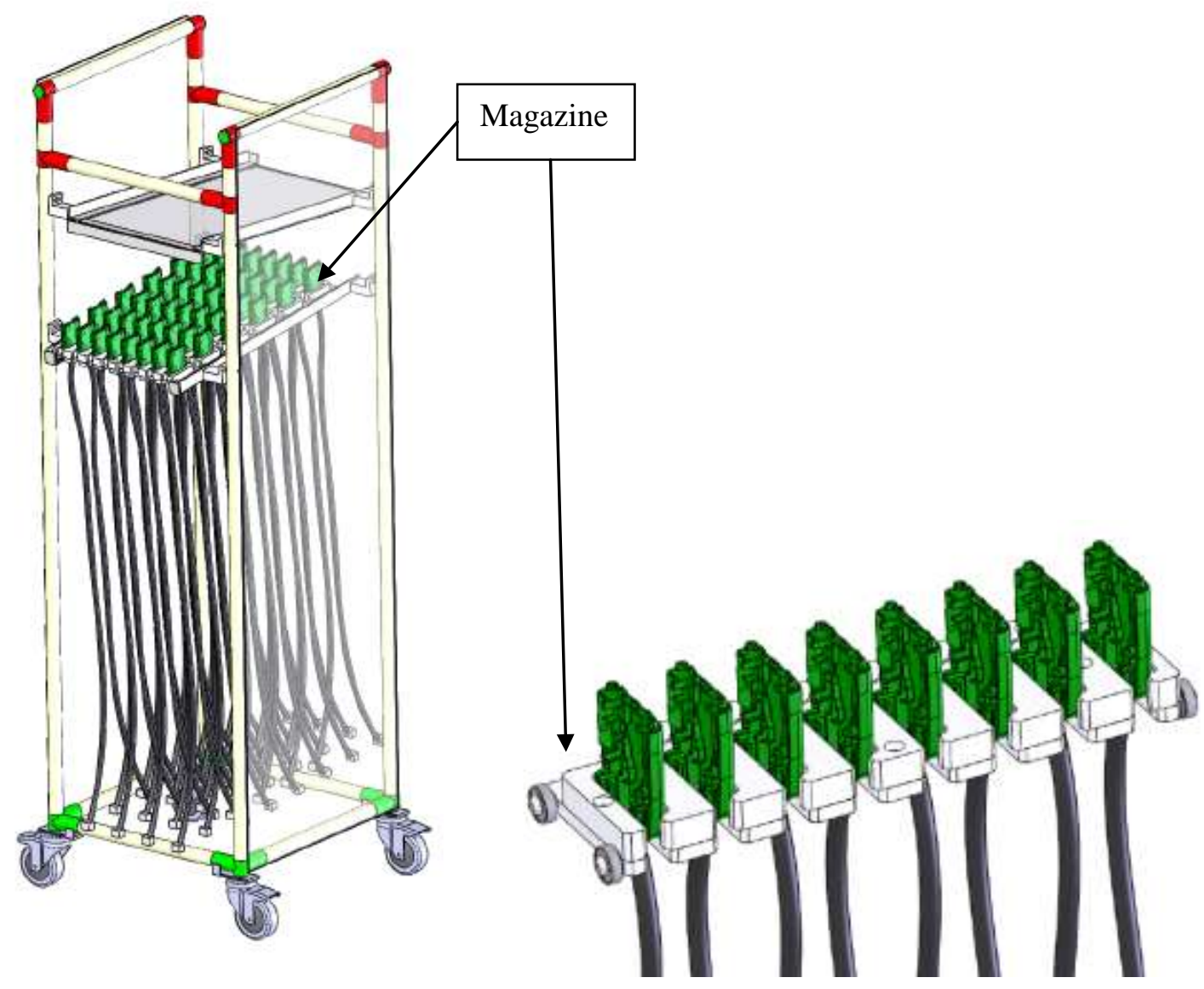

The Inconsistencies of Taping (OP 80) 
The last operation before packaging was to align the wire harness to the center of the metal strap and secure it in place with electrical tape. This is done for all buckles, and there is huge variety in the specifications for the many different wire harnesses and metal straps. Sometimes there is tape in one location, sometimes 2 ; these locations are very specific, and where the tape begins and ends is also called out on the specification. Once the bottleneck at OP 20 was relieved, the team was able to sustain a productivity of over 60 parts per man-hour, but now the obvious problem was variation in the taping process. Because of the variety of taping applications and the complexity of the process, 5 operators were required to do the work that 3 were supposed to do. Once again, the Mechanical Designer was assigned the task of redesigning this process for greater efficiency.

The Designer realized that the process of precisely locating the wire harness and adding electrical tape to exacting specifications was not easily automated and best done by humans. The key was to remove all the "noise" from the process; if the part could be presented to the operator exactly the same way every time, then the operator could consistently apply the tape in the exact location and the part could be passed along. He first made a small jig to hold the buckle head, with a cylinder to adjust the position of the metal strap for tape application to test this concept. Once proven, he worked with the machine vendor to design a conveyance loop to the end of the machine. After the test operation, the Denso robot would remove the assembly from the pallet, and then place it onto another pallet on the secondary conveyance system; this pallet would incorporate the prototype jig design and bring the assembly to the operator at OP 80 , presenting it in the exact location and orientation for tape application. After this step was completed, it would then be conveyed to the packaging operator. If a buckle required 2 tape applications, then a second station was provided for a second operator; otherwise, only one operator was required 
to maintain the machine cycle time. The taping system was installed over the Christmas shutdown period in 2014. In the next 4 months productivity increased $38 \%$, to over 80 parts per man-hour. Figure 19 shows the final configuration of the line after the installation of the taping conveyance system.

$\underline{\text { Figure } 19 \text { Final Assembly line Configuration }}$

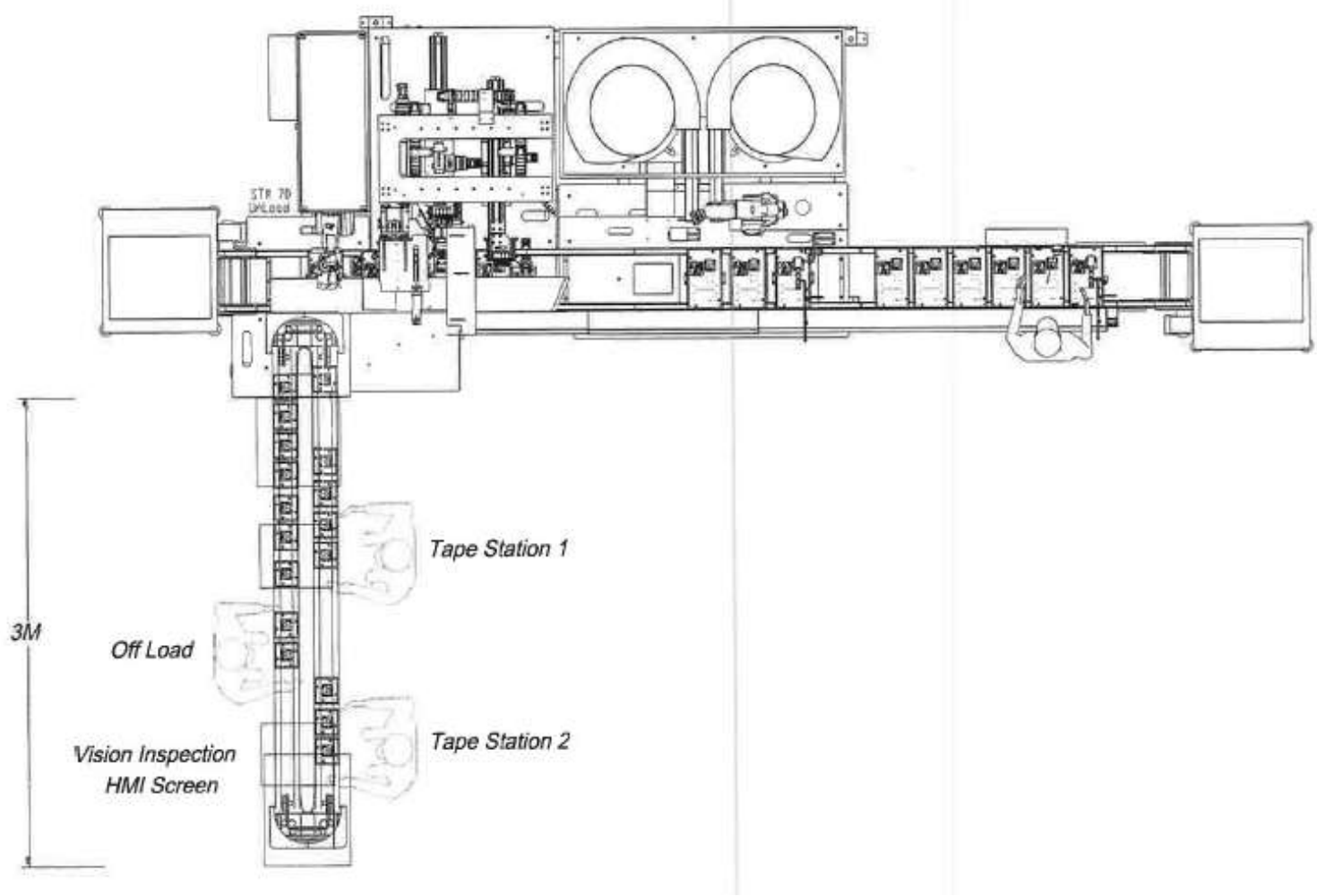

\section{Improvement to the Switch Assembly Process}

Using the cover/switch subassembly delivery system designed by the TRQSS Mechanical Designer, the subassembly area had begun supplying 2 additional manual buckle finishing lines. Activity led by the area Production Supervisor resulted in a productivity improvement of $13 \%$, eventually exceeding the designed productivity target. Each finishing line has an operator responsible for parts stocking; that is delivering the components required for each production build to each work station and moving the finished assemblies to the specified storage locations. 
The stock operators also have to disposition the returnable and expendable packaging associated with each component and ensure the correct routing of the kanban cards. In the buckle assembly area there was a stock operator supporting the 2 manual finishing lines, and a stock operator supporting the cover/switch subassembly area. The latter operator delivered all cover/switch subassemblies to the finishing lines and brought back the empty racks for the subassembly area to refill. The Supervisor and his team realized that both stock operators were underutilized, but both were required to execute the process as it existed.

The Supervisor and his team redesigned the cover/switch subassembly area so that the flow of component parts and packaging was improved, and the time spent by the stock operator was reduced. Next, they determined that the operators performing the cover/switch subassembly could deliver the full racks to the finishing lines and retrieve the empty racks. The stock duties for the subassembly area had now been reduced sufficiently that the formerly underutilized stock operator for the manual finishing lines could now handle both jobs. The need for a separate stock operator for the subassembly area was eliminated, and the productivity of the entire area improved, as the same amount of work was being completed by fewer operators.

\section{Comparison of actual results to original plan}

The AF1 assembly line is producing approximately 225,000 pieces per month with a productivity index of 1.07 .

Using the criteria from the original CER for the innovative buckle finishing process, the line should have been capable of producing 225,000 pieces per month with a productivity index of 1 .

The line is now exceeding the original expectations; however, upon review of Figure 16, the line did not meet those expectations until 18 months after starting mass production. The 
production output was limited by customer requirements, but the productivity levels were not achieved without ingenuity of in house designers and the continuous improvement efforts of the production team members.

\section{Case \#2 Innovative Finishing Process for a retractor assembly}

The retractor assembly stores the seat belt webbing, allows the webbing to be extracted by the occupant when using the seat belt, retracts the webbing into the system when not in use, and contains the sensing and locking mechanisms required to restrain the occupant in a crash situation by preventing the webbing from further extraction. When installed in a vehicle, most of the retractor assembly is invisible to the occupant; it is mounted to the vehicle body at the B pillar and is covered by interior trim. The visible portion of the assembly is the amount of webbing that the occupant needs to access and use the seat belt; incorporated to the webbing is a metal tongue plate used by the occupant to engage the buckle on the opposite side of the seat. The trim piece that covers the opening where the webbing exits the B pillar trim is also part of the retractor assembly, as is the visible anchor at the end of the webbing that is attached to the floor of the vehicle. All retractors consist of a metal frame, and a spool around which the seat belt webbing is stored. On one side of the frame there is a power spring mechanism that retracts the webbing to the spool when not in use. The other side of the frame contains the locking mechanism that senses the conditions when the spool should be locked from rotating and no additional webbing can be extracted. Some retractors contain a pretensioner; a device that begins to retract webbing in the milliseconds before the occupant moves forward in a crash event. See Figure 20.

Figure 20 Retractor Assembly

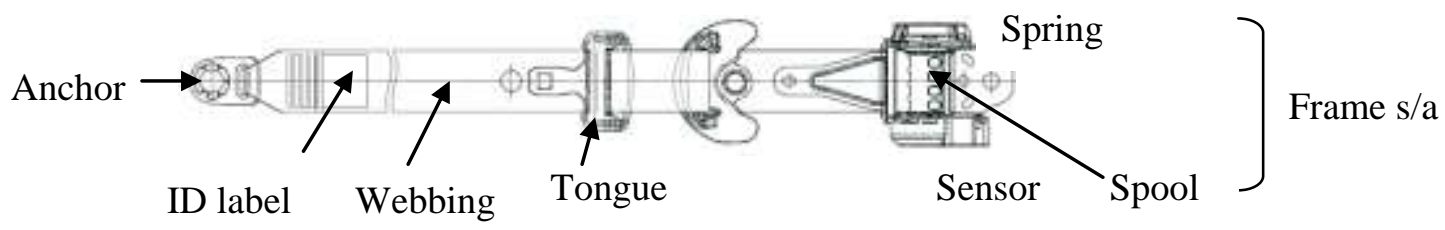




\section{Assembly Process and an alternative}

At TRQSS all retractor subassemblies (frame, spool, spring, and locking mechanism) are produced on automated assembly lines. Where the production conditions such as volume and design life do not warrant investment in automation, retractor assemblies are imported from other Tokai Rika divisions where they are being produced in higher volume. The retractor subassemblies are then delivered to various finishing lines, where the vehicle specific webbing, mounting hardware, and identification labels are added and the final assemblies are packaged in customer specified returnable containers. Most finishing lines contain some kind of functional testing equipment also, to check performance to regulatory specifications as well as other performance parameters.

Webbing for seat belts is delivered to TRQSS in 200m rolls. The seat belt webbing is then cut to specified lengths, and a stopper pin is sewn into one end of the cut piece. This subassembly is made in a central area and the delivered to the various finishing lines. Typically the first operation on the finishing line is to insert the webbing subassembly through the spool of the retractor subassembly, seating the stopper pin at the end into a recess in the spool with a predetermined force. Once assembled, a keeper is removed from the pre-wound power spring which allows the webbing to retract into the frame around the spool inside the assembly. After this, the assembly is tested and the various mounting hardware and trim components are added to the portion of the webbing remaining outside of the spool. The assembly is then packaged for shipment to the vehicle assembly plant.

Retractor finishing is a relatively labor intensive process, as the unit is handled several times and webbing is extracted and retracted throughout many assembly and test operations. For several years TRQSS engineers explored different ways to reduce the labor content in retractor 
finishing, but automation of these processes had proven difficult, as the webbing that is the base component being handled, oriented, and assembled is "soft". Tokai Rika had tried different automation options in Japan; although some were successful, the capital investment was very high, and flexibility was limited, as often the automated finishing line had to be dedicated to one particular model.

In 2004, the Director of Operations and the Manager of Production Engineering had developed a process concept for retractor finishing that reduced the total amount of labor required by rearranging the sequence of operations. This alternative concept started with the guideline that every time a component or subassembly is touched, then value added assembly steps should be executed; motions that merely move or reposition parts but add no value should be eliminated. This guideline led to the realization that retractor assembly was essentially composed of two subassemblies; the retractor mechanism that came from an automated assembly cell, and a webbing subassembly that consisted of a piece of seat belt webbing cut to a certain length, with trim pieces and mounting hardware attached by mostly manual processes. The crucial step where these two subassemblies were joined together was the seating of the stopper pin into the spool and the removal of the spring keeper. The problem with the conventional finishing assembly sequence was that the stopper pin was sewn into the webbing immediately after the piece was cut to length. As a result, joining the webbing to the retractor was the first step in the retractor assembly, and all of the mounting hardware was added subsequently. The alternative concept would create a webbing subassembly starting from the opposite end of the webbing and add the anchor, identification label and the tongue stopper first. Then all that remained would be to feed the unprocessed end of the webbing subassembly backward through the mounting hardware and back through the spool of the retractor subassembly a short distance 
to a sewing machine where the stopper pin could be sewn into place, effectively joining the two subassemblies together. The stopper pin end of the webbing could then be seated into the spool, the spring keeper removed, and the assembly would be completed as the webbing is retracted into the spool by the power spring. The only potential requirement remaining before packaging would be some sort of test. The attractiveness of this concept was that the labour intensive operations of producing the webbing subassembly, which consisted of all of the components that needed to be colour matched to the vehicle interior, were isolated from the final assembly and testing of the retractor. This separation could potentially facilitate the outsourcing of some labor intensive operations to low labor cost countries if the company chose to pursue that strategy in the future.

Although this concept existed on paper, it had never been put into practice because of the many unresolved issues such as:

a) Handling the webbing subassembly with all of the associated hardware without damage

b) Ensuring correct orientation of the webbing subassembly when back feeding through the mounting hardware and spool

c) Automation of stopper pin sewing

d) Verification of proper web length

e) Testing of the assembly after hardware installation

f) Cycle time of webbing sub assembly fabrication

All of these "problems" either did not exist or they had a feasible solution in the conventional process for retractor finishing. In the ensuing years, there was never a new vehicle program that required or was receptive to an unconventional method of finishing assembly, and 
there were always current production problems to deal with, so no Production Engineering resources were ever assigned to resolve any of these potential issues with this proposed concept.

\section{New Vehicle Program}

In 2014 TRQSS was awarded the business to provide seat belt assemblies for a new luxury SUV to be produced in Canada. The quality requirements were stringent, and the volume was moderate; to be profitable producing the seat belts in a high labor cost environment, TRQSS had to come up with a less labor intensive method of finishing these retractors. The front retractors for the new SUV would be common technology with some existing vehicles, so the incremental volume could be absorbed on current production assembly lines. The rear retractors however were unique. The low volume dictated that the retractor subassembly would be imported from a Tokai Rika plant in Asia, where that product was already produced in high volume. TRQSS would have to develop a finishing assembly line specifically for these rear retractors. The right and left hand retractors for this vehicle had the same mounting angle within the vehicle; because of this, many items were common between them such as the sensor mechanisms, webbing length, mounting anchor, and tongue. The only difference was the symmetrical mounting brackets that were added to the frame during finishing, and the identification label. These conditions, along with the moderate vehicle volume and only two interior colours presented a great opportunity for an innovative finishing process. The Manager of Production Engineering proposed that the ten year old concept for the Innovative Retractor Finishing Line be turned into reality for the rear retractors for this vehicle program. The Production Engineering department set to work with a machine vendor to develop the equipment required to bring the concept to reality.

\section{The Proposal}


The proposed assembly system would consist of 2 machines; one machine integrated a laser webbing cutter with a sewing machine for the mounting anchor and a small press for the tongue stopper button. The operator would load the mounting anchor to a fixture, and load the 2 small plastic pieces for the tongue stopper into the press and then start the machine. The machine would feed webbing from the $200 \mathrm{~m}$ roll through the anchor, fold and clamp the webbing, and transfer it to the sewing machine, which would clamp the folded webbing and cycle automatically. While the sewing operation was occurring, the tongue stopper would be pressed in the correct location and the other end of the webbing would be cut by a laser at the correct length. When completed, the machine would roll the subassembly into a convenient coil for the operator to remove before repeating the cycle. The machine would operate autonomously while the operator was free to do other tasks. The second machine integrated the web stopper pin sewing machine with an assembly and test machine. The operator would load the retractor subassembly, the tongue, and the web subassembly coil; the machine would feed the webbing back through the tongue plate and retractor spool to the automated stopper pin fold and sew operation. When the stopper pin sew was complete, the machine would seat the sewn stopper pin into the spool, remove the spring keeper, and then test the assembly. These steps were also performed autonomously while the operator was free to do other tasks. After testing, the identification label was attached to retractor assembly, and then it was ready for packaging.

The advantage of the proposed system was that 4 operators would be able to complete the work done by 8.5 operators in the traditional system. A large part of the advantage was that the entire assembly from webbing roll to completed part would be done at once; no significant subassembly inventory and transportation was required. As a result, the corresponding floor space for this system was $650 \mathrm{ft}^{2}$, roughly half of what was required by the conventional method. 
Based on these advantages, the proposed system was approved. The system started production in September, 2015. Figure 21 shows the historical performance of the Innovative Retractor Line, which was called IF1.

\section{Figure 21 Historical Performance of IF1}

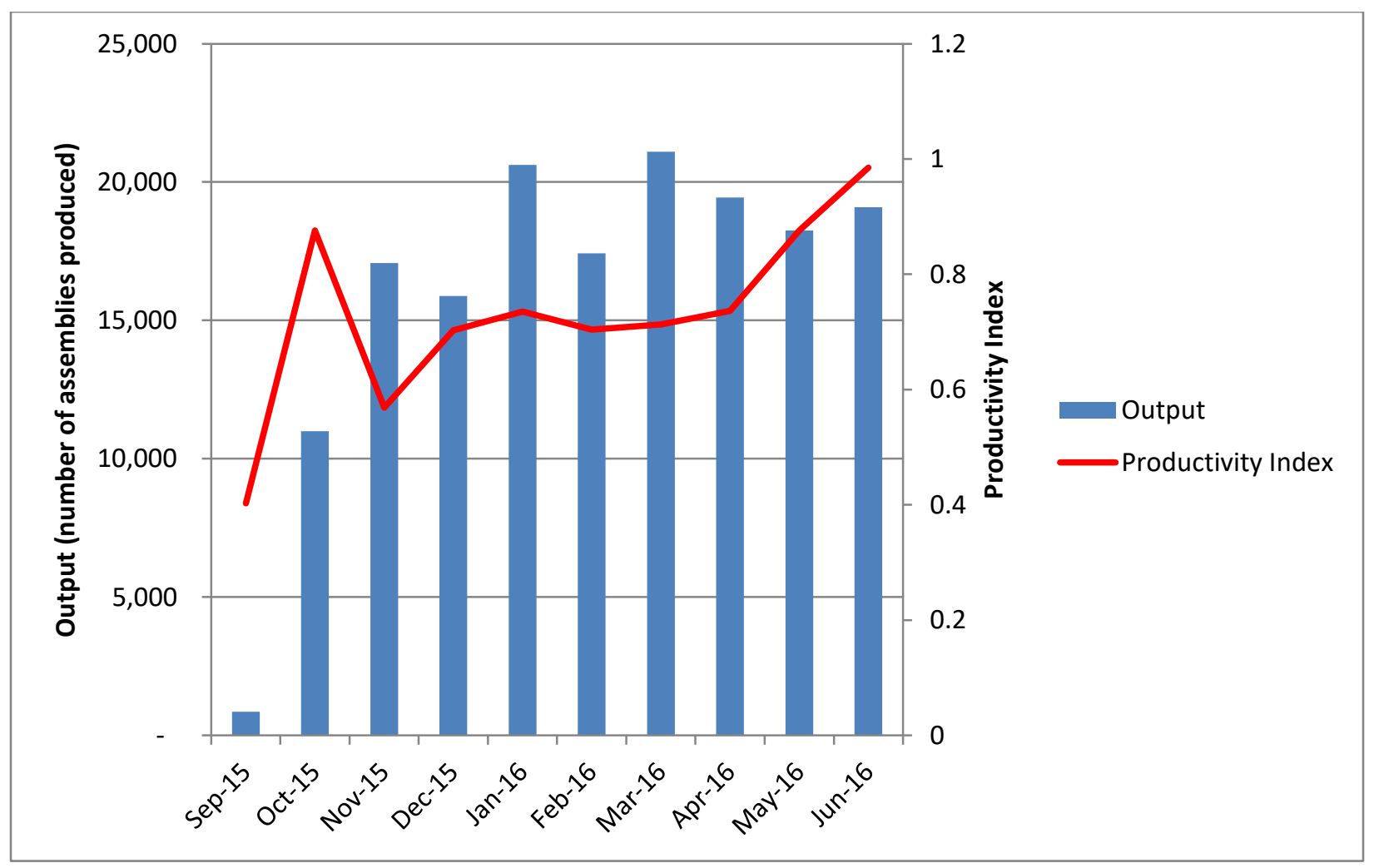

As seen in the graph, when the production volume increased in November, productivity suffered. Three problems that the joining line had upon installation were:

1. The automated stopper pin feeding system was unreliable. To save money, the engineers had used an existing bowl feeder and pneumatic chute to convey the stopper pin to the sewing machine. There were many machine stoppages as the pneumatic system struggled to convey the metal pin. If the pin wasn't properly located, poor sewing quality could result in a rejected part. 
2. The conveyance problems resulted in inconsistent folding of the webbing before sewing. This created a requirement that after the stopper pin sew was completed, the machine had to stop and signal an operator to inspect the fold and the sew condition. If the sew was verified OK, the operator had to resume the cycle. This increased the cycle time of the machine and reduced the autonomy of the operation; now the operator was not free for the entire cycle of the machine; he or she had to be available to inspect the pin sew then resume the machine operation.

3. The particular retractor subassembly was not produced at TRQSS, but imported from a sister division in Asia. Although the subassembly was tested for function when it was produced, the customer in North America required that confirmation tests be performed at TRQSS. The new system was equipped with the technology to perform the testing, but it added significant cycle time to the overall process.

Production Engineering, Design Engineering, and Quality worked together to eliminate any redundancies in the test cycle and to optimize the sequence of tests so that the cycle time was minimized. The Production department added one operator dedicated to the joining machine so that the machine never had to wait for an operator to do the stopper pin sewing inspection. These countermeasures reduced the cycle time sufficiently so that customer requirements could be produced without overtime.

Production engineering redesigned the stopper pin feeding and web folding mechanism and installed it during the Christmas shutdown period in December 2015.

Additionally, Production Engineering began investigating an automatic inspection device so that the operator inspection of the pin sew wasn't necessary and the machine could continue uninterrupted. It was believed by management that until this technology was installed, the 
Production Department would not be able to achieve the target of running the system with only 2 operators.

\section{Continuous Improvement Activity}

For the first few months of 2016, Production was able to meet customer volume requirements at a productivity index of 0.74. In April, the Production Department Section Manager and Team Leader utilized the Toyota Improvement Kata methodology to begin experimenting with methods for running the system with two operators rather than three, even while still having to perform the manual stopper pin sew inspection. ${ }^{10}$ First, they required a layout change to reduce the walking time of the two operators as they worked between the machines. This layout modification was done on a weekend. Next they began experimenting with dividing the various tasks between the two operators, always ensuring that one operator was available for the stopper pin sew inspection at the exact time required within the cycle. By June, 2016, both shifts in production were able to run the line with only 2 operators and achieve customer volume requirements without working overtime. This resulted in a $33 \%$ overall productivity improvement realized between April and June 2016.

\section{Comparison of actual results to original plan}

The original proposal was designed to produce 17,760 pieces per month at a productivity index of 1.0. In June, 2016 the line produced just over 19,000 pieces at a productivity index of 0.985 .

The production department was able to achieve this level within 9 months of starting the line, in spite of the fact that the automatic inspection of the pin sew operation has not yet been installed.

\footnotetext{
${ }^{10}$ The automated inspection technology was delayed because there was a product change from polyester thread to nylon thread. The vision system could not reliably detect variations in the nylon thread.
} 


\section{Case \#3 Innovative process for Front Retractor finishing assembly}

TRQSS produces approximately 12,000 standard type front retractors per day. The retractor subassembly includes a pretensioner and is produced in an automated assembly cell. These retractor subassemblies are then sent to various finishing lines for final assembly and packaging. The finishing lines add the webbing, labels, and hardware that make the retractor assembly vehicle specific, then package the product in customer specific returnable containers.

The front retractor finishing lines obtain the webbing from a central production area. It is delivered to the finishing lines cut to length with the stopper pin sewn in. A front retractor finishing line is capable of producing 1,200 pieces per shift with a productivity index of 0.72 .

In 2015, TRQSS was awarded the business to supply front retractor assemblies for a high volume mid-sized sedan to begin production in the summer of 2017 for the 2018 model year. The product design would utilize the standard retractor subassembly currently in production on the automated assembly cell, but the target assembly cost for the finished product would be substantially less than the current model. Replicating the current assembly method would not be an acceptable option. An innovative solution was required.

The first operation on the finishing cell is the insertion of webbing into the spool of the retractor assembly. At this machine the overall length is checked, the stopper pin is seated to the spool with a specified force, and then the spring keeper is removed, allowing the spring to retract the webbing around the spool in the assembly. The second operation adds the mounting hardware and the tongue stopper to the webbing. The final operation is to sew the mounting anchor and the identification label to the end of the webbing and package the assembly into the customer designated returnable container. The Production Engineering department proposed a solution that would integrate the operations of the first two work stations into one machine, 
thereby reducing required labour on the line. If the cycle time of the new integrated machine could be balanced with the remaining anchor and label sew operation, then the new finishing line could be run with one operator; although the throughput would be less than the current line, the productivity would be substantially higher. An additional benefit would be that each finishing line would require less floor space, perhaps enabling co-location of the web cutting cells with the retractor finishing cells, further reducing material handling and floor space.

In order to meet the target assembly cost, the capital investment required for the new equipment had to meet a threshold. Production Engineering worked with a local equipment supplier who had fabricated the existing web pull machines to develop the new integrated machine. TRQSS was able to reduce the price of the equipment by doing all of the programming for the control of the machine in house; the machine was specified by TRQSS, and the equipment supplier was able to build it to the design specification. TRQSS controls engineers went onsite at the equipment vendor to test the program as the machine developed.

The machine was delivered to TRQSS In June, 2016, a year in advance of the production requirement for the new vehicle. After the appropriate safety approvals were completed, the machine was able to be used by production operators. Production Engineering and the Production Department worked together to organize production trials whereby current operators would use the new machine to make current products. The operators could develop their standardized work for the new process, and provide feedback to the engineers on which features could be improved or rearranged. The results of these initial trials are shown in Figure 22. What is interesting is that the designed productivity index level of this line is 1.0 ; after one week of production trials, $84 \%$ of this level was achieved. TRQSS plans to utilize this machine for current production requirements, continuing to refine the process for a full year in advance of the 
new vehicle start of production. Presently, design work has begun on the next iteration of this machine, which will eliminate a quality concern and increase productivity by incorporating the assembly of the anchor to the webbing.

Figure 22 Results of Production Trials for F45

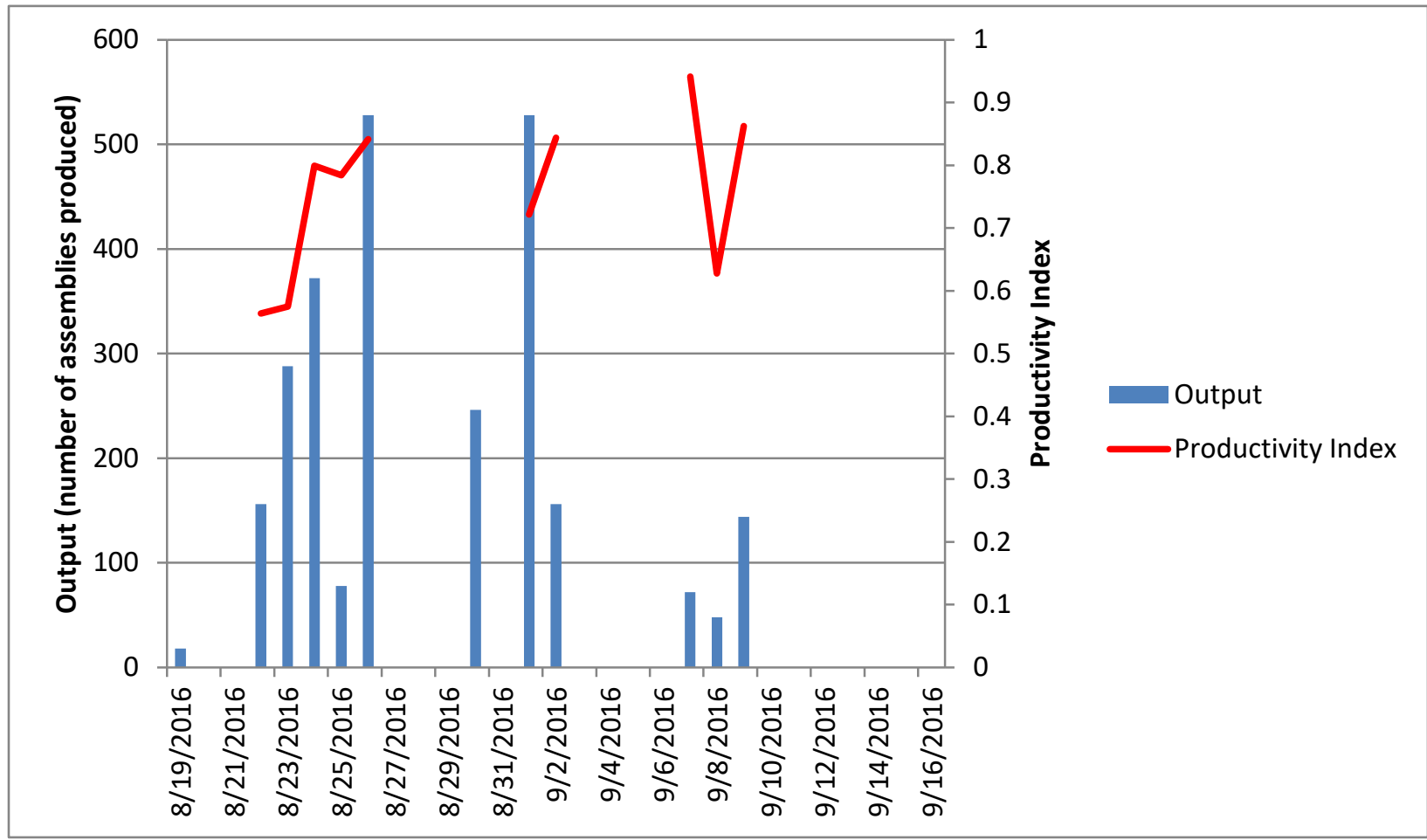

\section{Discussion of the Cases}

This discussion will begin with Level 2 questions to be answered by the case study research.

\section{What was the existing circumstance/need that determined that some action was} required?

In all three cases, the organization was facing a situation where additional assembly capacity had to be implemented for a product; in the first two cases, the product was new to the 
organization, while in the third case it was additional capacity for an existing product. In each case, the product was a variation or improvement of a current product; as such, conventional methods existed for assembling these products. The need for an innovative solution came from the identification of a problem: in all three cases, the conventional assembly process would not be able to meet the target cost requirement based on the market price for the new product, ${ }^{11}$ and a solution would not be realized through incremental improvement. This circumstance demanded that some creativity was required; the tried and true solution would no longer meet requirements, so "thinking outside the box" was a necessity.

\section{What was the existing procedure for addressing the circumstance/need?}

The procedure for installing new assembly capacity starts with the identification of a need for additional volume, or an engineering change to current product. The next step is a process design, prepared by the Production Engineering department that is able to meet the customer requirements including capacity timing, quality, and cost. When a design is proposed, funds must be approved for capital spending to begin. Approval level is dependent on the amount being requested; in all cases, the CER had to be approved by the President. ${ }^{12}$ Usually the primary concern of Production Engineering is to ensure that they can secure capacity with their equipment vendors so that production and assembly processes will be ready for the vehicle assembler's pre-production build trials. A pre-production build takes a tremendous coordination of effort among all suppliers; no supplier wants to be the one that prevents the vehicle assembler from achieving their timelines. Because of this timeline pressure, PE often proposes replications of current assembly processes for new vehicle programs, as these will be the easiest to install

\footnotetext{
${ }^{11}$ This is not an unusual situation in the automotive parts industry, especially for parts that are somewhat commoditized.

${ }^{12}$ A capital plan is prepared and approved annually based on estimates of activity for the year; however, as each project begins, the specific amount for the project must be approved with supporting details.
} 
with minimal quality risk. In the first case, that is exactly what was proposed until the PE department was explicitly made aware of the assembly cost and capital investment constraints, which necessitated that something innovative was necessary. In the second case, two years later, the PE team was already aware of the target assembly cost at the outset and they knew that the traditional assembly process would not meet the cost constraint. As there had been some precedent for assembly innovation with the automated buckle finishing cell, the company was willing to entertain innovative proposals for retractor assembly. ${ }^{13}$ In the third case, PE was well aware of the target assembly cost constraint, and was developing an innovative solution and seeking approval a full year in advance of the critical path timing.

\section{How was the implemented solution developed? Why was it chosen?}

In the first case, the Production Engineering department worked with a selected equipment supplier to develop an innovative assembly process that centralized the cover press, latch test, and switch test operations using proven parts feeding and conveyance technology. Most of the effort by the vendor and the engineers was in developing the switch testing portion, as there were many varieties of wire harnesses and connectors, and meeting the cycle time would be a challenge. The engineers expended little design effort at this stage on the manual operations that fed subassemblies to the line or that occurred after the testing operation, as it was felt that there was little risk involved with these proven manual operations. Like most innovations, the proposed assembly system used proven technologies, but combined in a new way. The proposed sequence of operations for buckle finishing assembly was unique in the industry.

In the second case, the idea for the innovative retractor finishing assembly method existed for quite some time before it was eventually implemented. It was chosen for the rear retractors

\footnotetext{
13 The capital investment for the innovative retractor finishing line was higher than budgeted, but the expenditure was approved as some amount could be recovered through R\&D tax credits.
} 
for the new SUV due to the particular circumstances; unique application, limited volume, limited mounting hardware, common web length and mounting angle. These circumstances eliminated some of the earlier concerns with this proposed assembly method. Once again, PE worked with an equipment supplier (not the same supplier as in Case 1) to develop the technologies required to support the proposed assembly method. When asked why the earlier concerns were never resolved or even worked on, the manager of Production Engineering responded that "there wasn't any time; there was always some other more urgent problem, and since there wasn't a vehicle platform that needed it, we didn't work on it." One advantage of the passage of time was that some technologies like sensing, vision, and logic controllers became much less expensive to procure and much more reliable to use; not only were earlier process concerns more easily addressed, but the implemented process was able to include functional testing of the retractor assembly, an integration that was originally considered not feasible.

In the third case, the proposed solution was an evolution of assembly technology that currently existed in the organization. Again, PE worked with an equipment supplier to provide the required hardware; however, considerable capital expenditure was reduced by doing the machine control programming in house. In this way the PE department was able to reduce both labor and capital investment in the innovative assembly solution.

\section{Who was involved and what was their role?}

In these cases we can categorize the roles of the individuals involved into three groups; Management, Production Engineering, and Production. We will examine the role of each group separately in the context of all three cases.

\section{Management}


In the first case, the catalyst for the innovation was the request by the Vice President for an alternative to the process that was being proposed by Production Engineering. The VP had knowledge of the present and future cost requirements that were not met by the existing and proposed processes. This could be classified as one type of Problem Finding in Basadur's model for Creativity in Organizations (Basadur, 1992)It was the responsibility of the VP to share this knowledge with the engineering team, so that alternatives could be evaluated quickly and withheld from consideration if requirements were not met. In all cases, Management had to evaluate the proposals being submitted in the Capital Expenditure Request procedure. This vetting or evaluation process requires not only technical knowledge, but judgement skills in terms of feasibility and risk. When initial results were not swiftly achieved in the first case, management had to allocate resources to achieve the proposed results. This is sometimes considered the implementation phase of the judgement process (Tichy \& Bennis, 2009), or part of Solution Implementation (Basadur, 1992). In all cases, Management's role was to clearly define and communicate the targets, and use judgement to evaluate alternatives and approve a proposal, then ensure that implementation is facilitated.

\section{Production Engineering}

In all cases it was the responsibility of the Production Engineering department to propose assembly process designs for the new products. When replication of the existing processes would not satisfy cost requirements, they had to propose alternative processes that could meet the criteria of cost, quality, delivery, safety, and technical feasibility. The members of the engineering department worked with equipment suppliers to get ideas and information regarding equipment capabilities and costs. Upon installation of the equipment, engineering and maintenance were responsible for safety approvals and training of company employees. In the 
first case, a designer from the engineering department was assigned by management to provide better tools for the production workers to do their jobs. The designer worked with the assembly operators to understand the specific problems with existing methods, and had them try out prototypes of new tools to provide feedback. Ideation for solutions came from the designer himself, using the guideline of "operator as surgeon": in a surgical procedure, the surgeon does not waste time looking for tools; everything is handed to him on command. Applying this principle to Operator 1 , the designer started with the detailed task of creating a method for holding and presenting the individual parts to the operator, and gradually worked outward toward the "bigger picture", experimenting and testing with the production group ways of loading, unloading and moving parts between stations.

In the second case, the original idea for the assembly system came from PE, but it was implemented only when product conditions were optimal and equipment technology had matured and become less expensive. The Production Engineering department was able to recognize these conditions when they presented themselves and propose the idea without prompting from Management. In the ASQ definition of the innovation process, these are the steps of Finding the Opportunity and Connecting to the Solution (Merrill, 2008). The specific method for automatically feeding the seat belt webbing through the anchor was designed by a member of the Production Engineering department, and the equipment vendor incorporated this into the belt subassembly machine. In both cases, many of the most creative ideas came from the production engineering department and the equipment vendor, either as proposals for new equipment or improved tool designs for remaining manual assembly work.

In the third case, PE had fully internalized the ideation process, and taken ownership of the implementation phase, as they worked with the equipment supplier at their site to program the 
machine control, and then with the Production department members to design countermeasures to operators concerns in a series of pre-production builds.

\section{Production}

On a daily basis, it is the role of the Production department to execute their jobs according to engineering standards, ensuring that the desired quantity of goods is produced in the most cost effective way possible. In the case of a new start up, it is expected that there will be a learning curve to reach standard, and the production operators are in the best position to identify the problems encountered during this phase. In the first case, the production operators worked with the assigned mechanical designer, providing valuable input to the creation of improved material handling tools for the switch subassemblies. Later, as the new material handling tools enabled the operators to work smoothly, the production team was able to rearrange their work to realize a $13 \%$ productivity improvement without assistance from PE.

In the second case, the Production department was able to reduce the learning curve, eventually reaching a plateau in productivity that was assumed would remain until the inspection of the pin sew was automated. However, the Production department was able to overcome this plateau by rearranging their work to incorporate the additional inspection and still achieve cycle time.

In the third case, the Production team began working with PE as the equipment was being designed and built, running trials on the new equipment and providing feedback on aspects of the design that could be improved before it was released for production. In so doing, the Production department is helping to minimize the learning curve when mass production starts.

In all cases, these improvements in productivity came from the efforts of the production group utilizing continuous improvement methods and led by the Team Leader. This is consistent 
with the earlier dissertation research results correlating the productivity results of the work group with the relationship with the supervisor. We can also see from the three cases that with each successive installation of an innovative process, the Production department improved in their ability to execute proactively. In the first case, they responded to the efforts of the designer assigned by management; in the second, they conducted the improvement effort after production started, but before the promised automated inspection was installed; and in the third case, they were working proactively with PE before mass production started. The knowledge possessed by production operators in a mass production environment about the problems hampering performance is very specific. The Team Leaders used the methodology described in Toyota Kata (Rother, 2010), which follows the scientific method practiced by engineers, but targeted in scope to the span of control of the production work group. As a result, problems are identified quickly.

One might presume that this type of work should always be done before the lines are delivered to the production floor, but in the first two cases it is questionable if the required level of problem detail would have been available before production actually began in significant volume. As some of these operations were performed manually without incident in the pre production, it was assumed that the production situation would be no different. However, doing something manually in small quantities with a generous deadline is not an accurate representation of having to do the same task flawlessly in a fast paced high volume environment. It is almost impossible to replicate high volume production conditions in advance of production starting, because of the number of parts, components and personnel required to run experiments on all combinations for extended periods of time.

\section{How did it work compared with what was expected?}

In the first two cases, neither solution worked as expected immediately upon installation. In both cases, unexpected situations or effects were realized that had to be resolved in order to 
achieve the stated goals. In the first case, the manual material handling and assembly operations that were presumed easy turned out to be roadblocks that required a dedicated designer to resolve. After that, the production team was able to implement continuous improvement activities in order to realize the design targets for productivity. In the second case, an inspection operation was required that had not been part of the original process design. However, the original targets were achieved eventually; in the first case, it took 24 months, in the second case, it took 9 months. In the third case, the organization is attempting to achieve the designed target upon start of production.

\section{What was the reaction of the organization?}

In the first case, the designed productivity targets took 24 months to achieve. At this time, the organization seemed tentative in reacting to the innovative assembly process. Management waited until a proposal was submitted before informing Production Engineering of the assembly cost constraint. The maintenance department waited for the machine vendor to work out some of the issues with the test machine and got involved perhaps later than they could have. The PE department waited for management to assign a Designer to work on improving solution implementation, and the Production department reacted to the work of the Designer. At this time, the Organization seemed passive to the innovation process, as the idea and implementation was very "top down." By the time of the second case, the organization was achieving results with the

first innovative project, and thus was more active in the implementation, fixing some of the mechanical issues without waiting for the equipment vendor, and making productivity improvements before all the mechanical issues were resolved. By the time of the third case, the organization was proactive, with PE, the equipment supplier, and the Production department 
working together to create a successful innovative assembly process before the start of production.

These three cases illustrate the evolution of the organization's capability to improve competitiveness through process innovation. Each group is figuring out their role in the process: Management has to set the strategy, and clearly articulate the competitive landscape that the organization faces in mid range time frame; Production has to use the tools of continuous improvement to reach the performance limits of current processes, thereby defining the specific problems that need to be overcome with innovation; and Production Engineering needs to continuously develop innovative solutions that address both the long term strategy and the current thresholds.

\section{Capability improvement over time}

The time span from the catalyst for the first case until the implementation of the third case is 4 years. Table 5 shows the performance of the organization in the execution of each phase of the process. Each cell contains the time duration, measured in months, for each stage of each case, from the creation of the idea to the achievement of the desired result.

Table 5 Completion time for each phase of innovation process (months)

\begin{tabular}{|c|c|c|c|c|}
\hline Case & Year Approved & Idea to Approval & $\begin{array}{c}\text { Approval } \\
\text { to Implementation }\end{array}$ & $\begin{array}{c}\text { Implementation } \\
\text { to Achievement }\end{array}$ \\
\hline 1 & 2012 & 1.5 & 7 & 24 \\
\hline 2 & 2014 & 120 & 9 & 9 \\
\hline 3 & 2015 & 0.75 & 4 & 1 \\
\hline
\end{tabular}

In each case the organization conceived of an idea for an innovative solution to be implemented in response to changes in the competitive environment. The ability to continuously 
do this efficiently, effectively, and proactively would be a dynamic capability of continuous innovation that the organization can use to compete with rivals in low labor cost environments.

Table 5 shows a measure of the organization's ability to successfully execute the innovation process, from ideation to achievement of design targets for the three cases of assembly process innovations implemented over the span of four years. Minimizing the time spent to move through each phase would be a measure of success in this process, as that would theoretically increase the organization's capacity for innovation. By this measure, Case \#3, the most recent, was the most successful execution of the innovation process. The following discussion will compare the cases relative to each phase of the innovation process to illustrate how the organization learned and improved its performance by the third case.

\section{Idea to Approval}

In all cases, the idea for the innovative solution came from Production Engineering and Management was responsible for approval. In Case \#1, PE proposed the idea in response to Management's request; after 1.5 weeks of iteration, the idea was approved. In Case \#2, PE conceived of the idea with no specific application; consequently, the idea lingered for 10 years without any activity until an opportunity was identified. These two cases illustrate a lack of alignment in this phase. In order to execute this phase efficiently and effectively, it is imperative that Production Engineering is always aware of the competitive challenges and opportunities that lay before the organization; this is information that Management possesses. If Management is continuously surveying the competitive environment, identifying the challenges and opportunities, and constantly communicating to the organization, then it is less likely that Production Engineering would spend time creating ideas that have no support for development or 
would have to be told that a creative solution is required for a current problem. Innovation is need driven, and Management is responsible for keeping the organization aware of the need.

In Case \#3 this phase was executed in less than 1 month. At the outset of this case, PE was well aware of the cost challenges that the organization faced on the new vehicle program and Management was equally aware of the solutions that PE was proposing. This improved two way communication facilitated an efficient execution of this phase of the innovation process.

\section{Approval to Implementation}

In this phase, Production Engineering is working with equipment suppliers to build the necessary machinery and tooling that the Production department will use in mass production. For

Cases \#1 and \#2, this process took 7 and 9 months respectively, and was largely controlled by the supplier. For Case \#3, the organization was able to significantly reduce the amount of time by taking on more of the responsibility internally. Industrial machinery is comprised of three major components: equipment, tooling, and software. Equipment is commercially available from a number of approved suppliers; tooling is custom made for the specific work pieces. Much of the creativity, cost and time is spent on software; the sequence of commands that control what the equipment and tooling will actually do. In Case \#3, the organization took on the responsibility for this portion internally, which allowed them to control a much larger portion of this phase of the innovation process. Coincidentally and not inconsequential was the reduction in cost of the machinery being purchased because this portion of the knowledge work could be done in house.

\section{Implementation to Achievement}

In this phase, the machinery developed by Production Engineering and the equipment supplier is delivered and released to the Production department to begin operations. Success in this phase would be defined by achieving design targets in the shortest possible time. 
In Case \#1, this phase took 24 months to complete. Part of the reason for this was the assumption by PE that the manual processes of switch assembly and taping would be easy to replicate at high volume without additional attention or investment. When this turned out to be incorrect, further innovation was required; countermeasures had to be taken which involved designing and building custom tools for the efficient execution of these jobs. This took a long time, as the organization was now in the mass production stage. Once these tools were developed, the Production department was able to execute the operation according to design, and additionally they were able to increase productivity beyond that target level by rearranging their work more effectively. In Case \#2 execution of this phase was reduced to 9 months. When the equipment was delivered, certain problems existed and a design change resulted in unforeseen added inspection that compromised productivity. However, the Production department was able to achieve the target productivity through continuous improvement activity in spite of the fact that an anticipated equipment modification has not been implemented. These cases illustrate the vital role of Production in the innovation process. By utilizing continuous improvement methodology such as the Toyota Kata (Rother, 2010), Production is able to identify and highlight problems that arise from mass production and quickly address them, continuously executing Basadur's Creativity Model at the scope of the work group level (Basadur, 1992). When they can resolve these problems without engineering intervention, time and money are saved. Engineering involvement is required when the Production department has identified a technological threshold, which can be interpreted as an organizational need to be solved with an innovative solution.

In Case \#3, the PE department incorporated learning from the earlier cases and involved the Production department in Phase 2, working together as the machinery was developed. In Phase 3, the Production department conducted equipment trials and provided feedback to PE, 
who immediately addressed these concerns. As a result, the designed productivity levels could be achieved within one month.

\section{Conclusions of the Case Study Research}

The case study research was done initially to evaluate Hypothesis 4, that the most highly engaged work groups would exhibit higher levels of innovative behavior. According to the quantitative study, the work groups with the highest levels of the Emotional Engagement construct were Management and Production Engineering. The case studies explored the implementation of actual innovative assembly processes in the organization, and the Production Engineering work groups were responsible for the actual creative solutions; Management was responsible for identifying the strategic need for the innovation and for evaluating the proposed solution. The Production work groups were responsible primarily implementing the solution, which after successive iterations of Continuous Improvement activity results in identifying the next problem in the form of a technological threshold.

Analysis of the three cases implemented over a four year period at TRQSS shows that the firm improved its capability for process innovation throughout this time. Specifically the firm got better at executing the Innovation Process (Merrill, 2008) and Basadur's Creative Thinking Model of Problem Finding, Problem Solving, and Solution Implementation (Basadur, 2004). The best results were achieved when organizational alignment was achieved among Management, Production Engineering, and Production. When Management clearly articulated and consistently communicated the mid-term cost challenges, and the Production department defined technological thresholds through Continuous Improvement activities and preproduction trials, they were effectively facilitating the Problem Finding activity. Then the Production Engineering department (the most engaged group of employees at TRQSS) were more effective at proposing 
innovative solutions for Problem Solving. When the organizational elements were aligned and focused on their respective roles, Solution Implementation was enhanced and the time required to achieve designed results was reduced.

This study contributes to the literature by demonstrating the actual evolution of innovation capability development through case study research. This research was able to examine one organization over a period of time in great detail. By examining three cases in one organization, many factors were essentially constant: the business climate was relatively stable throughout this period, and several of the participants in the Management and Engineering groups were constant in all three cases. Also, the cases are relatively recent; ample documentation is available within the organization, and participant recall is relatively good. Since case study research reveals events as they actually happened, it is possible to observe the organizational learning that occurred with each successive implementation of an innovative process solution and gain a perspective on the enterprise transformation.

The limitation of this type of study stems from the same conditions of its strength, that is, it is difficult to generalize a prescription for action based on the results of one firm. However, the conclusion is a general one of the importance organizational alignment in the creative thinking process rather than a specific endorsement of a particular tool or methodology. Additionally, most mass production organizations would have work groups within the broad functional areas of Management, Engineering, and Production; understanding the roles of each so that better alignment can be achieved in the creative thinking process is certainly generalizable.

In order to support this general conclusion for capability development, future researchers could use the case study method to examine similar phenomena in other firms. Many auto parts firms in high wage rate jurisdictions need to develop an innovation capability in order to 
compete using a differentiation strategy. Although the manufacturing process is a good place to start, innovation opportunities exist in other areas of business activity as well (Keeley, Pikkel, Quinn, \& Walters, 2013). Organizations need to be able to clearly identify strategic problems to be solved in order to remain competitive, and ensure that the organization is aligned so that the most engaged employees are enabled to develop creative solutions. 


\section{CHAPTER 8 CONCLUSIONS OF THE DISSERTATION RESEARCH}

Our research question asks how a manufacturing plant operating in a high wage environment can develop a capability of continuous innovation to compete with firms operating in low wage jurisdictions. Through this extensive study of an auto parts manufacturing firm in Ontario, Canada we can draw the following conclusions.

\section{Employee Engagement}

Within the mass production factory, employees involved in management, professional, and technical support roles experienced higher levels of engagement than those involved in mass production operations roles. The level of engagement for mass production employees was driven largely by the employees' perception of how effectively the Organization supports them. Engaged employees are willing to give discretionary effort toward the achievement of company goals, but the state of engagement is not sufficient to achieve results. Performance results at the work group level were driven by the effectiveness of the supervisor relationship with the work group. Production work groups with higher engagement levels did not necessarily achieve higher performance levels that those groups that had lower engagement scores. Higher engagement levels tended to indicate better levels of voluntary attendance, but actual production performance was better correlated to the relationship between the Supervisor and the work group.

If Engagement levels are an indication of intrinsic motivation levels (or autonomous extrinsic motivation levels) which is required for creative thinking, then we should expect that more creative ideas of the kind required for innovation should emerge from the management and technical support group (employees in the Support data set). Examination of three cases of implemented process innovations at the same organization showed this to be true. This is not to say that creative ideas that spawn innovative solutions will never emerge from employees in 
direct production roles, just that the probability is lower given the limits on engagement levels experienced by this group.

\section{Developing Innovation Capability}

To develop a capability of innovation in a mass production organization, we must utilize our most engaged employees most effectively. In the three research cases, the most creative and innovative ideas came from the engineering and technical support group. To maximize the performance of this ability, it is imperative that this group of employees is constantly aware of the problems faced by the organization that require innovative solutions. This is the Problem Finding step in Basadur's Organizational Creativity Model (Basadur, 1992), or the Opportunity Finding step of the ASQ definition of the Innovation Process (Merrill, 2008). For the organization, these problems and opportunities can be of two types and can come from two different sources. First, Management must identify the strategic problems facing the organization in the competitive environment, and these problems can be immediate or they may be in the mid to long range outlook. Second, Production must utilize continuous improvement methodology to identify technological thresholds that exist in the current production processes. Both of these types of problems are opportunities for innovation in the organization. The extent to which the entire organization is aware of the problems, thresholds, and opportunities is an indicator of how effectively the innovation process will be executed in the steps of Problem Solving and Solution Implementation.

Top management has broad knowledge of the competitive environment and future product development, typically with a long time horizon. From this knowledge they must define the operating constraints for the organization. If management can continuously define, refine, and communicate these requirements throughout the organization, then the support groups in the 
levels below will be aware of the future challenges and constraints that will require innovative solutions. Management must also continue to refine the policies of the organization, specifically those that engender the perception of support among the employees, thereby having a positive influence on engagement levels. The definition of engagement is giving discretionary effort toward achieving company goals; it is imperative that the employee must first know clearly what those goals are.

\section{Role of the Supervisor and Production Work Groups}

At the outset of this research, it was thought that the organization could improve its capability for innovation by increasing the engagement levels of the mass production employees, thereby creating the conditions for creative acts to spontaneously occur. As revealed by the quantitative study, the actual performance of mass production work groups as illustrated by factory data representing continuous improvement and innovative behavior was influenced more by supervisor relationship than by engagement levels alone. The case study research revealed that production work groups have a specific role to play in the development of an organizational capability for innovation.

As illustrated in the first two cases, the production work groups under the direction of their team leaders were able to make productivity gains of greater than $10 \%$ when given clear system requirements. In the first case, this was done after working with a designer to develop better tools after a technological threshold had been identified. In the second case, it was done even prior to all of the expected machine improvements being completed. In both cases, the team leader was utilizing Toyota improvement kata methodology to understand the challenge, create an interim target, and conduct experiments toward the target. With this methodology, production work groups are able to solve many daily production problems by themselves, without the daily 
involvement of production engineers, which allows the latter group more time to be working on innovative solutions. Additionally, through continuous improvement activity the production departments are developing very specific knowledge about problems in a mass production environment. Contrary to executive management knowledge, production operator knowledge is very specific and deals with a short time horizon; however, this knowledge is equally critical to the production engineering department in terms of defining constraints requiring innovative solutions.

As seen in the two cases, the specified performance levels of both innovative assembly processes could not be realized without the continuous improvement activities of the production work groups; analysis of empirical data revealed that Supervisor Relationship is a critical component of work group performance. This underscores another critical task for the mass production organization in developing innovation capability, that is the hiring and training of supervisors. In the 1940's the TWI Service concluded that the supervisor's role was critical to factory performance improvement, and this remains true today. However, the definition of performance ant the work group level must include continuous improvement, and supervisors can be trained in the tools required to achieve this in the work group. This is critical to the organization, not because this is where creative ideas and innovative solutions are most likely to emerge, but because as the production work groups continue to challenge the limits of what can be achieved by existing systems, they are also performing the function of identifying the next problem to be solved with creative thinking and innovative solutions, a critical step in the innovation process (Basadur, 1992; Merrill, 2008). By the time of the third case, the organization was realizing this fact as the Production Engineering group was engaging the Production group 
to try early versions of the innovative process to identify potential problems in the process before the start of mass production.

\section{Conclusion}

The mass production organization in a high cost environment must compete in the global market with a differentiation strategy, by developing a capability of continuous innovation. Employee Engagement is a required ingredient, as innovative solutions stem from creative ideas, the source of which is an autonomously extrinsically motivated individual. However, engagement is experienced differently among different groups of employees within a mass production organization. While necessary, Engagement alone is insufficient unless it can be effectively harnessed within three groups of employees in the organization; Management, Engineering, and Production. Executive management must understand the competitive environment, and be able to effectively communicate this to the organization in terms of competitive challenges and constraints. Production operations must be engaged in continuous improvement activities to be achieving the limits of current systems and defining the next problems to be solved with innovative solutions. For this to occur, effective supervision is essential. The Engineering groups must be taking the input from both of the other groups and thinking creatively to develop the next innovative proposals that address the current problems and future constraints. As all three groups of employees understand and execute their respective roles, then the goal of continuous innovation can be achieved through the iterative cycle of innovation and improvement. Innovative solutions aren't effectively implemented without the continuous improvement activity of the work group with effective supervision; and this continuous improvement activity is essential to identify the next problem to be solved with innovation. 


\section{APPENDIX CONSTRUCTS AND SURVEY}

$\underline{\text { Job Engagement Scale (Rich et al., 2010) }}$

$1=$ strongly disagree, $5=$ strongly agree

\section{Physical Engagement}

1. I work with intensity on my job

2. I exert my full effort to my job

3. I devote a lot of energy to my job

4. I try my hardest to perform well on my job

5. I strive as hard as I can to complete my job

6. I exert a lot of energy on my job

\section{Emotional Engagement}

1. I am enthusiastic in my job

2. I feel energetic at my job

3. I am interested in my job

4. I am proud of my job

5. I feel positive about my job

6. I am excited about my job

\section{$\underline{\text { Cognitive Engagement }}$}

1. At work, my mind is focused on my job

2. At work, I pay a lot of attention to my job

3. At work, I focus a great deal of attention to my job

4. At work, I am absorbed by my job

5. At work, I concentrate on my job

6. At work, I devote a lot of attention to my job

$\underline{\text { Perceived Organizational Support (Eisenberger et al., 2001) }}$

$1=$ strongly disagree, $5=$ strongly agree

1. The takes pride in my accomplishments.

2. The __ really cares about my well being.

3. The __ values my contributions to its well being.

4. The __ strongly considers my goals and values.

5. The __ shows little concern for me. (R)

6. The __ is willing to help me if I need a special favor. 
$\underline{\text { Resource Supply (Scott \& Bruce, 1994) }}$

1=strongly disagree, $5=$ strongly agree

1. Assistance in developing new ideas is readily available.

2. There are adequate resources devoted to innovation in this organization.

3. There is adequate time available to pursue creative ideas here.

4. Lack of funding to investigate creative ideas is a problem in this organization. (R)

5. Personnel shortages inhibit innovation in this organization. (R)

6. This organization gives me free time to pursue creative ideas during the workday.

$\underline{\text { Supervisor Relationship (Graen \& Uhl-Bien, 1995) }}$

1. Do you know where you stand with your leader...do you usually know how satisfied your leader is with what you do?
a. Rarely
b. Occasionally
c. Sometimes
d. Fairly Often
e. Very Often

2. How well does your leader understand your job problems and needs?
a. Not a bit
b. A little
c. A fair amount
d. Quite a bit
e. A great deal

3. How well does your leader recognize your potential?
a. Not at all
b. A little
c. Moderately
d. Mostly
e. Fully

4. Regardless of how much formal authority he/she has built into his/her position, what are the chances that your leader would use his/her power to help you solve problems in your work?
a. None
b. Small
c. Moderate
d. High
e. Very high 
5. Again, regardless of the amount of formal authority your leader has, what are the chances he/she would "bail you out" at his/her expense?
a. None
b. Small
c. Moderate
d. High
e. Very high

6. I have enough confidence in my leader that I would defend and justify his/her decision if he/she were not present to do so.
a. Strongly disagree
b. Disagree
c. Neutral
d. Agree
e. Strongly agree

7. How would you characterize your working relationship with your leader?
a. Extremely ineffective
b. Worse than average
c. Average
d. Better than average
e. Extremely effective 


\begin{tabular}{|c|c|c|c|c|c|c|}
\hline Q\# & & SD & D & $\mathbf{N}$ & A & SA \\
\hline 1 & At work, I concentrate on my job & 1 & 2 & 3 & 4 & 5 \\
\hline 2 & I am proud of my job & 1 & 2 & 3 & 4 & 5 \\
\hline 3 & My team leader recognizes my potential & 1 & 2 & 3 & 4 & 5 \\
\hline 4 & I strive as hard as I can to complete my job & 1 & 2 & 3 & 4 & 5 \\
\hline 5 & $\begin{array}{l}\text { Personnel shortages inhibit innovation in this } \\
\text { organization }\end{array}$ & 1 & 2 & 3 & 4 & 5 \\
\hline 6 & $\begin{array}{l}\text { The company strongly considers my goals and } \\
\text { values }\end{array}$ & 1 & 2 & 3 & 4 & 5 \\
\hline 7 & At work, my mind is focused on my job & 1 & 2 & 3 & 4 & 5 \\
\hline 8 & $\begin{array}{l}\text { Regardless of formal authority, my team leader } \\
\text { would "bail me out" at his/her expense }\end{array}$ & 1 & 2 & 3 & 4 & 5 \\
\hline 9 & $\begin{array}{l}\text { The company values my contributions to its well } \\
\text { being }\end{array}$ & 1 & 2 & 3 & 4 & 5 \\
\hline 10 & The company takes pride in my accomplishments & 1 & 2 & 3 & 4 & 5 \\
\hline 11 & I am interested in my job & 1 & 2 & 3 & 4 & 5 \\
\hline 12 & I devote a lot of energy to my job & 1 & 2 & 3 & 4 & 5 \\
\hline 13 & $\begin{array}{l}\text { Assistance in developing new ideas is readily } \\
\text { available }\end{array}$ & 1 & 2 & 3 & 4 & 5 \\
\hline 14 & I exert my full effort to my job & 1 & 2 & 3 & 4 & 5 \\
\hline 15 & $\begin{array}{l}\text { My team leader would use his/her power to help me } \\
\text { solve problems in my work regardless of formal } \\
\text { authority }\end{array}$ & 1 & 2 & 3 & 4 & 5 \\
\hline 16 & I am enthusiastic in my job & 1 & 2 & 3 & 4 & 5 \\
\hline 17 & $\begin{array}{l}\text { There are adequate resources devoted to innovation } \\
\text { in this organization }\end{array}$ & 1 & 2 & 3 & 4 & 5 \\
\hline 18 & At work, I focus a great deal of attention to my job & 1 & 2 & 3 & 4 & 5 \\
\hline 19 & I feel positive about my job & 1 & 2 & 3 & 4 & 5 \\
\hline
\end{tabular}




\begin{tabular}{|c|c|c|c|c|c|c|}
\hline 19 & I feel positive about my job & 1 & 2 & 3 & 4 & 5 \\
\hline 20 & At work, I pay a lot of attention to my job & 1 & 2 & 3 & 4 & 5 \\
\hline 21 & The company really cares about my well being & 1 & 2 & 3 & 4 & 5 \\
\hline 22 & $\begin{array}{l}\text { Lack of funding to investigate creative ideas is } \\
\text { a problem in this organization }\end{array}$ & 1 & 2 & 3 & 4 & 5 \\
\hline 23 & I am excited about my job & 1 & 2 & 3 & 4 & 5 \\
\hline 24 & $\begin{array}{l}\text { I usually know where I stand with my team } \\
\text { leader and how satisfied he/she is with what I } \\
\text { do }\end{array}$ & 1 & 2 & 3 & 4 & 5 \\
\hline 25 & The company shows little concern for me & 1 & 2 & 3 & 4 & 5 \\
\hline 26 & $\begin{array}{l}\text { My team leader understands my job problems } \\
\text { and needs }\end{array}$ & 1 & 2 & 3 & 4 & 5 \\
\hline 27 & I try my hardest to perform well on my job & 1 & 2 & 3 & 4 & 5 \\
\hline 28 & $\begin{array}{l}\text { There is adequate time available to pursue } \\
\text { creative ideas here }\end{array}$ & 1 & 2 & 3 & 4 & 5 \\
\hline 29 & At work, I devote a lot of attention to my job & 1 & 2 & 3 & 4 & 5 \\
\hline 30 & $\begin{array}{l}\text { I have enough confidence in my team leader } \\
\text { that I would defend and justify his/her decision } \\
\text { if he/she were not present to do so }\end{array}$ & 1 & 2 & 3 & 4 & 5 \\
\hline 31 & $\begin{array}{l}\text { The company is willing to help me if I need a } \\
\text { special favor }\end{array}$ & 1 & 2 & 3 & 4 & 5 \\
\hline 32 & I work with intensity on my job & 1 & 2 & 3 & 4 & 5 \\
\hline 33 & I feel energetic at my job & 1 & 2 & 3 & 4 & 5 \\
\hline 34 & $\begin{array}{l}\text { This organization gives me free time to pursue } \\
\text { creative ideas during the workday }\end{array}$ & 1 & 2 & 3 & 4 & 5 \\
\hline 35 & I exert a lot of energy on my job & 1 & 2 & 3 & 4 & 5 \\
\hline 36 & At work, I am absorbed by my job & 1 & 2 & 3 & 4 & 5 \\
\hline 37 & $\begin{array}{l}\text { I have an effective working relationship with } \\
\text { my team leader }\end{array}$ & 1 & 2 & 3 & 4 & 5 \\
\hline & Years with company & $0-5$ & $5-10$ & $10-15$ & $15-20$ & $20+$ \\
\hline & Employment Status (circle one) & \multicolumn{2}{|c|}{ Temporary } & \multicolumn{2}{|l|}{ Contract } & $\begin{array}{l}\text { Full } \\
\text { Time }\end{array}$ \\
\hline
\end{tabular}




\section{REFERENCES}

Anand, G., Ward, P. T., \& Tatikonda, M. V. (2010). Role of explicit and tacit knowledge in Six Sigma projects: An empirical examination of differential project success. Journal of Operations Management, 28(4), 303-315.

Anand, G., Ward, P. T., Tatikonda, M. V., \& Schilling, D. A. (2009). Dynamic capabilities through continuous improvement infrastructure. Journal of Operations Management, 27(6), 444-461.

Andriopoulos, C. (2001). Determinants of organisational creativity: a literature review. Management Decision, 39(10), 834-840.

Andriopoulos, C., \& Lewis, M. W. (2009). Exploitation-Exploration Tensions and Organizational Ambidexterity: Managing Paradoxes of Innovation. Organization Science, 20(4), 696-717.

Barney, J. B. (1991). Firm Resources and Sustained Competitive Advantage. Journal of Management, 17(1).

Basadur, M. (1992). Managing Creativity: A Japanese Model. The Executive, 6(2), 29-42. doi: $10.2307 / 4165063$

Basadur, M. (2004). Leading others to think innovatively together: Creative leadership. The Leadership Quarterly, 15(1), 103-121. doi: http://dx.doi.org/10.1016/j.leaqua.2003.12.007

Basadur, M., \& Gelade, G. A. (2006). The Role of Knowledge Management in the Innovation Process. Creativity and Innovation Management, 15(1), 45-62. 
Bates, K. A., Amundson, S. D., Schroeder, R. G., \& Morris, W. T. (1995). The Crucial Interrelationship between Manufacturing Strategy and Organizational Culture. MANAGEMENT SCIENCE, 41(10), 1565-1580.

Bettencourt, L. A., \& Ulwick, A. W. (2008). The Customer-Centered Innovation Map. Harv Bus $\operatorname{Rev}(\mathrm{May})$.

Birkinshaw, J., \& Gibson, C. B. (2004). Building Ambisexterity into an Organization. MIT Sloan Management Review, 47-55.

Byrne, B. M. (2010). Structural Equation Modeling with AMOS: Basic Concepts, Applications, and Programming. Second Edition (Second Edition ed.). New York: Routledge.

CANSIM. (2016). Table 281-0047 Survey of Employment Payrolls and Hours (SEPH) by NAICS. from Statistics Canada

Christensen, C. M. (1997). The Innovator's Dilemma: When New Technologies cause Great Firms to Fail. Boston, Massachusetts: Harvard Business School Press.

Cole, D. E. (2011). The Auto Sun is Rising. Monahan Endowment Lecture. Detroit, Michigan: Wayne State University.

Conti, T., Kondo, Y., \& Watson, G. H. (Eds.). (2003). Quality into the 21 st Century: Perspectives on Quality and Competitiveness for Sustained Performance. Milwaukee, Wisconsin: ASQ Quality Press.

Coy, P. (2012). Making the Case for a Manufacturing Bias. Bloomberg Businessweek, April 16 April 22, 12-13.

Deutsch, M. M. (2011). Employee Engagement:understanding the business case and providing tools for increasing engagement in the workplace. Milwaukee, Wisconsin: ASQ. 
Dinero, D. A. (2005). Training Within Industry: The Foundation of Lean. Boca Raton FL: CRC Press.

Eisenberger, R., Armeli, S., Rexwinkel, B., Lynch, P. D., \& Rhoades, L. (2001). Reciprocation of Perceived Organizational Support. Journal of Applied Psychology, 86(1), $42-51$.

Eisenhardt, K. M., \& Graebner, M. E. (2007). Theory building from cases: opportunities and challenges. Academy of Managment Journal, 50(1), 25-32.

Fairbank, J. F., \& Williams, S. D. (2001). Motivating Creativity and Enhancing Innovation through Employee Suggestion System Technology. Creativity and Innovation Management, 10(2), 68-74. doi: 10.1111/1467-8691.00204

Fujimoto, T. (1999). The evolution of a manufacturing system at Toyota. New York: Oxford University Press.

Gagne, M., \& Deci, E. L. (2005). Self-determination theory and work motivation. Journal of Organizational Behavior, 26, 331-362.

Graen, G. B., \& Uhl-Bien, M. (1995). Relationship-Based Approach to Leadership: Development of Leader-Member Exchange (LMX) Theory of Leadership over 25 years: Applying a Multi-Level Multi-Domain Perspective. Leadership Quarterly, 6(2), 219-247.

Graupp, P., \& Wrona, R. J. (2011). Implementing TWI: Creating and Managing a Skills-Based Culture. New York, NY: CRC Press.

Grove, A. S. (2010, July 5). How America can create jobs. Bloomberg Businessweek. Gupta, P. (2009). The Innovation Solution (Pre-publication Edition ed.): Accelper Consulting. Hafeez, K., Zhang, Y., \& Malak, N. (2002). Core Competence for Sustainable Competitive Advantage: A Structured Methodology for Identifying Core Competence. IEEE Transactions on Engineering Management, 49(1), 28-35. 
Harter, J. K., Frank L. Schmidt, and Theodore L. Hayes. (2002). Business Unit level relationship between Employee Satisfaction, Employee Engagement, and Business Outcomes: a metaanalysis. Journal of Applied Psychology, 87(2), 268-279.

Herzberg, F. (2003). One more time: how do you motivate employees? 1968. Harv Bus Rev, 81(1), 87-96.

Holstein, W. J. (2013, Spring). Hyundai's Capabilities Play. strategy+business, 62-73.

Huntzinger, J. (2002). The Roots of Lean. Target, 18.

Ingrassia, P. (2010). Crash Course: the American automobile industry's road from glory to disaster. New York: Random House.

Jaruzelski, B., Loehr, J., \& Holman, R. (2011, Winter). The Global Innovation 1000: Why Culture is Key. strategy+business.

Kaushal, A., Mayor, T., \& Riedl, P. (2011, Autumn). Manufacturing's Wake-Up Call. strategy+business, 31-43.

Keathley, J., Merrill, P., Owens, T., Meggarrey, I., \& Posey, K. (2014). The Executive Guide to Innovation: Turning Good ideas into Great Results. Milwaukee, WI: ASQ Quality Press.

Keeley, L., Pikkel, R., Quinn, B., \& Walters, H. (2013). Ten types of Innovation: the discipline of building breakthroughs. Hoboken, NJ: John Wiley \& Sons.

Keenan, G. (2013, March 2). Made (smarter) in Canada: Inside a world-beating factory, The Globe and Mail, pp. B6-B7.

Liker, J. K., \& Ballé, M. (2013). Lean Managers must be Teachers. Journal of Enterprise Transformation, 3(1), 16-32.

Macey, W. H., and Benjamin Schneider. (2008). The Meaning of Employee Engagement. Industrial and Organizational Psychology, 1, 3-30. 
Marciano, P. L. (2010). Carrots and sticks don't work: building a culture of Employee Engagement with the principles of RESPECT. New York: McGraw Hill.

Martin, R. L. (2011). The Innovation Catalysts. Harvard Business Review.

Medlin, B. a. K. G. J. (2008). The relationship among goal setting, optimism, and engagement: the impact on employee performance. Paper presented at the Academy of Organizational Culture, Communications, and Conflict, Tunica.

Merrill, P. (2008). Innovation Generation: creating an innovation process and an innovative culture. Milwaukee, Wisconsin: ASQ Quality Press.

Mintzberg, H., Pascale, R. T., Goold, M., \& Rumelt, R. P. (1996). The Honda Effect Revisited. California Management Review, 38(4).

Nonaka, I. (1991). The Knowledge-creating company. Harvard Business Review, 69(6), 96-104.

Norausky, P. H. (2000). The Customer and Supplier Innovation Team Guidebook. Milwaukee, Wisconsin: ASQ Quality Press.

Pink, D. H. (2009). Drive: The surprising truth about what motivates us. New York: Riverhead Books.

Pisano, G. P., \& Shih, W. C. (2012a). Does America Really Need Manufacturing? Harvard Business Review, 90(3).

Pisano, G. P., \& Shih, W. C. (2012b). Producing Prosperity: Why America needs a manufacturing renaissance. Boston, Massachusetts: Harvard Business Review Press.

Porter, M. E. (1980). Competitive Strategy: Techniques for Analyzing Industries and Competitors. New York: The Free Press.

Porter, M. E., \& Rivkin, J. W. (2012). Choosing the United States. Harvard Business Review, $90(3)$. 
Prahalad, C., \& Hamel, G. (1990). The Core Competence of the Corporation. Harvard Business Review, 68(3).

Raisch, S., \& Birkinshaw, J. (2008). Organizational Ambidexterity: Antecedents, Outcomes, and Moderators. Journal of Management, 34(3), 375-409.

Recht, R., \& Wilderom, C. (1998). Kaizen and culture: on the transferability of Japanese suggestion systems. International Business Review, 7, 7-22.

Rich, B. L., Lepine, J. A., \& Crawford, E. R. (2010). Job Engagement: Antecedents and effects on job performance. Academy of Managment Journal, 53(3), 617-635.

Robinson, A. G., \& Schroeder, D. M. (2006). Ideas are Free. San Francisco: Berrett-Koehler Publishers Inc.

Robinson, A. G., \& Schroeder, D. M. (2009). The role of front-line ideas in lean performance improvement. Quality Management Journal, 16(4), 27-40.

Robinson, A. G., \& Schroeder, D. M. (2014). The Idea-Driven Organization. San Francisco: Berrett-Koehler Publishers, Inc.

Robinson, A. G., \& Stern, S. (1997). Corporate Creativity: How Innovation and Improvement Actually Happen. San Francisco CA: Berrett-Koehler Publishers, Inc.

Rother, M. (2010). Toyota kata: Managing people for improvement, adaptiveness, and superior results: McGraw-Hill.

Royal, M., \& Agnew, T. (2012). The enemy of engagement. New York: American Management Association.

Ryan, R. M., \& Deci, E. L. (2000). Self-Determination Theory and the Facilitation of Intrinsic Motivation, Social Development, and Well-Being. American Psychologist, 55(1), 68-78. 
Schein, E. H. (2010). Organizational Culture and Leadership - Fourth Edition. San Francisco, CA: Jossey-Bass.

Schroeder, R. G., Bates, K. A., \& Junttila, M. A. (2002). A Resourced-Based View of Manufacturing Strategy and the Relationship to Manufacturing Performance. Strategic Management Journal, 23(2), 105-117.

Scott, S. G., \& Bruce, R. A. (1994). Determinants of Innovative Behavior: A Path Model of Individual Innovation in the Workplace. Academy of Managment Journal, 37(3), 580607.

Shook, J. (2007). Training Within Industry and Toyota. TWI Summit. Orlando, Florida.

Sloan, A. P. (1963). My Years with General Motors. New York: Doubleday.

Soltero, C. (2012, November). Rediscovering the kata way. Industrial Engineer, 44, 28-33.

Soltero, C., \& Boutier, P. (2012). The 7 Kata. Boca Raton, FL: CRC Press.

Teece, D. J., Pisano, G. P., \& Shuen, A. (1997). Dynamic Capabilities and Strategic Management. Strategic Management Journal, 18(7), 509-533.

Tichy, N. M., \& Bennis, W. G. (2009). Judgement: how winning leaders make great calls (Updated edition ed.): Portfolio.

Towers-Perrin. (2003). Working Today: Understanding what drives Employee Engagement Towers Perrin Talent Report: Towers Perrin.

van Dijk, C., \& van den Ende, J. (2002). Suggestion systems: transferring employee creativity into practicable ideas. $R \& D$ Management, 32(5), 387-395.

Wagner, R., \& Harter, J. K. (2006). 12: the elements of great managing. New York: Gallup Press.

Yin, R. K. (2009). Case Study Research: Design and methods (4 ed.). Thousand Oaks, CA: Sage. 


\section{ABSTRACT \\ DEVELOPING INNOVATION CAPABILITY IN A MASS PRODUCTION ORGANIZATION}

by

\section{MARK DOLSEN}

\section{May 2017}

Advisor: Dr. Ratna Babu Chinnam

Major: Industrial Engineering

Degree: Doctor of Philosophy

Auto parts manufacturing is a key element of the North American automotive supply chain, and a significant component of the economy of Ontario, Canada. Employment in this sector declined $40 \%$ from 2003 to 2010 as the industry experienced a recession, and many firms relocated to lower wage jurisdictions as the Canadian currency strengthened against the US dollar. Experts contend that the solution for the industry lies in innovation; however, recommendations found in the current literature are general, with no clear guidance for mass production firms. This situation is urgent, because as manufacturing firms disappear, the potential for innovative opportunity is reduced as well. Mass production firms in high wage rate jurisdictions need to develop a capability of continuous innovation to survive and compete in the global marketplace.

This dissertation addresses this problem through the study of an auto parts manufacturing firm in Ontario, Canada. Theory states that innovation is born of creative ideas from intrinsically motivated individuals, and that every employee in a firm is a potential source of ideas. Employee engagement, a proxy for intrinsic motivation, is defined as giving discretionary effort in 
achieving company goals, and literature indicates that performance of a firm is proportional to engagement levels of its employees.

To investigate the firm's potential for innovation, a survey was administered to the firm's employees to measure engagement levels and theoretical constructs for engagement drivers. A structural equation model was used to analyze the significance of these relationships. Subsequently, factory performance data representative of innovative and improvement behavior was collected for the same time period as the survey, and correlations were examined between work group engagement levels, engagement drivers, and the performance data at the work group level.

Following this, case study research was used to examine how the process of innovation actually happens in the firm. Literature defines creative thinking as a continuous process of problem finding, problem solving, and solution implementing. Three cases of process innovations implemented over a three year period were studied to reveal how the organization executed the creative thinking process, the significance of employee engagement levels and drivers in that execution, and how innovation capabilities improved through experiential learning.

From the two components of the study, a recommendation is offered for how an auto parts firm in a high wage rate jurisdiction can compete with a differentiation strategy by developing a continuous innovation capability. Organizational elements must be aligned in the execution of the three step creative thinking process, so that problems are clearly identified, and the most highly engaged employees are focused on creative problem solving. 


\section{AUTOBIOGRAPHICAL STATEMENT}

Mark Dolsen was born and raised in Chatham, Ontario Canada. After graduating from Chatham Collegiate Institute in 1982 he earned a Bachelor's degree in Electrical Engineering from GMI Engineering and Management Institute (now Kettering University) in Flint Michigan, while working co-op terms at General Motors of Canada Trim Plant in Windsor, Ontario. His undergraduate thesis focused on the application of the relatively new Japanese manufacturing techniques to the mass production of automotive interior trim. After earning a Master's degree in Industrial Engineering in 1990 from Wayne State University in Detroit, Michigan, he joined Quality Safety Systems, a Canadian joint venture subsidiary of Tokai Rika Company, where he has spent the majority of his career learning the Toyota Production System directly as a Tier 1 supplier in the Toyota group in North America.

Mark is currently President of TRQSS Inc. He lives in Tecumseh, Ontario with his wife Margo. They have two children, Amelia and Graham. 